DANIEL FERNANDES THEOPHILO DE ALMEIDA PIRES

\title{
PROPOSTA DE UM SISTEMA DE DISTRIBUIÇÃO DE LICENÇAS DE USO PARA IPTV
}

\author{
Dissertação apresentada à Escola \\ Politécnica da Universidade de São Paulo \\ para obtenção do Título de Mestre em \\ Engenharia
}

São Paulo 
DANIEL FERNANDES THEOPHILO DE ALMEIDA PIRES

\title{
PROPOSTA DE UM SISTEMA DE DISTRIBUIÇÃO DE LICENÇAS DE USO PARA IPTV
}

\author{
Dissertação apresentada à Escola \\ Politécnica da Universidade de São Paulo \\ para obtenção do Título de Mestre em \\ Engenharia \\ Área de Concentração: Sistemas Digitais \\ Orientadora: Profa. Dra. Regina Melo \\ Silveira
}


Este exemplar foi revisado e alterado em relação à versão original, sob responsabilidade única do autor e com a anuência de seu orientador.

São Paulo, 10 de agosto de 2007.

Assinatura do autor

Assinatura do orientador

FICHA CATALOGRÁFICA

Pires, Daniel Fernandes Theophilo de Almeida

Proposta de um sistema de distribuição de licenças de uso para IPTV / D.F.T.A. Pires. -- ed.rev. -- São Paulo, 2007.

$121 p$.

Dissertação (Mestrado) - Escola Politécnica da Universidade de São Paulo. Departamento de Engenharia de Computação e Sistemas Digitais.

1.Sistemas de informação 2.Sistemas multimídia 3.Redes e comunicação de dados 4.Segurança de redes I.Universidade de São Paulo. Escola Politécnica. Departamento de Engenharia de Computação e Sistemas Digitais Il.t. 


\section{DEDICATÓRIA}

Aos meus pais, pelo constante apoio e incentivo em minhas decisões. 


\section{AGRADECIMENTOS}

À Profa . Regina Melo Silveira, orientadora, chefe e, acima de tudo, amiga. Agradeço por toda paciência e dedicação durante a concepção desse trabalho. $E$ mais do que no mestrado, te agradeço por todas oportunidades, conversas e ensinamentos em todos esses anos trabalhando juntos.

Ao Professor Wilson Ruggiero e Professora Tereza Cristina, por criarem esse ambiente acolhedor que é o LARC. Agradeço a vocês pela chance de participar de um grupo de pessoas tão dedicadas. Obrigado por proporcionar um lugar onde nossas opiniões são ouvidas e respeitadas.

A todos os colegas do LARC, professores e funcionários. Foram vários anos em que conheci pessoas maravilhosas. Fico muito feliz por ter aprendido um pouco com cada um de vocês, por ter feito mais do que colegas de trabalho, por ter ganho vários amigos.

Tenho que agradecer aos meus irmãos neste processo, Christiane e lan. Nós viemos na mesma empreitada desde o começo, compartilhando as dores de cabeça, preocupações e palhaçadas! Vocês me ensinaram a não desistir e a enfrentar melhor as preocupações do dia-a-dia. Obrigado por estarem comigo em todos esses momentos.

Agradeço à minha família, sempre mais do que presente em minha vida (quase $90 \%$ desse tempo em churrascos). Dessa convivência intensa com pessoas como vocês eu ganhei muito e, mesmo um pouco mais longe, vocês continuam presentes em mim. Faço um agradecimento especial ao meu padrinho, por todas as aulas de física pro afilhado que só gostava de estudar de véspera - a física eu aprendi, já a procrastinação é um processo mais delicado.

A todos os grandes amigos. Por todo o apoio de vocês nas vezes em que tinha que deixar de comparecer na praia ou no boteco por causa dos estudos, trabalhos e provas.

Por último, mas nem um pouco menos importante, agradeço muito à minha pequena, Luísa. Pelas revisões, puxões de orelha, saudades e por me convencer a correr atrás do nosso sonho. Obrigado, meu amor. 


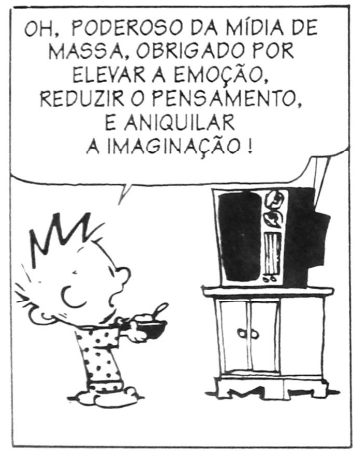

OBRIGADO PELA

ARTIFICIALIDADE DAS

SOLUČÕES RÁPIDASE

PELA MANIPULACÃO

TRAICOEIRA DOS DESEJOS

HUMANOS PARA FINS

COMERCIAIS.
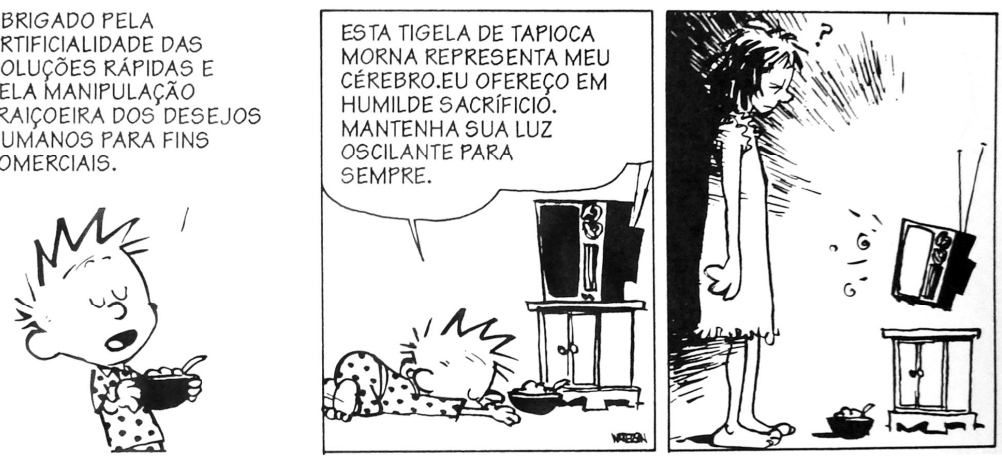

(Calvin and Hobbes, por Bill Watterson) 


\section{RESUMO}

A Internet consolidou as redes IP como uma infra-estrutura de transporte de dados barata e versátil, fato que justifica o crescente interesse nela como infraestrutura de transporte para outros serviços, como telefonia e TV. Esta convergência de serviços tem base no amadurecimento das tecnologias de redes de transmissão de dados, que proporcionou o aumento da velocidade de conexão residencial, tornando cada vez mais viável o uso de aplicações multimídia, inclusive em tempo real. Desta demanda de serviços convergentes, nasceu a digitalização da TV e, posteriormente, a possibilidade de transmissão pelas redes IP, conhecida como IPTV.

Este trabalho analisa o cenário atual de IPTV para distribuição de conteúdo multimídia em redes de acesso privadas. Parte-se da necessidade de mecanismos de segurança para distribuição e controle do consumo das mídias digitais no sistema. O trabalho analisa, portanto, mecanismos para descrição inequívoca dos direitos que os usuários têm sobre o conteúdo adquirido, bem como a utilização de tecnologias para a transmissão do conteúdo de forma segura.

O trabalho visa contribuir para a comunidade científica a partir da utilização de padrões abertos na especificação de um elemento de distribuição de vídeo em uma plataforma IPTV. Este elemento se baseia em políticas de uso da linguagem de expressão de direitos do MPEG-21 para reforçar os direitos de autoria e distribuição do conteúdo durante seu manuseio em toda a cadeia de negócios. 


\begin{abstract}
Internet consolidated IP networks as a versatile and accessible data transport infrastructure, thus justifying the growing interest on it as a transport network for several services, such as telephony and TV. The convergence leverages on the maturity of network technologies, responsible for the increasing availability of bandwidth for residential access, making the use of multimedia applications, including interactive ones, possible. From the demand for convergence, Digital TV has born, and later on, its transmission through IP networks, know as IPTV.

This work analyzes current IPTV scenario for multimedia content distribution in the scope of private networks. It is based on the need for security mechanisms for digital content delivering and control of consumption in the system. Therefore it analyzes mechanisms for rights description, as well as security transmission of content.

This work's contribution stems from the reutilization of open standards in the specification of a distribution broker in the IPTV environment. Such broker is based on the MPEG-21 digital rights description to enforce copyright of digital content during handling in the entire value chain.
\end{abstract}




\section{LISTA DE FIGURAS}

Figura 1.1 - Interface do programa de TV Digital Interativa .................................21

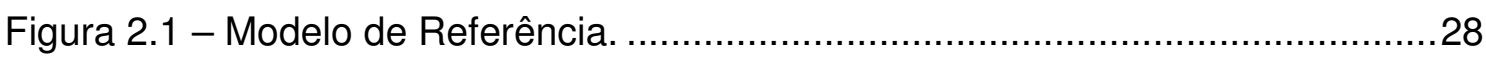

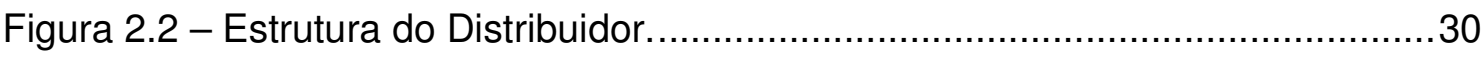

Figura 2.3 - trecho de arquivo XML descrevendo álbuns de música........................32

Figura 2.4 - Requisitos de estrutura para linguagem (PARROT, 2001) .....................33

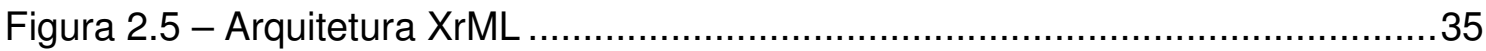

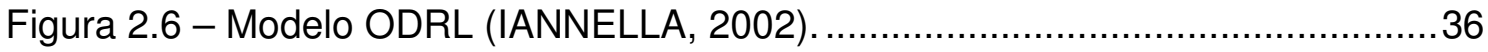

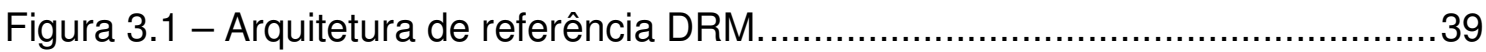

Figura 3.2 - Fluxo de dados do WMRM (MICROSOFT, 2006). ...............................42

Figura 3.3 - Arquitetura de transporte ISMA (ISMA, 2005)..................................46

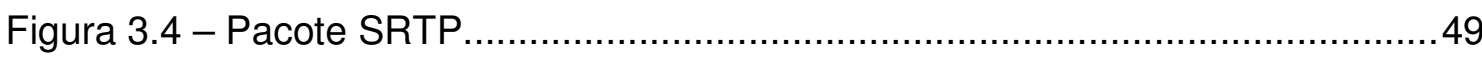

Figura 3.5 - Imagem com marca d'água visível. .................................................51

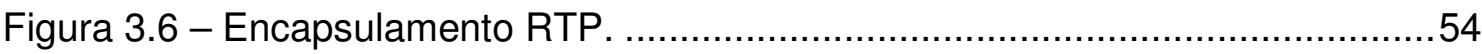

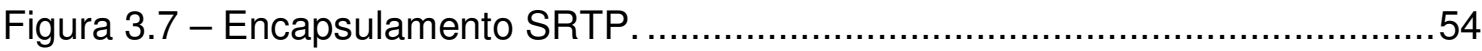

Figura 3.8 - Multiplexação de pacotes RTCP em uma Transmissão UDP...............55

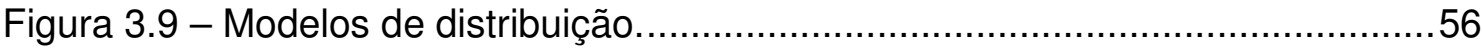

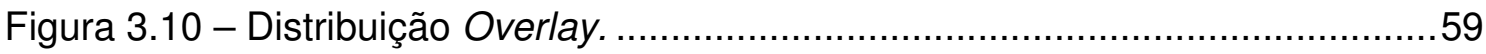

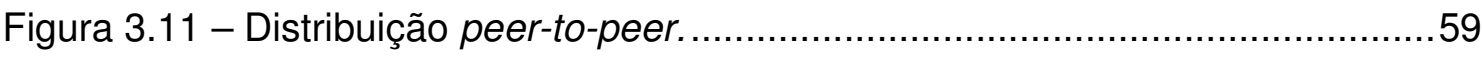

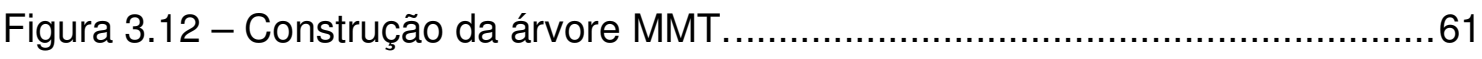

Figura 4.1 - Interfaces do Distribuidor. .......................................................... 73

Figura 4.2 - Broker: Interfaces e lógica interna............................................... 74

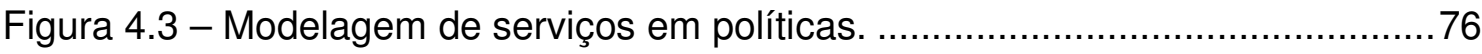

Figura 4.4 -Bloco de geração de licenças. ......................................................77

Figura 4.5 - Processo de criação de Licenças de uso. ..........................................78

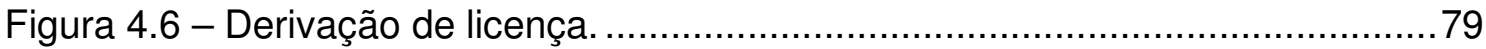

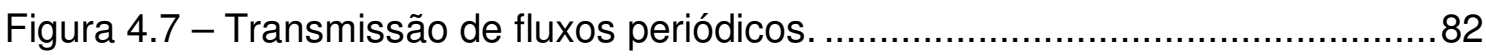

Figura 4.8 - Pilha de protocolos de distribuição.................................................. 83

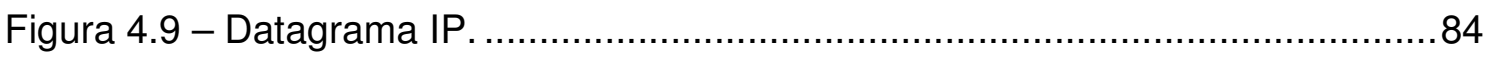

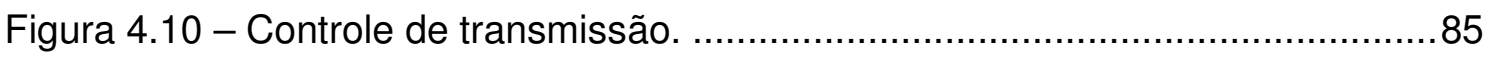

Figura 4.11 - Estrutura de Licença (WANG et al., 2005) ....................................87

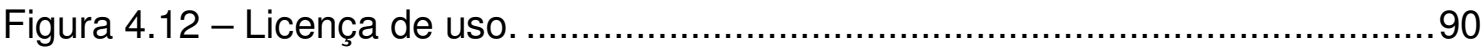

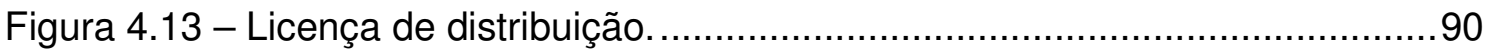




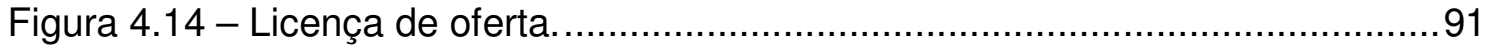

Figura 4.15 - Licença com restrição de dispositivo ...............................................

Figura 5.1 - Diagrama de caso de uso - Distribuidor e Produtor..............................95

Figura 5.2 - Diagrama de caso de uso - Cliente e Distribuidor. ..............................97

Figura 5.3 - Diagrama de Atividade para geração de licença de uso. ....................100

Figura 5.4 - Diagrama de Atividade para exibição de conteúdo.............................101

Figura 5.5 - Diagrama de seqüência para criação de licença no Distribuidor..........102

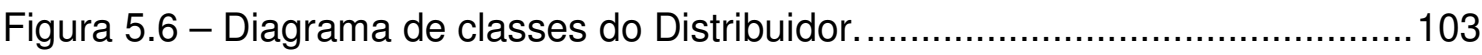

Figura 5.7 - Diagrama de seqüência para mudança de canal no Cliente................104

Figura 5.8 - Diagrama de classes do Cliente........................................................105

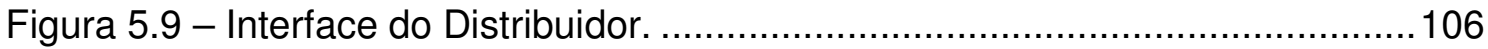

Figura 5.10 - Guia de programação - fluxo de canal de TV.................................107

Figura 5.11 - Guia de programação - VoD..................................................108

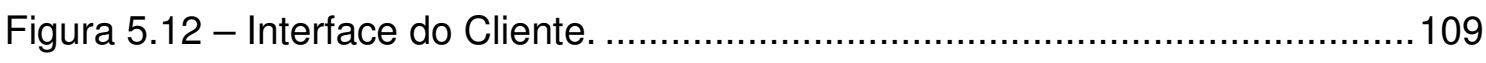




\section{LISTA DE TABELAS}

Tabela 4.1 - Requisitos funcionais para manipulação de mídia - Produtor ................70

Tabela 4.2 - Requisitos funcionais para manipulação de mídia - Distribuidor ..........71

Tabela 4.3 - Requisitos funcionais para manipulação de mídia - Cliente ................72

Tabela 4.4 - Requisitos funcionais para manipulação de mídia - Rede de Acesso .72 


\section{LISTA DE ABREVIATURAS E SIGLAS}

\begin{tabular}{|c|c|}
\hline ATM & Asynchronous Transfer Mode \\
\hline AWT & Abstraction Window Toolkit \\
\hline $\mathrm{CA}$ & Certification Authority \\
\hline $\mathrm{DCl}$ & Digital Cinema Initiatives \\
\hline DiffServ & Differentiated Services \\
\hline Dos & Denial of Service \\
\hline DRM & Digital Rights Management \\
\hline DSCP & Differentiated Service Code Point \\
\hline DVB & Digital Video Broadcasting \\
\hline DVMRP & Distance Vector Multicast Routing Protocol \\
\hline EPG & Electronic Program Guide \\
\hline GPL & GNU General Public License \\
\hline HDTV & High Definition Television \\
\hline HTML & Hypertext Markup Language \\
\hline IGMP & Internet Group Management Protocol \\
\hline IPSEC & IP Security \\
\hline IPTV & Internet Protocol Television \\
\hline ISMA & Internet Streaming Media Alliance \\
\hline JPEG & Joint Photographic Experts Group \\
\hline JVLC & Java VideoLAN Client \\
\hline$L S P$ & Label Switched Path \\
\hline Mbps & Megabits por segundo \\
\hline MMT & MPLS Multicast Tree \\
\hline MPEG & Moving Pictures Expert Group \\
\hline MPLS & Multi-Protocol Label Switching \\
\hline NIMS & Network Information Manager System \\
\hline ODRL & Open Digital Rights Language \\
\hline OMA & Open Mobile Alliance \\
\hline P2P & peer-to-peer \\
\hline PIM-SM & Protocol Independent Multicast - Sparse Mode \\
\hline PNG & Portable Network Graphics \\
\hline PPV & pay-per-view \\
\hline QoS & Quality of Service \\
\hline
\end{tabular}




$\begin{array}{ll}\text { REL } & \text { Rights Expression Languages } \\ \text { RP } & \text { Rendezvous Point } \\ \text { RSVP } & \text { Resource ReSerVation Protocol } \\ \text { RTCP } & \text { RTP Control Protocol } \\ \text { RTP } & \text { Real Time Protocol } \\ \text { RTSP } & \text { Real Time Streaming Protocol } \\ \text { SDK } & \text { Software Development Kit } \\ \text { SMPTE } & \text { Society of Motion Pictures and Television Engineers } \\ \text { SRTCP } & \text { Secure RTP Control Protocol } \\ \text { SRTP } & \text { Secure Real-time Transport Protocol } \\ \text { SSM } & \text { Source Specific Multicast } \\ \text { TCG } & \text { Trusted Computing Group } \\ \text { TI } & \text { Tecnologia da Informação } \\ \text { TLS } & \text { Transport Layer Security } \\ \text { TPM } & \text { Trusted Platform Module } \\ \text { TS } & \text { Transport Stream } \\ \text { TVoIP } & \text { TV-over-IP } \\ \text { UML } & \text { Unified Modeling Language } \\ \text { URI } & \text { Uniform Resource Identifier } \\ \text { URN } & \text { Uniform Resource Name } \\ \text { VHS } & \text { Video Home System } \\ \text { VLC } & \text { VideoLAN Client } \\ \text { VoD } & \text { Video on Demand } \\ \text { VoIP } & \text { Voice over IP } \\ \text { W3C } & \text { World Wide Web Consortium } \\ \text { WMRM } & \text { Windows Media Rights Management } \\ \text { XML } & \text { eXtensible Markup Language } \\ \text { XrML } & \text { eXtensible Rights Markup Language } \\ & \end{array}$




\section{SUMÁRIO}

CAPÍTULO 1 - APRESENTAÇÃO DO CENÁRIO DE IPTV ..................................16

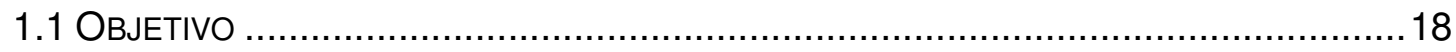

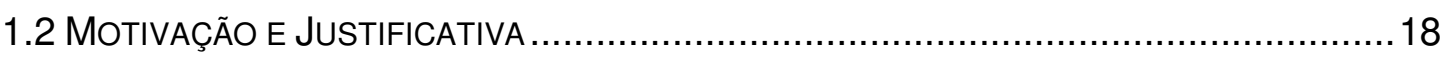

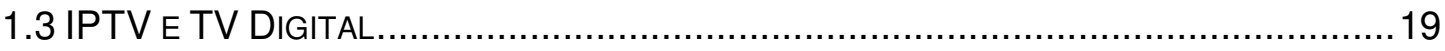

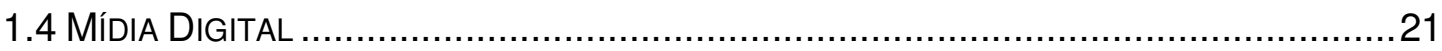

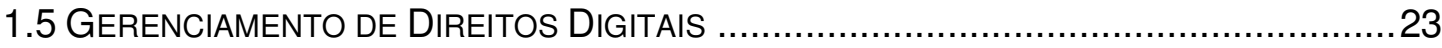

CAPÍTULO 2 - MODELO DE REFERÊNCIA DE UM SISTEMA IPTV .....................25

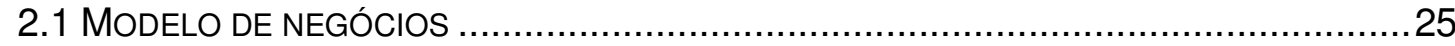

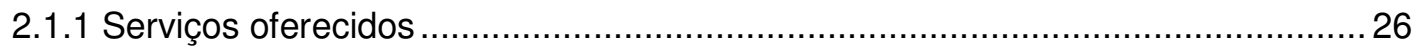

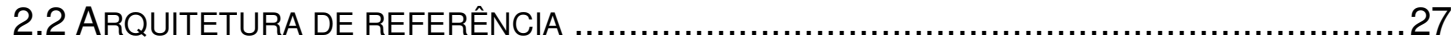

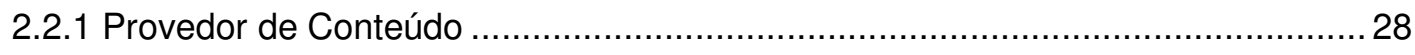

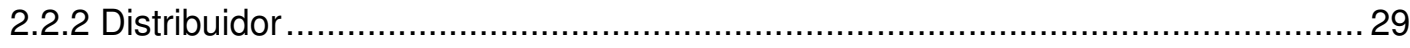

2.2.3 Rede de Acesso …….............................................................................. 31

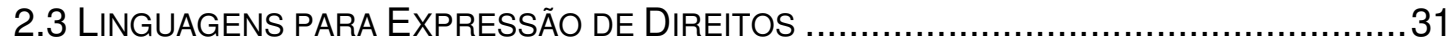

2.3.1 Requisitos para a linguagem de expressão de direitos.......................................... 33

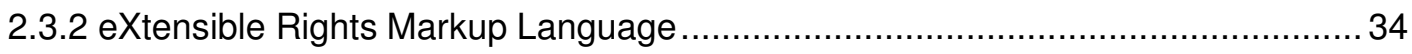

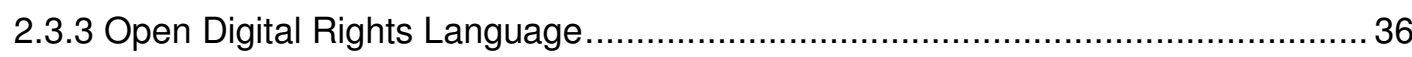

CAPÍTULO 3 - TECNOLOGIAS PARA SUPORTE AO IPTV .................................38

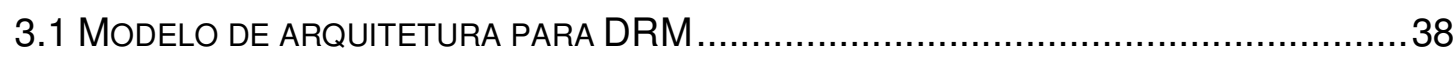

3.2 PRINCIPAIS SISTEMAS DRM COMERCIAIS ..................................................... 41

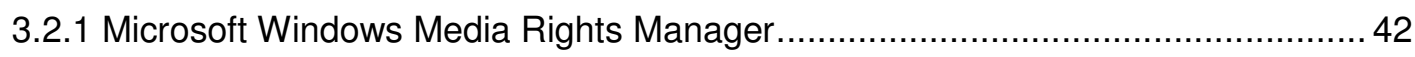

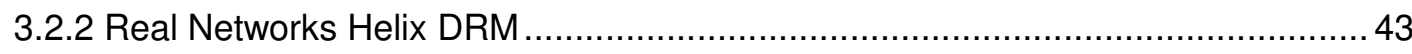

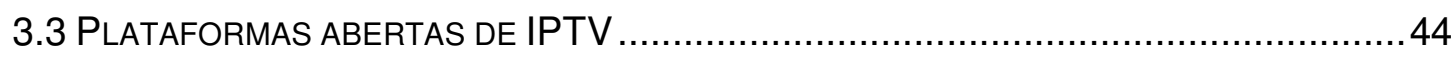

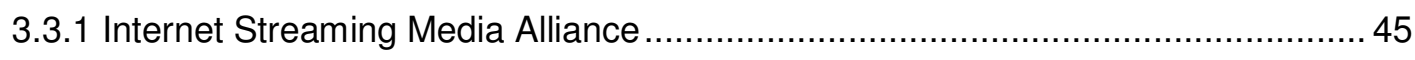

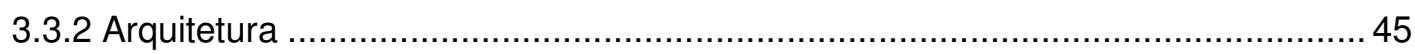

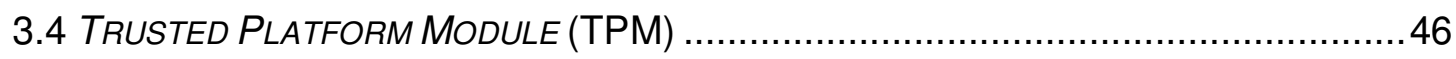

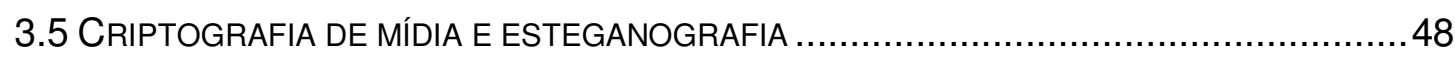

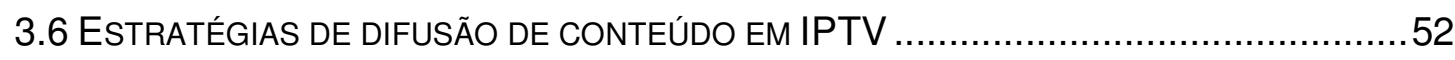

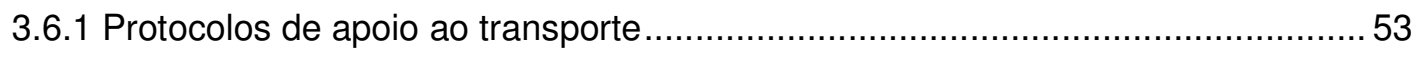

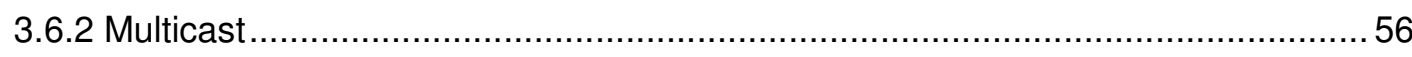

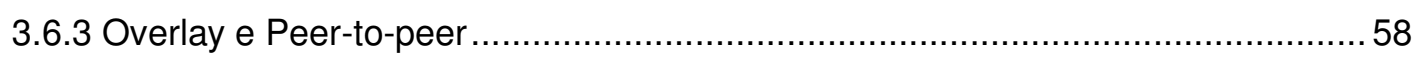

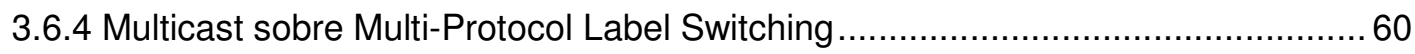


CAPÍTULO 4 - ESPECIFICAÇÃO DO ELEMENTO DE DISTRIBUIÇÃO..................63

4.1 POLÍTICAS PARA MANIPULAÇÃO DA MÍDIA NO SISTEMA ..........................................63

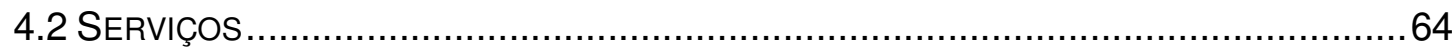

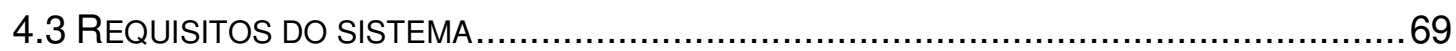

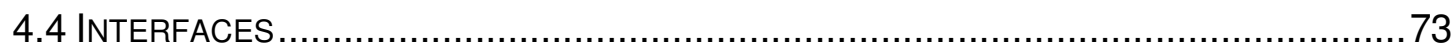

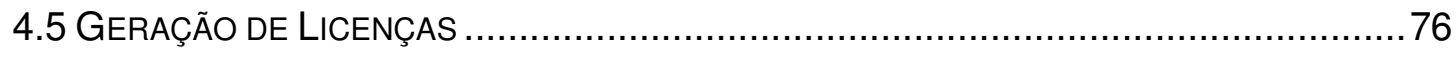

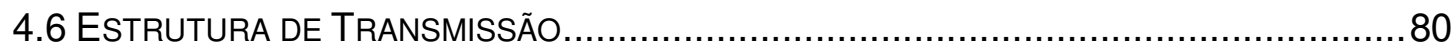

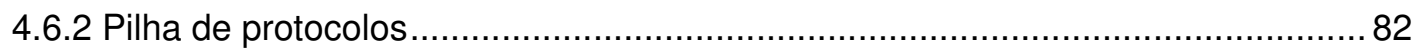

4.7 ESCOLHA DA LINGUAGEM DE EXPRESSÃO DE DIREITOS ................................ 85

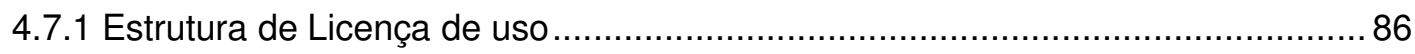

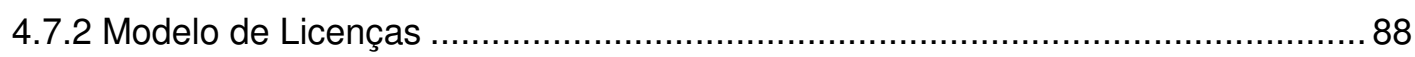

4.7.3 Exemplos de principais políticas no sistema IPTV .......................................90

CAPÍTULO 5 - CASO DE VALIDAÇÃO..................................................................94

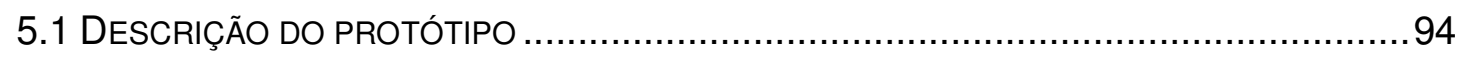

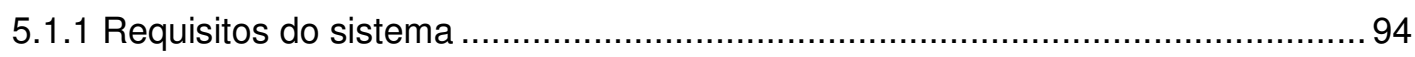

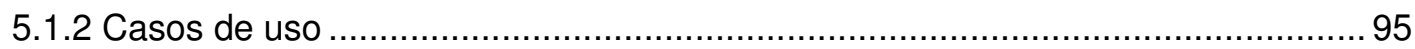

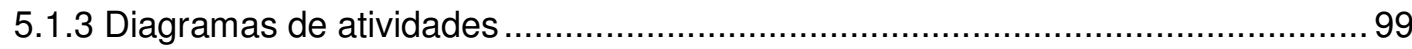

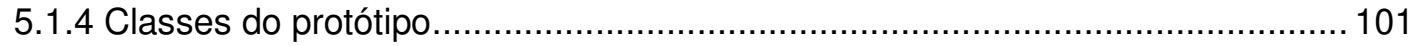

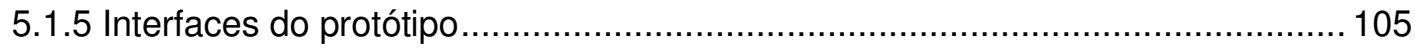

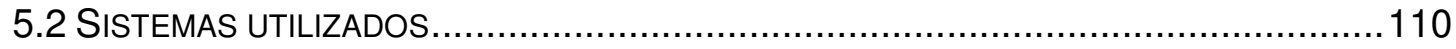

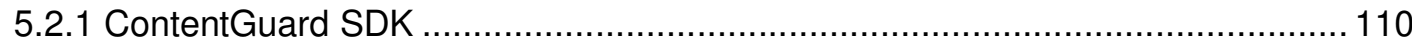

5.2.2 Java VideoLAN Client ........................................................................... 111

CONCLUSÃO ....................................................................................................113

BIBLIOGRAFIA ............................................................................................116 


\section{Capítulo 1 - Apresentação do Cenário de IPTV}

Em meados da década de 90 a Internet começou a fazer parte da realidade dos usuários domésticos e com o passar dos anos sua importância foi aumentando. Da mesma forma que os sistemas computacionais evoluem, elevando os requisitos de equipamentos, o parâmetro que indica essa evolução na Internet é a largura de banda. O amadurecimento das tecnologias de redes de transmissão de dados proporcionou o aumento da velocidade de conexão residencial, tornando cada vez mais viável o uso de aplicações multimídia, inclusive em tempo real.

A Internet consolidou as redes IP como uma infra-estrutura barata e versátil, fato que justifica o crescente interesse nela como infra-estrutura de transporte para outros serviços, como telefonia e TV. Isso é o que se conhece na área de Tecnologia da Informação (TI) como Convergência (SCHOEN et al., 1998).

Um indício da convergência é a tecnologia de voz sobre IP (Voice over IP), ou VoIP (AUDIN, 2001). O VolP é um termo popular para designar o transporte de conversas telefônicas através de uma rede IP como a Internet. Este tipo de aplicação já existe há anos e foi muito utilizado ${ }^{1}$ para dar suporte a jogos multiplayer na Internet. Apesar de possuir poucos requisitos computacionais - tanto do ponto de vista de processamento, como de banda de transmissão - esta tecnologia começou a ser utilizada comercialmente há pouco tempo. A maior motivação para sua expansão comercial foi a utilização de padrões abertos, que possibilitam à interoperabilidade e escalabilidade de sistemas entre fabricantes diferentes.

Outro serviço que vem ganhando espaço é a transmissão de vídeo pela Internet, tanto de fluxos sob demanda (Video on Demand - VoD) quanto os de fluxo de canal de TV. Apenas recentemente as conexões domésticas se tornaram capazes de receber e exibir fluxos de vídeo em tempo real. Como exemplos desses serviços, podem ser citados os portais de vídeo da Google e YouTube ${ }^{2}$. Estes portais trabalham essencialmente com vídeos de baixa resolução, no entanto existem alguns sítios que já disponibilizam conteúdo em alta definição, como a Apple $^{4}$, que provê principalmente trailers de lançamento de filmes. O exemplo mais

\footnotetext{
${ }_{1}^{1}$ Um dos programas mais usados foi o Roger Wilco, disponível em <http://rogerwilco.gamespy.com/>.

2 Google Video: <http://video.google.com/>.

3 YouTube: <http://www.youtube.com/>.

${ }^{4}$ Apple: <http://www.apple.com/trailers>.
} 
comum de aplicação com fluxos de vídeo em tempo real, contudo, são aplicações de videoconferência. Usuários domésticos já conseguem usar videoconferência de baixa resolução, ao passo que as plataformas profissionais estão sendo comercializadas com codificadores de vídeo mais eficientes e de maior resolução (como, por exemplo, o H.264 ${ }^{5}$ ).

A utilização das redes IP para transmissão de sinal televisivo representa um próximo passo em convergência, comumente denominado IPTV (BENJAMIN, 2005)( FLEURY, 2005). Entretanto, a taxonomia para esse tipo de aplicação ainda não é muito precisa, como será verificado ao longo deste texto.

O termo IPTV tem sido usado amplamente, tanto na indústria quanto na Academia, podendo ter mais de um significado. Pode-se dizer, de forma resumida, que existem duas frentes conflitantes atualmente: propostas destinadas às redes privadas e propostas para a rede pública (Internet) (ALBUQUERQUE; PROENÇA; OLIVEIRA, 2006). Os Sistemas de IPTV destinados à rede privada que estão sendo usados comercialmente possuem um escopo bem definido em uma rede de usuários pertencentes a um único domínio e, dessa forma, podem garantir qualidade de serviço (QoS) e escalabilidade de distribuição do conteúdo. Em contrapartida, sistemas para redes públicas são normalmente caracterizados pela utilização de redes Overlay ${ }^{6}$ ou peer-to-peer (P2P) na distribuição do conteúdo para Internet (ELSAYED; ROCA; MATHY, 2003).

Inicialmente, cabe ressaltar que a TV possui requisitos muito maiores de banda de transmissão do que outros serviços citados $^{7}$, exigindo também maior poder computacional para codificação e decodificação do sinal. No entanto, talvez mais determinante que os requisitos exigidos pelas características de vídeo é o aspecto crítico desta aplicação quanto à segurança do conteúdo. Garantir que conteúdo digital seja entregue através de uma distribuição 1-para-n, com garantias de integridade e segurança dos dados, permanece sendo um desafio para as redes atuais.

\footnotetext{
${ }^{5}$ H.264/AVC - Recomendação da ITU-T <http://www.itu.int/rec/T-REC-H.264/en>. Tecnicamente idêntico ao MPEG-4 parte 10 do comitê MPEG (ISO) (MARPE; WIEGAND; SULLIVAN, 2006).

${ }^{6}$ As redes Overlay são redes que utilizam a camada de aplicação, além de contar com infra-estrutura auxiliar distribuída para prover funcionalidades na falta das mesmas em camadas inferiores.

${ }^{7}$ Nesse caso, os requisitos de banda são por causa da alta resolução com que as novas plataformas de TV têm sido propostas.
} 


\subsection{Objetivo}

Este trabalho visa contribuir para a comunidade científica a partir da utilização de padrões abertos na especificação de um elemento de controle e distribuição de vídeo em uma plataforma IPTV. Este elemento se baseia em políticas de uso para reforçar os direitos de autoria e distribuição do conteúdo durante seu consumo no sistema.

\subsection{Motivação e Justificativa}

Atualmente é possível encontrar implementações comerciais dos sistemas de IPTV em diversos países, contando com aproximadamente um milhão de usuários em 2004 e uma previsão de 25 milhões até 2008, segundo Fleury (FLEURY, 2005). Porém, essas implementações são, em boa parte, proprietárias. A falta de padronização implica na precária (porventura possível) interoperabilidade entre fabricantes. $O$ estudo a ser apresentado aqui, se encontra no contexto da parceria entre a ERICSSON e o Laboratório de Arquitetura e Redes de Computadores da Escola Politécnica da Universidade de São Paulo (LARC-EPUSP), onde atualmente vem sendo desenvolvido o projeto IPTV.

Sem padronização, cada fabricante tem que desenvolver produtos que abranjam todos os aspectos do negócio, dificultando a entrada de pequenas empresas no mercado. Os produtos desenvolvidos nem sempre permitem interoperabilidade, além de não dar garantias que suportarão novas funcionalidades. Dessa forma, um provedor de acesso que queira implantar uma solução de IPTV em sua rede terá que adotar uma solução completa de um único fabricante, criando uma situação indesejável de dependência, ao passo que equipamentos e softwares baseados em padrões abertos possibilitam maior interoperabilidade e geram maior concorrência no mercado.

Outro aspecto que evidencia a pertinência de uma plataforma de IPTV é a possibilidade de transmissão de um conteúdo por um terceiro, e não mais apenas pelas emissoras de TV. Essa mudança de paradigma passa o controle do negócio para a rede de transmissão, o que pode não ser interessante para o criador do 
conteúdo. Ainda que boa parte das questões relacionadas ao uso e distribuição do conteúdo sejam resolvidas de forma contratual, mecanismos tecnológicos devem existir para apoiar o emprego das políticas de uso da mídia. É respondendo a esta necessidade que este trabalho visa especificar uma entidade responsável pela distribuição de conteúdo, capaz de reforçar as políticas de uso da mídia de forma confiável através da utilização de práticas de gerenciamento de direitos digitais (Digital Rights Management - DRM) (MICROSOFT, 2001) (BORMANS et al., 2003), de forma a dar segurança ao criador do conteúdo mesmo quando o conteúdo se encontrar fora do seu domínio.

\subsection{IPTV e TV Digital}

Ao se falar de IPTV, a comparação com a TV Digital é inevitável. A diferenciação entre esses dois sistemas é importante, portanto, para a compreensão do panorama em que o IPTV se enquadra. A seguir, este assunto será tratado em pormenores.

A TV Digital, como vem sendo proposta recentemente em vários países do mundo ${ }^{8}$, é uma evolução direta da televisão tradicional. Essa evolução propõe que todos os processos referentes à TV passem a ser digitais, incluindo a produção, finalização, transmissão e consumo, garantindo assim melhor qualidade, ou menor degradação do sinal final. Mudanças no canal de transmissão também são propostas, onde há agora a opção de transmissão de sinal em alta definição (HDTV) ou de manter a resolução padrão transmitindo mais canais, sempre utilizando a mesma faixa de freqüência da TV analógica. Além disso, o conteúdo deverá sofrer mudanças significativas, como será abordado posteriormente neste item.

Os padrões de TV Digital regulamentam a transmissão de sinal de várias formas: terrestre (pelo ar), satélite, cabo e até mesmo pela rede de telefonia celular. Vale ressaltar que essa tecnologia pode ser utilizada tanto para TV paga quanto para TV aberta. No caso do Brasil, o governo aposta na TV Digital para criar novos serviços para a população através de canais de saúde, educação, correio eletrônico,

\footnotetext{
${ }^{8}$ No momento em que esse documento estava sendo escrito, o Brasil acabara de anunciar que o padrão de TV Digital brasileiro será baseado no padrão japonês, o ISDB.
} 
etc. Essa aposta parte da premissa de que o parque de aparelhos de televisão instalados no país possibilitará acesso à informação em locais remotos.

Entre as características fundamentais que diferenciam a TV Digital do IPTV, as principais são:

- Os sistemas de IPTV limitam-se, obrigatoriamente, a infra-estruturas que suportem a transmissão de pacotes IP, diferente da TV Digital, onde pode haver mais de um meio de transmissão (terrestre, cabo, satélite, etc). Dessa forma, os interessados em implementar um sistema desse tipo são tipicamente empresas que possuem infra-estrutura para prover acesso a serviços de telefonia e Internet, como as empresas de telecomunicações. Uma plataforma de IPTV, assim, é atraente principalmente para empresas com esse perfil que queriam começar a investir na venda do serviço de TV.

- O IPTV não está limitado à transmissão de conteúdo ao vivo, mas pode também ser usado para vender fluxos de vídeo individuais a clientes. $\mathrm{Na}$ verdade, o VoD vem sendo visto como o mote para o IPTV.

- A arquitetura de transmissão do serviço de IPTV requer uma infra-estrutura privada, conforme será visto no próximo capítulo. Essa exigência faz com que esse serviço seja essencialmente pago; diferente da TV Digital, que pode utilizar transmissão terrestre, minimizando o custo de transmissão e viabilizando a TV aberta.

Apesar dessas diferenças de utilização, os dois sistemas possuem um aspecto importante em comum: o conteúdo. A rigor, nada impede que o conteúdo de um sistema IPTV seja utilizado na TV Digital, e vice-versa. Essa interoperabilidade é crucial para manter os sistemas de IPTV competitivos.

A programação para os novos sistemas de TV conta com equipamentos capazes de certo grau de processamento; a isso se alia um canal de retorno que possibilita a interatividade do conteúdo. Essa interatividade poderá se dar de diversas formas: seleção de diferentes ângulos de câmera; informações textuais sobrepostas ao vídeo; compras diretamente pela TV, entre outras. Pode-se citar como exemplo o programa proposto pelo LARC no Sistema Brasileiro de TV Digital (SBTVD), dentro do projeto de conteúdo áudio visual para TV Interativa, o MAESTRO (SILVEIRA; PIRES, 2005). O programa consistia na apresentação de 
uma orquestra, onde o telespectador tinha acesso a opções de câmera, canais de áudio para cada naipe de instrumentos e informações textuais sobre o próprio intérprete e obra sendo executada. Na Figura 1.1, pode-se observar uma imagem obtida durante a execução do programa.

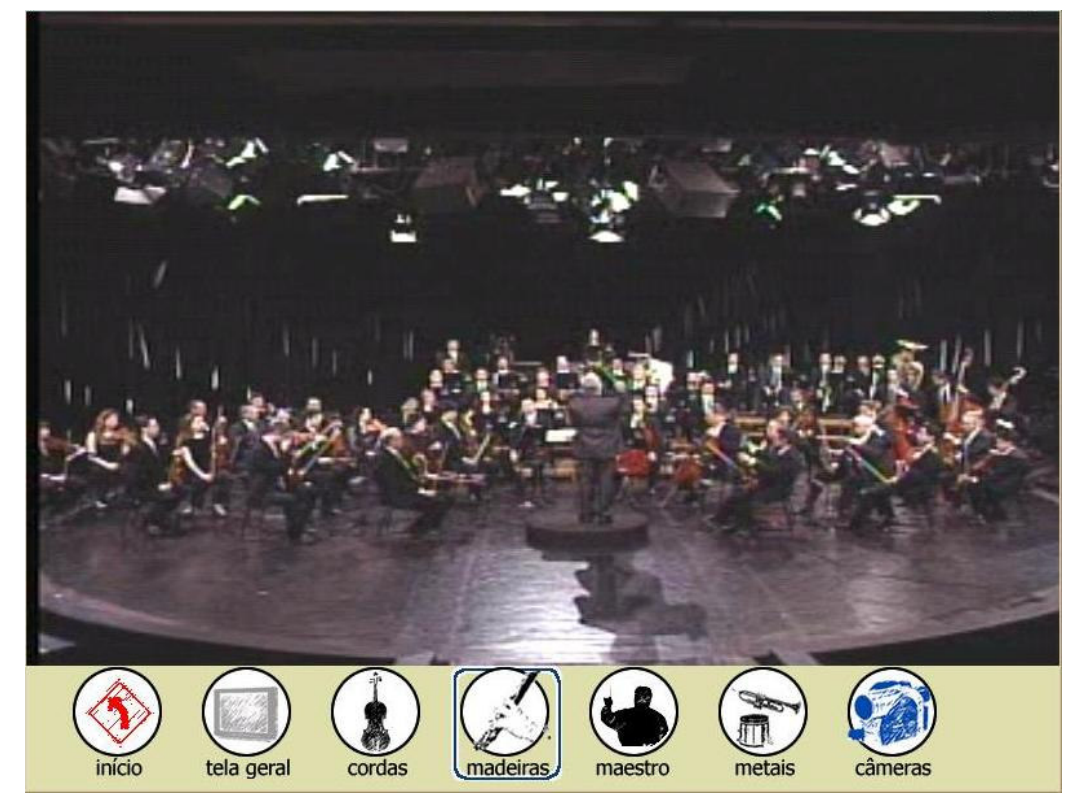

Figura 1.1 - Interface do programa de TV Digital Interativa

Exemplos como esse evidenciam que do ponto de vista de criação, as mudanças de paradigma na TV abrem espaço para diversas novas experiências. Seguramente, a perspectiva tecnológica também é positiva, porém ainda existem grandes desafios a serem superados na transposição da mídia analógica para a digital. Este trabalho analisará especificamente o consumo de conteúdo em um sistema de IPTV, visando transportar os direitos autorais existentes no mundo analógico para o mundo digital.

\subsection{Mídia Digital}

A evolução dos sistemas de televisão traz mudanças não só para o meio de transmissão do conteúdo, mas principalmente para a forma pela qual este conteúdo é utilizado. Aqui será reforçado o porquê dessas mudanças e como elas têm afetado a indústria. 
Até alguns anos atrás, consumidores compravam diversos tipos de conteúdos (livros, álbuns de música, fitas de vídeo, etc.) que, devido às limitações tecnológicas de então, eram mais difíceis de serem copiados indevidamente e passados adiante para outros consumidores que não o tinham comprado. Por exemplo uma pessoa que alugava um filme na locadora para assistir no seu videocassete poderia copiar esta fita, somente se tivesse um outro equipamento de vídeo disponível. Ainda assim, a cópia feita não seria perfeita, pois o processo de gravação analógico da mídia insere pequenas falhas durante o processo.

O mesmo acontecia com outras mídias, como os discos gravados em fita cassete, livros fotocopiados e mesmo programas de TV gravados em VHS. Em todos esses processos havia uma deterioração da mídia original no momento da cópia. Ainda que sutil, a degeneração aliada a processos demorados de cópia, inibiam a reprodução indevida em diversas situações.

Com o advento da mídia digital, um consumidor consegue copiar uma mídia de forma rápida e, o que é ainda mais importante, exatamente igual à original. Essa melhora no processo é, conseqüentemente, um grande atrativo para a pirataria. Um dos primeiros e mais notáveis exemplos nesse sentido foi o caso do programa de compartilhamento de músicas Napster ${ }^{9}$. O programa consistia em um software peerto-peer para compartilhamento de arquivos de música no formato mp3 através da Internet. Como as transações eram feitas diretamente entre indivíduos, sem nenhum tipo de controle externo, a maior parte do conteúdo trocado era ilegal. O caso do Napster pode ser considerado um marco na história da pirataria digital. À medida que ganhou notoriedade, a indústria fonográfica americana $\left(\right.$ RIA $\left.^{10}\right)$ teve que tomar medidas para conter seu "sucesso", como rastrear transações ilegais na rede do programa e processar usuários; além de claro, processar o criador do Napster.

Em face desses problemas com as novas mídias, as empresas de distribuição começaram a tomar providências para tentar garantir algum tipo de "controle" sobre a mídia. Essas tentativas resumem-se basicamente a implementações proprietárias, tentando proibir a cópia de conteúdos.

As tentativas de coibir têm, contudo, sido ineficientes, sendo na maior parte das vezes quebradas em pouco espaço de tempo e conseguindo, no máximo, irritar

\footnotetext{
${ }^{9}$ O Napster ainda existe, porém é um serviço pago e totalmente legal nos Estados Unidos, ao contrário das versões iniciais. Encontra-se disponível em: <http://www.napster.com/>.

${ }^{10}$ Recording Industry Association of America: <http://www.riaa.com/>.
} 
os consumidores legítimos; vide o caso do mecanismo de proteção contra cópias de CDs, lançado pela Sony BMG em 2005 ${ }^{11}$. O sistema instalava um programa malicioso no computador do usuário, que abria brechas de segurança e possibilitava que informações do usuário fossem obtidas. O impacto nos meios de comunicação foi tão negativo que obrigou a Sony a fazer recall dos CDs "protegidos" pela referida tecnologia. A Sony BMG vem perdendo processos na justiça americana e negocia as indenizações para os clientes lesados.

\subsection{Gerenciamento de Direitos Digitais}

Casos como o da Sony mostram o lado negativo dos mecanismos de segurança, situações em que o usuário se sente impedido de fazer o pleno uso do produto que comprou. Cria-se assim um dilema para os vendedores de conteúdo: como distribuir uma determinada mídia, possibilitando ao comprador toda a versatilidade que ele espera do formato digital e, ao mesmo tempo, protegê-la contra a pirataria?

Esta é a justificativa para os recentes sistemas de gerenciamento de direitos digitais, ou Digital Rights Management (DRM). São sistemas complexos que se preocupam em gerenciar a utilização - por utilização entenda-se: armazenamento, controle de acesso, venda, transmissão, etc. - de determinados conteúdos em um sistema multimídia. Segundo lannela (IANNELLA, 2001), uma definição genérica para o termo é dada da seguinte maneira: "DRM cobre a descrição, identificação, comercialização, proteção, monitoração e rastreamento de todas as formas de direito de uso sobre propriedades intelectuais, tanto tangíveis, como intangíveis".

Rump afirma, de forma sintetizada (RUMP, 2003), que, DRM pode ser considerado tudo que se pode fazer com um determinado conteúdo para comercializá-lo. De acordo com o autor, DRM é primeiramente uma forma de "gerenciar direitos digitais"; onde os detentores dos direitos precisam: identificar seu conteúdo, coletar as informações sobre este conteúdo, definir quais serão os termos dos royalties utilizados e só aí desenvolver um modelo de negócios para distribuí-lo.

\footnotetext{
${ }^{11}$ Mais informações sobre o processo contra a Sony: <http://www.sonysuit.com/>.
} 
Por outro lado, DRM também deve ser capaz de "gerenciar digitalmente direitos" 12; fazer com que as regras determinadas durante a negociação do conteúdo sejam respeitadas (RUMP, 2003). Rump liga essa declaração com a definição de lannela, sugerindo que esta é a forma como as plataformas DRM são normalmente vistas, apenas como softwares de "proteção" do conteúdo.

Essa má impressão sobre o DRM não existe por acaso. Sistemas DRM são quase sempre implementados por empresas que querem, acima de tudo, proteger seu conteúdo. Dessa forma, a usabilidade do usuário é deixada para segundo plano. Da falta de cuidado com os direitos do usuário resultam sistemas extremamente restritivos quanto ao uso da mídia, causando antipatia por parte da comunidade de clientes e até mesmo certos distribuidores ${ }^{13}$. Devido a essas restrições, nasceu o movimento chamado Fair Use ${ }^{14}$ (OLSON, 2005) que se baseia nas leis de direito de cópia (copyright) americanas para reivindicar melhores direitos para o consumidor de conteúdo digital.

O trabalho aqui desenvolvido preza a liberdade de uso do conteúdo legalmente adquirido através de técnicas mais flexíveis de proteção, utilizando as licenças de uso para permitir portabilidade da mídia.

\footnotetext{
${ }^{12}$ No original, Rump brinca com as palavras para descrever as duas funções: "managing digital rights" e "digitally manage rights".

${ }^{13}$ Caso da Apple, que começou a vender música sem DRM em sua loja virtual por causa das constantes reclamações dos clientes.

${ }^{14}$ No português, algo como "uso justo".
} 


\section{Capítulo 2 - Modelo de referência de um sistema IPTV}

Este capítulo detalha o funcionamento de um sistema de IPTV, a partir, em um primeiro momento, do modelo de negócios que motiva a existência desse tipo de sistema. Posteriormente será apresentada a estrutura de referência para ele e, por fim, a estrutura de licenças de uso necessárias para proteção do conteúdo.

\subsection{Modelo de negócios}

Já foi abordado neste trabalho que o desenvolvimento de sistemas de transmissão de TV em redes IP encontra diversas dificuldades para sua implementação. Dessa forma, qual é a grande motivação para o seu desenvolvimento?

A popularização da Internet e o crescimento dos sistemas de VolP são alguns dos principais fatores responsáveis pela queda (da ordem de 18 a 23\%) nos lucros das empresas de Telecomunicações ${ }^{15}$. Conseqüentemente, elas são as maiores interessadas no desenvolvimento do IPTV como forma de criar novos serviços para seus clientes e gerar receita adicional.

O caso específico das operadoras de telecom utiliza redes IP privadas, formadas pela rede de clientes; rede essa que usualmente possui mecanismos de gerenciamento, podendo vir a utilizar mecanismos de controle de qualidade de serviço (QoS). A característica de rede privada é o que diferencia o IPTV dos sistemas que atuam sobre a Internet, chamados TVolP (ALBUQUERQUE; PROENÇA; OLIVEIRA, 2006).

O funcionamento do TVolP é bem diferente do que se tem atualmente nas transmissões de TV, sendo até mesmo difícil compará-los. Como atua sobre uma rede sem garantias de entrega, o TVolP tem mais vantagens na distribuição de conteúdo sob demanda do que o broadcast de canais de TV. Uma das grandes

\footnotetext{
${ }^{15}$ De acordo com os dados de Evalueserve (EVS) Business Research, disponível em: $<$ http://joung.im.ntu.edu.tw/teaching/distributed_systems/2005EMBA/ImpactofSkypeonTelecomServi ceProviders.pdf $>$. Acessado em outubro de 2006.
} 
apostas nesse tipo de serviço é o Joost ${ }^{16}$, criado pelos mesmos criadores do Skype $^{17}$. O Joost é um sistema de distribuição de conteúdo sob demanda que utiliza servidores centrais aliados a servidores geograficamente distribuídos, além de contar também com os próprios clientes para um esquema de peer-to-peer. Em contraste com os sistemas de IPTV, o Joost aposta na receita baseada em propagandas inseridas no conteúdo distribuído, sem cobrar assinatura ou mesmo taxas para baixar os vídeos.

A receita do serviço de IPTV provém em parte da assinatura de canais (como acontece nas TVs a cabo), parte da compra de conteúdos exclusivos sob demanda e também de novos serviços que vêm sendo disponibilizados, como por exemplo a videoconferência. Podendo contar com uma rede gerenciada e alto grau de convergência dos meios, o IPTV dispõe de uma gama maior de serviços disponíveis em relação a outros sistemas, como TV a cabo tradicional e TV Digital.

\subsubsection{Serviços oferecidos}

Diversos são os serviços que podem ser oferecidos aos clientes em um sistema de IPTV. Segue uma relação destes serviços, que serão posteriormente mapeados para as tecnologias necessárias para sua implementação.

Assinatura mensal de pacote de canais - a assinatura mensal é o serviço mais comum na TV. O cliente paga uma mensalidade por um ou mais grupos de canais de TV; os canais são transmitidos continuamente com programação variada.

Canal de Pay-per-view (PPV) - o PPV não é um termo preciso nas TVs por assinatura. Em alguns casos pode ser considerado como um canal qualquer, vendido em assinatura mensal separada dos outros pacotes; neste caso, sem ter nenhuma diferença do ponto de vista tecnológico para o caso acima. A outra possível situação é quando o cliente paga uma taxa para assistir a um determinado trecho (normalmente filme ou programa) da programação de um canal.

Vídeo sob Demanda (VoD) - é a obtenção de um certo conteúdo individualmente por um cliente. $\mathrm{O}$ VoD geralmente atua na distribuição de filmes como uma locadora virtual. Cada requisição de cliente é tratada de forma individual.

\footnotetext{
${ }_{16}$ Joost: <http://www.joost.com/>.

17 Skype: <http://www.skype.com>.
} 
Normalmente os serviços de VoD também oferecem ao cliente funcionalidades como pausar, retroceder e avançar .

Near-VoD - O Near-VoD utiliza transmissão para grupos com algumas otimizações a fim de minimizar o impacto das requisições individuais feitas no sistema. A idéia, contudo, é que o cliente seja atendido como se estivesse recebendo o conteúdo individualmente. Algumas técnicas para tanto serão apresentadas adiante.

Outros serviços - além dos serviços principais de vídeo, outros serviços podem ser agregados, como: jogos (locais ou em rede), videoconferência, e-mail, etc.

Esta lista de serviços não pode ser considerada exaustiva uma vez que novos serviços continuam sendo criados pelos provedores. A integração de voz e Internet, por exemplo, viabiliza uma gama de possíveis novos serviços, que dependem apenas da criatividade e visão dos provedores para serem desenvolvidos.

Apesar da receita gerada pela assinatura de canais, as empresas que implementam o serviço de IPTV apostam fortemente no VoD como a aplicação com maior potencial. Apesar de não excluir necessariamente outros serviços, este trabalho focará principalmente as necessidades das transmissões de fluxos de vídeo; tanto fluxos de VoD quanto os fluxos de canal de TV.

\subsection{Arquitetura de referência}

Esta seção define o modelo de referência para a arquitetura do sistema IPTV proposto neste trabalho. Algumas práticas das arquiteturas de DRM que ele emprega serão apresentadas no próximo capítulo, adaptando-as para o cenário específico da distribuição de mídia contínua em redes de pacotes.

O modelo utilizado tem uma organização semelhante ao modelo de Rosenblatt (ROSENBLATT; TRIPPE; MOONEY, 2002) (visto em detalhes no terceiro capítulo). Da mesma forma que o autor separa seu modelo em três entidades, a referência aqui definida também o fará. A Figura 2.1 ilustra, em alto nível, a cadeia de funcionamento do sistema IPTV de referência. A seguir é feita a descrição de cada componente da arquitetura. 


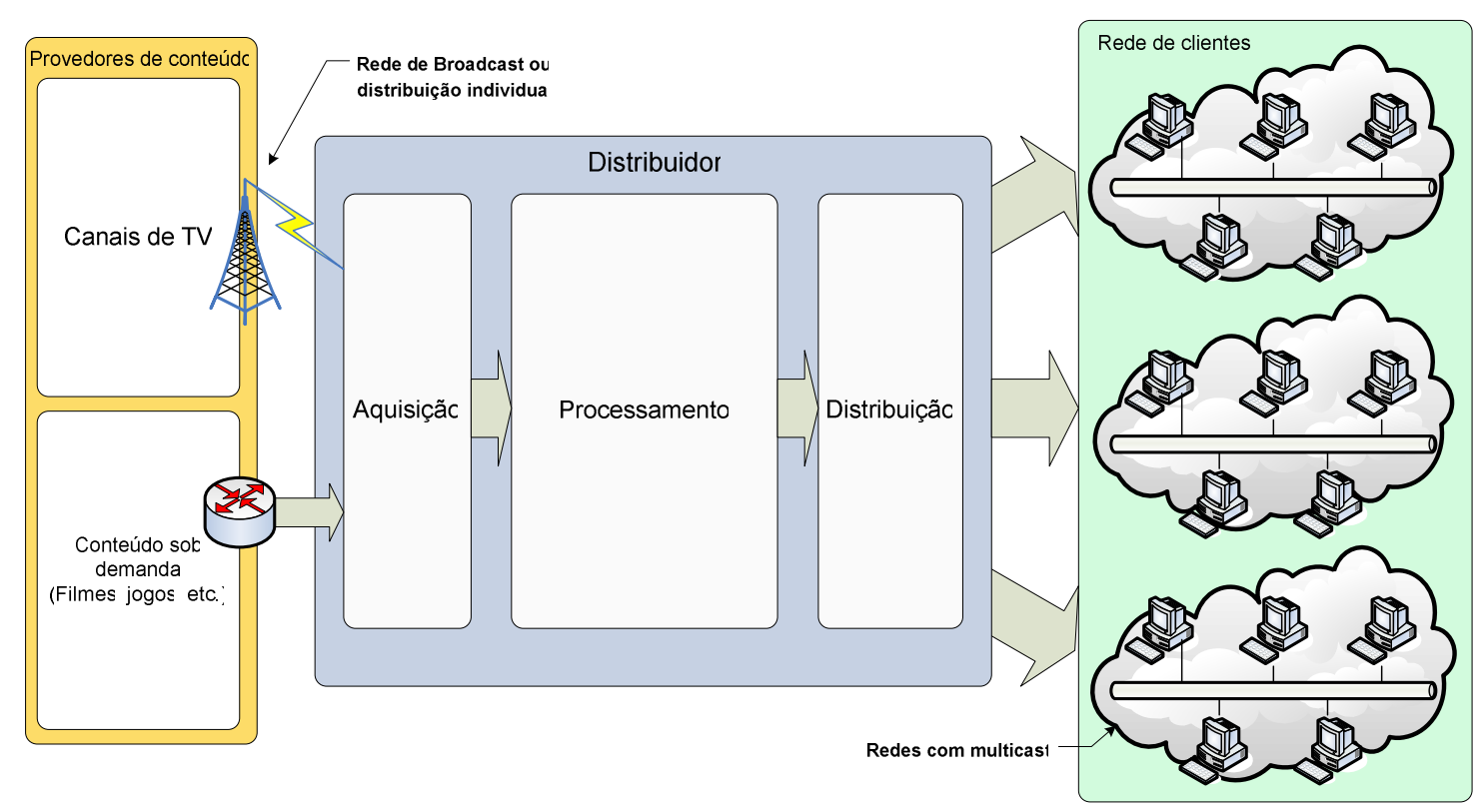

Figura 2.1 - Modelo de Referência.

\subsubsection{Provedor de Conteúdo}

Os Provedores de Conteúdo representam os produtores e/ou detentores dos direitos de mídia. O provedor vende os direitos de transmissão de um determinado canal de TV para o Distribuidor, analogamente ao que as emissoras fazem com os provedores de TV a cabo. Filmes e outros conteúdos podem ser adquiridos individualmente para serem disponibilizados sob demanda.

Algumas técnicas de proteção ao conteúdo podem ser utilizadas aqui. Primeiramente, o provedor de conteúdo pode criptografar as mídias a serem distribuídas antes mesmo de enviá-las ao Distribuidor. Um fator que deve ser considerado é que a inclusão de criptografia desde o primeiro estágio pode vir a criar mais atraso no sistema, quando a latência gerada no processo deve ser minimizada justamente devido à natureza do serviço de TV. Como o acesso ao conteúdo nesta etapa do processo é muito restrito, acrescentar criptografia neste enlace pode não ser, portanto, pertinente. 


\subsubsection{Distribuidor}

Este elemento é responsável pela rede de distribuição, onde será feito o controle da rede de clientes e a gerência do consumo das mídias. Este bloco deve ter ainda meios para reforçar as políticas de uso vindas do Provedor de Conteúdo, podendo acrescentar também suas próprias.

Conforme foi citado anteriormente, dentro do cenário de IPTV quem faz as vezes do Distribuidor são empresas de telecomunicações. Essas empresas tipicamente já possuem a infra-estrutura necessária para a rede IP - usualmente oferecem também acesso a Internet para os usuários domésticos - e estão interessadas em criar novos serviços para seus usuários.

O diferencial a ser apresentado no modelo de referência deste trabalho é um servidor de distribuição de conteúdo de forma segura, baseado em políticas de uso, localizado no Distribuidor. Esse elemento será denominado $B r o k e r{ }^{18}$, e é responsável pelo controle da distribuição do conteúdo segundo regras definidas entre Provedor de Conteúdo e o Distribuidor. Novamente, o Distribuidor também pode acrescentar novas regras conforme o tipo de negócio que faz com o cliente, sempre respeitando, contudo, os direitos iniciais previstos pelo produtor.

Como a Figura 2.2 ilustra, o Broker é o elemento central na estrutura do bloco de distribuição. A mídia chega (protegida ou aberta) do Provedor de Conteúdo e pode ser armazenada em um repositório, no caso de conteúdo sob demanda, ou ser enviada diretamente ao Broker para distribuição (caso de fluxos de canais de TV). A inserção de material de propaganda deverá ser feita anteriormente ao Broker.

\footnotetext{
${ }^{18}$ Do inglês, Broker é o termo designado a um intermediário entre vendedor e comprador.
} 


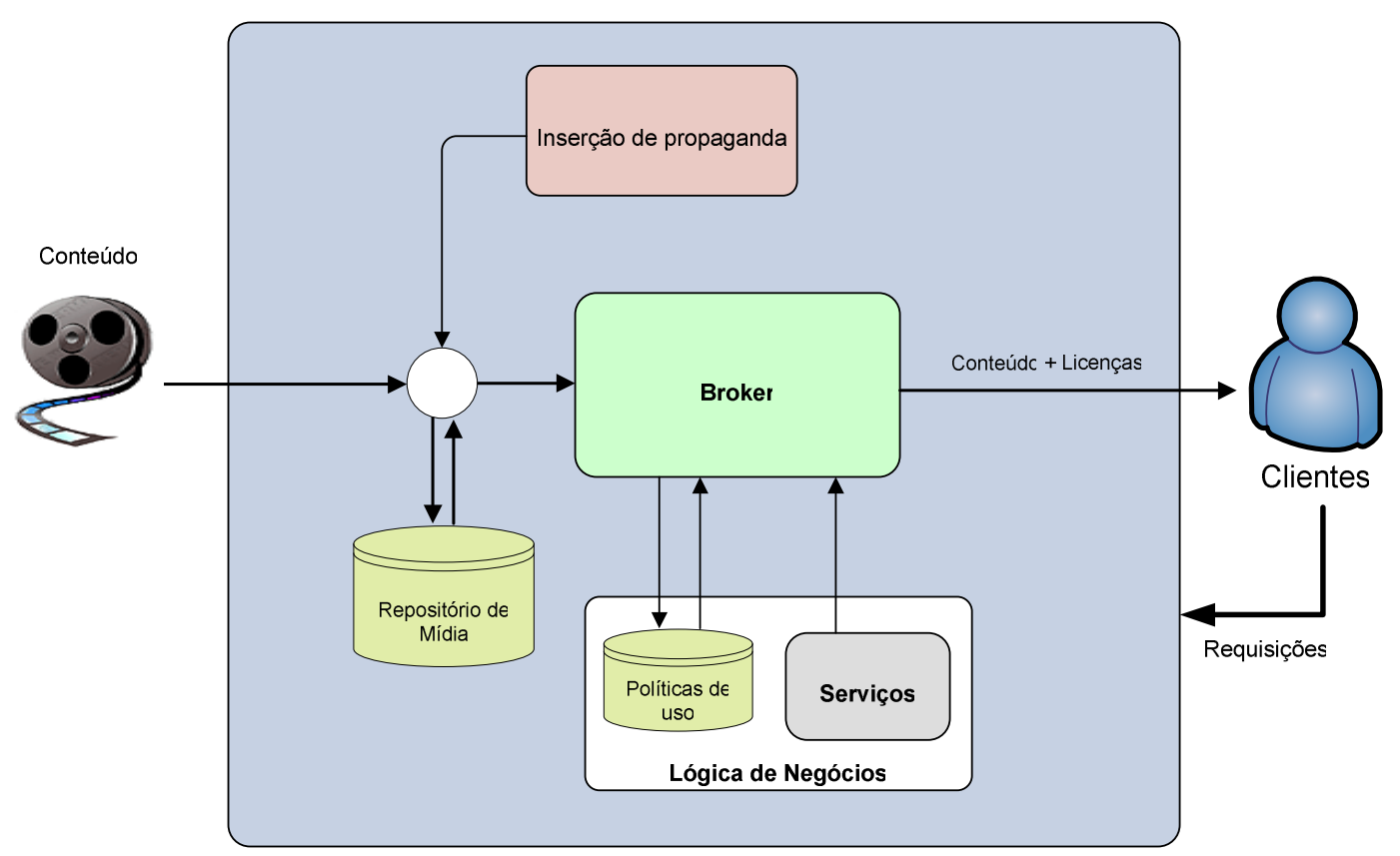

Figura 2.2 - Estrutura do Distribuidor.

O conceito de entidade de distribuição tem base nas recentes propostas de arquitetura para Cinema Digital $(\mathrm{DCl}, 2004)$ da Digital Cinema Initiatives $(\mathrm{DCl})^{19}$. A $\mathrm{DCl}$ é um empreendimento conjunto formado pelas sete maiores produtoras de Hollywood, com o intuito de agilizar o processo de padronização para o Cinema Digital. A proposta se encontra em fase de aprovação pela Society of Motion Pictures and Television Engineers (SMPTE) ${ }^{20}$, órgão responsável pela padronização no setor. O padrão proposto é aberto e baseado em algoritmos e protocolos amplamente utilizados na indústria. A mídia é distribuída e armazenada criptografada, só sendo aberta quando chega na "cabeça" do projetor, último passo antes de ser exibida. Sua exibição só é permitida quando as políticas de uso são asseguradas, políticas estas que são extremamente restritivas, determinando um número máximo de exibições, datas, horários e inclusive o projetor em que a mídia poderá ser executada.

Este trabalho prevê o uso de mecanismos para assegurar o conteúdo distribuído no sistema, porém é de suma importância que este conteúdo possa ser consumido pelos clientes com certo grau de flexibilidade. Esta facilidade deve ser obtida através das licenças que serão produzidas no Broker.

\footnotetext{
${ }^{19}$ Digital Cinema Initiatives (DCl): <http://www.dcimovies.com>.

${ }^{20}$ Society of Motion Picture Television Engineers (SMPTE): <http://www.smpte.org>.
} 


\subsubsection{Rede de Acesso}

Trata-se da Rede IP privada que dá acesso aos clientes do sistema IPTV. Essa rede deve, necessariamente, utilizar mecanismos de distribuição para grupos (1para- $n$ ) de forma a fornecer escalabilidade ao sistema. Vários esquemas de distribuição podem ser utilizados, no entanto, a distribuição multicast (DEERING, 1989) é a mais conhecida e com maior suporte por parte dos equipamentos de rede atuais. O multicast e outros mecanismos de distribuição para grupos serão analisados em detalhes no próximo capítulo.

\subsection{Linguagens para Expressão de Direitos}

O modelo de sistema IPTV aqui apresentado se baseia em políticas de uso para distribuição e consumo do conteúdo. Essas políticas devem representar uma forma padronizada e inequívoca de expressar os direitos e deveres dos envolvidos no sistema, servindo como guias para os mecanismos de segurança desde a entrada da mídia no sistema, até seu consumo pelo usuário.

Primeiramente cabe ao produtor definir a quem é dada a permissão de manipular seu conteúdo. Tradicionalmente isto é realizado através de contratos entre as partes envolvidas. No caso do IPTV, o Distribuidor poderá receber conteúdos de vários produtores, sendo que estes podem ter contratos diferentes. Dentro desse panorama, o Distribuidor acaba tendo que fazer mais restrições aos clientes para não deixar de cobrir nenhuma exigência dos produtores. Através das políticas de uso as mídias podem ter tratamento individual, oferecendo maior flexibilidade ao sistema.

Políticas de uso são regras descritas através de linguagens de alto nível, chamadas de linguagem de descrição de direitos, ou Rights Expression Languages (RELs), comumente baseadas em eXtensible Markup Language (XML) (W3C, 2004). O XML é uma recomendação do World Wide Web Consortium (W3C) ${ }^{21}$ para compartilhamento de dados entre sistemas em um ambiente heterogêneo justamente por ser extremamente flexível, podendo ser particularizado (e estendido

\footnotetext{
${ }^{21}$ World Wide Web Consortium (W3C): <http://www.w3.org>.
} 
através de XML Schemas) para qualquer aplicação. Existem também algumas propostas de REL que não se baseiam em XML (CHONG et al., 2003), porém devido a baixa adoção desses modelos, este trabalho se concentrará nas REL baseadas em XML.

Dentre os objetivos pretendidos pelo XML Working Group, merecem destaque:

- Os documentos XML devem poder ser lidos diretamente por uma pessoa (usualmente arquivos de texto puro);

- A facilidade para criação dos documentos XML;

- A busca da facilidade da implementação de programas que processem (parsers) as informações de documentos XML.

Um documento XML consiste basicamente em um arquivo texto e a sintaxe do código é controlada através de tags, assim como no HTML. Na verdade, a estrutura do XML é muito parecida com HTML, com a diferença de que o XML permite que novas tags sejam criadas a qualquer momento. A Figura 2.3 mostra um trecho de um documento XML:

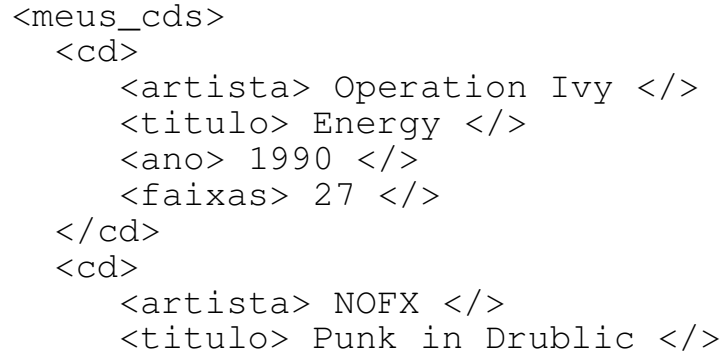

Figura 2.3 - trecho de arquivo XML descrevendo álbuns de música.

Ao se criar um arquivo XML que será passado para outro sistema, é necessário que o destinatário tenha como verificar se o arquivo está em conformidade com as regras acordadas. A definição de regras no XML é possível através do uso de modelos, chamados XML Schemas (W3C, 2000). Estes são modelos de particularizações para a criação de um determinado documento XML. Os schemas podem ser usados para "guiar" a criação de um documento XML e durante a utilização do mesmo, a fim de validar o formato.

O conjunto de políticas de uso para uma determinada mídia contém as regras de manipulação dessa mídia, ou seja, os deveres que o cliente deve respeitar e os direitos que lhe serão garantidos uma vez que os deveres sejam observados. A 
compilação dessas regras gera a licença de uso, um arquivo XML com todas as regras descritas através de uma determinada REL.

\subsubsection{Requisitos para a linguagem de expressão de direitos}

O principal requisito de uma linguagem de expressão de direitos (REL) é a declaração inequívoca de um direito sobre um conteúdo, mediante o cumprimento de obrigações. De acordo com Parrot (PARROT, 2001), a definição adequada dentro do contexto abordado seria:

"Um direito é o máximo que alguém pode fazer com uma propriedade intelectual; uma obrigação é o mínimo que alguém precisa fazer para obter o direito (alternativamente, obrigação é o que cada parte deve impor em contrato, de forma a assegurar os direitos)." (PARROT, 2001, p. 5, tradução nossa)

As RELs geralmente possuem propósito geral, sendo maleáveis para se aplicar sobre qualquer modelo de negócios. Tendo isso em vista, a maioria das linguagens disponíveis utilizam uma organização baseada na de Parrot, ilustrada na Figura 2.4.

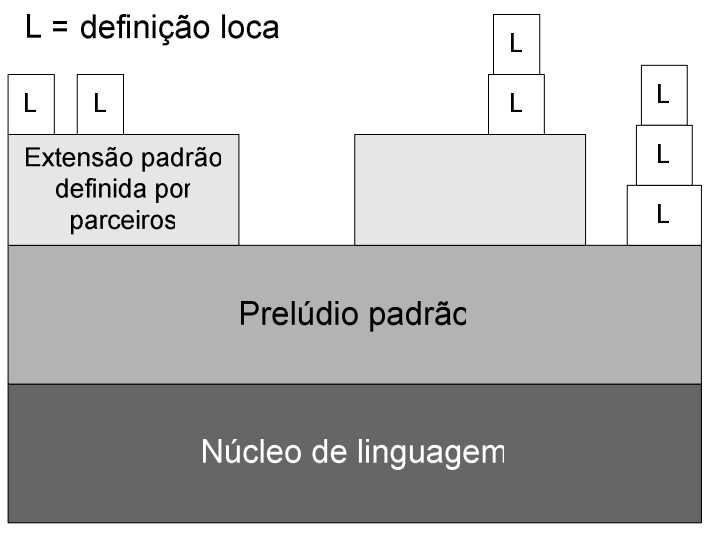

Figura 2.4 - Requisitos de estrutura para linguagem (PARROT, 2001).

Segue a descrição das camadas que compõem o modelo:

Núcleo de linguagem - conjunto mínimo de construtores primitivos da linguagem. Não se emprega à lógica de negócios, apenas às ações principais (ao invés de pay-per-view, aqui se descreve apenas "pagamento").

Prelúdio padrão - um conjunto de ferramentas para aplicação em situações genéricas. Usando conceitos baseados em Orientação a Objetos, as ferramentas do 
prelúdio devem poder ser reescritas pelas camadas superiores. Nesta etapa já surgem os modelos de negócios, como PPV, locação, assinatura, etc.

Acima dessas duas camadas existem as definidas por algumas partes interessadas que podem ser disponibilizadas entre comunidades e escopos locais. Cabe ressaltar que não há necessariamente um limite superior para o número de camadas.

\subsection{2 eXtensible Rights Markup Language}

O eXtensible Rights Markup Language (XrML) (W3C, 2002) é uma linguagem de expressão de direitos baseada em XML, criada pela Xerox Parc ${ }^{22}$ em meados da década de 90. A linguagem já possuía certo grau de maturidade quando foi proposta - e posteriormente adotada - como base para a REL do padrão MPEG-21 (RIGHTSCOM, 2003).

O XrML conta com uma proposta simples de arquitetura que consiste em quatro entidades e seus relacionamentos. O relacionamento básico no sistema é conhecido por "permissão" (no original, Grant). Como pode ser visto na Figura 2.5, a permissão compreende:

- O destino para qual a permissão é concedida;

- O direito que a permissão concede;

- A mídia a qual o direito se aplica;

- A condição que deve ser satisfeita antes do direito poder ser exercido.

\footnotetext{
${ }^{22}$ Xerox Parc: <http://www.parc.xerox.com/>.
} 


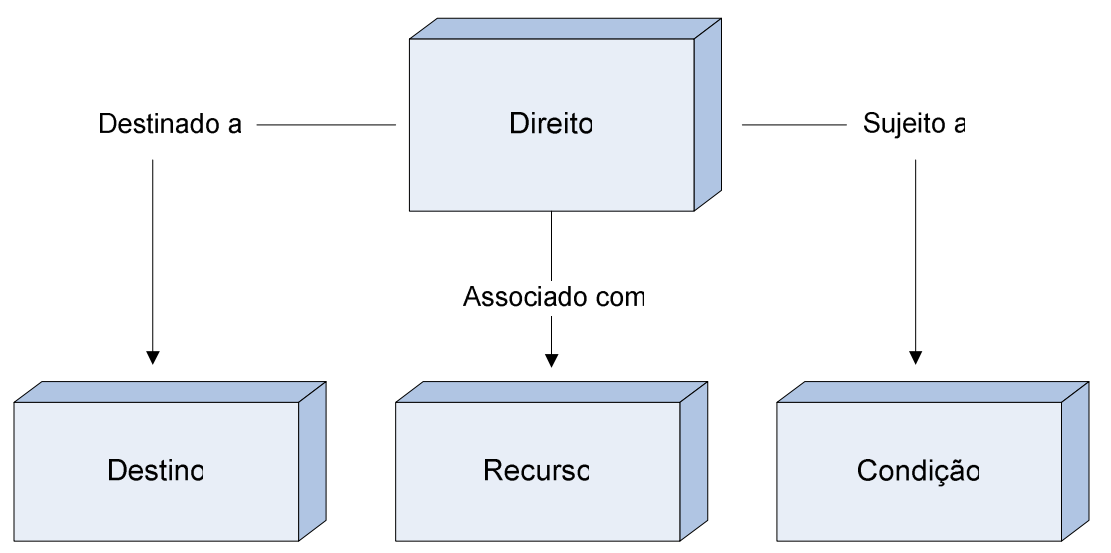

Figura 2.5 - Arquitetura XrML

Com referência ao que foi indicado, os elementos em questão são assim caracterizados:

- Destino: contém a identificação do(s) destinatário(s) para o(s) qual(is) os direitos devem ser garantidos. Cada Destino identifica precisamente o que pode ser uma pessoa, um dispositivo eletrônico ou um nó de rede.

- Direito: cada direito é uma ação que pode ser executada em um determinado conteúdo, respeitando-se certas condições.

- Recurso: é o identificador para o conteúdo digital que está sendo negociado.

- Condição: são as regras que devem ser respeitadas para que o Destino possa exercer seu Direito sobre o Recurso. Aqui reside a maior parte da complexidade da linguagem. $O$ XrML já possui um grande número de condições, porém novas poderão ser implementadas a partir de extensões que podem ser facilmente acrescidas ao sistema.

A adoção pelo comitê $M P E G^{23}$ é de suma importância para a disseminação desta linguagem, devido ao status que seus padrões alcançaram na indústria audiovisual. Além do MPEG, o XrML também conta com o apoio da Microsoft, que o utiliza para sua plataforma Windows Media Rights Management - WMRM (BIRNEY; GILL, 2003).

${ }^{23}$ Comitê da ISO/IEC responsável pelo desenvolvimento de padrões de codificação de áudio e vídeo. 


\subsubsection{Open Digital Rights Language}

O Open Digital Rights Language (ODRL) ${ }^{24}$ foi desenvolvido por uma iniciativa de empresas com o intuito de criar um padrão aberto para o setor de gerência de direitos digitais (IANNELLA, 2002). O ODRL foi adotado pelo Open Mobile Alliance $(\mathrm{OMA})^{25}$ como linguagem de expressão de direitos, além de ter sua versão mais recente (1.1) co-publicada pelo W3C. O modelo organizacional está ilustrado na Figura 2.6:

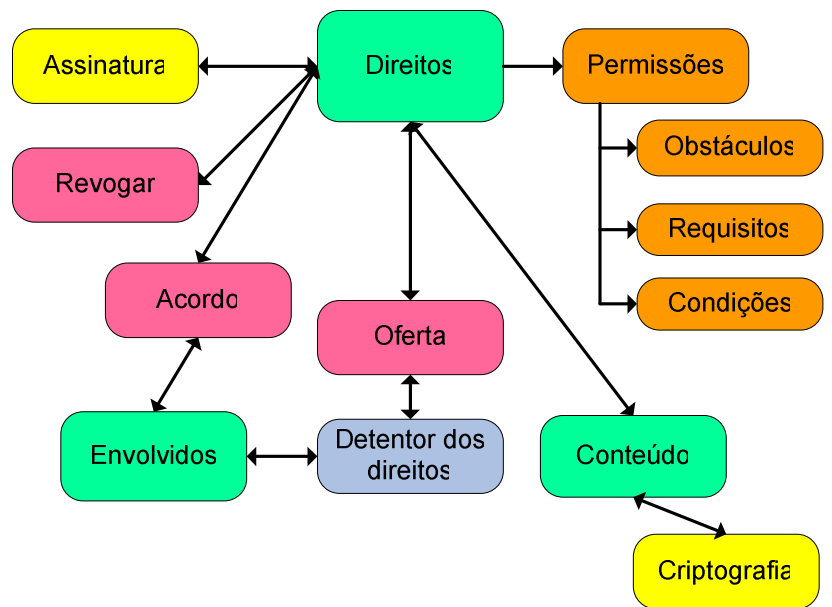

Figura 2.6 - Modelo ODRL (IANNELLA, 2002).

As principais entidades que aparecem no modelo são:

- Conteúdo: mídia em qualquer formato, desde que possa ser unicamente identificada. Pode estar criptografada para distribuição.

- Direitos: os direitos neste modelo se dividem em:

- Permissões - possíveis usos sobre a mídia.

- Obstáculos - limites para as permissões.

- Requisitos - obrigações exigidas para executar a permissão.

- Condições - exceções para as permissões concedidas.

- Envolvidos: usuário final, detentor de direitos ou qualquer um que possa exercer controle sobre o conteúdo e/ou suas permissões.

- Oferta: proposta do detentor de direitos para definição dos Direitos sobre um determinado conteúdo.

\footnotetext{
${ }^{24}$ Open Digital Rights Language: <http://odrl.net>.

${ }^{25}$ Open Mobile Alliance: <http://www.openmobilealliance.org>.
} 
- Acordo: contrato entre os envolvidos para lidar com certas ofertas.

O ODRL se baseia em XML e utiliza dois schemas: um para definir os elementos da linguagem de expressão e suas construções e outro para definir os elementos do dicionário de dados. A ODRL é expansível a partir do momento que pode ter novos schemas de dicionário acrescidos à linguagem para definir novos elementos ou mesmo estender o significado dos existentes.

Deve ficar claro que, ainda que sistemas de IPTV (como o aqui definido) apresentem a forte tendência de serem caracterizados como sistemas puramente comerciais, não devem ser confundidos com sistemas proprietários. Uma das metas neste trabalho é se valer de padrões e plataformas abertas que sustentem a especificação de um sistema IPTV que seja transparente. Esta confusão inicial é comum e prejudica o entendimento dos sistemas IPTV como aplicações potenciais de pesquisa.

Este capítulo apresentou a arquitetura de referência para um sistema IPTV, além de introduzir as linguagens de expressão de direitos. Com isso, tem-se uma visão completa do cenário, permitindo a especificação do objeto do trabalho mais adiante. O próximo capítulo introduz tecnologias e mecanismos necessários para a viabilidade do sistema. 


\section{Capítulo 3 - Tecnologias para suporte ao IPTV}

Este capítulo analisará modelos para sistemas de gerenciamento de direitos e outras tecnologias atuais para dar suporte à distribuição de conteúdo seguro. Estes sistemas servem de guia para algumas práticas que serão aplicadas ao modelo de IPTV proposto neste trabalho.

Primeiramente são apresentados os sistemas DRM, modelos baseados em distribuição de conteúdo protegido por criptografia e controle rigoroso de consumo. Alguns dos conceitos de segurança utilizados nestes modelos são relevantes para os sistemas de IPTV, porém este cenário usualmente possui grandes restrições para a manipulação da mídia, sendo pouco flexíveis para o consumidor.

Mais adiante neste capítulo serão apresentadas propostas de arquiteturas baseadas em padrões abertos para sistemas de IPTV. As mais importantes são destacadas e embasam a especificação do Distribuidor no capítulo a seguir.

Ao final do capítulo são analisados modelos de distribuição e tecnologias empregadas para prover o serviço de IPTV e a extrema importância da utilização de distribuição para grupos devido ao alto consumo de banda característico das aplicações de vídeo.

\subsection{Modelo de arquitetura para DRM}

É possível utilizar a arquitetura proposta por Rosenblatt (ROSENBLATT; TRIPPE; MOONEY, 2002) para ilustrar um sistema de DRM. O autor divide o sistema em três blocos principais, compostos por: servidor de conteúdo, servidor de licença e o cliente. A Figura 3.1 representa os blocos e conexões lógicas entre eles. Seguem a ela as descrições de cada elemento destacado. 


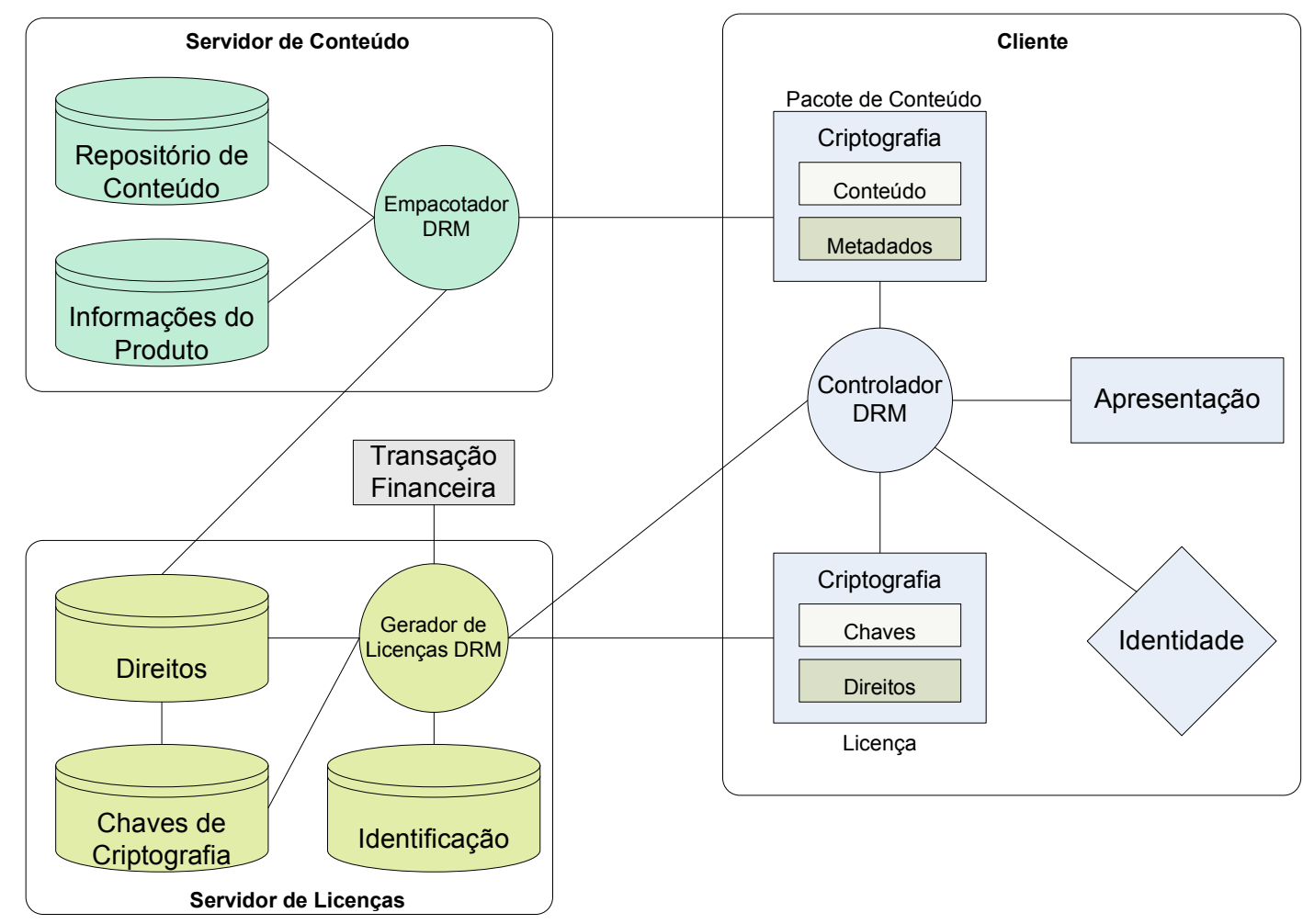

Figura 3.1 - Arquitetura de referência DRM.

\section{Servidor de Conteúdo}

Este bloco é responsável pelo armazenamento do conteúdo, de informações adicionais sobre o mesmo e rotinas para criação de mídia segura a partir de criptografia utilizando as chaves do servidor de licenças. Conforme exibido na figura, os principais elementos que compõem o servidor são:

- Repositório de conteúdo: contém a mídia que será distribuída para os clientes, podendo estar em um formato pronto para distribuição ou mesmo ser preparado sob demanda;

- Informações de Produto: o repositório de informações sobre os produtos pode conter dados da mídia, como duração, resolução, entre outros. Apesar de vários dados poderem estar diretamente inseridos na mídia, é conveniente que informações sigilosas ou dados como preço sejam armazenados separados dela.

- Empacotador: representa a funcionalidade que prepara o conteúdo para ser distribuído e é responsável pela criptografia da mídia. Quando criptografa a mídia, o empacotador gera também o conjunto de políticas de uso, que, junto com as chaves usadas para a criptografia do conteúdo são enviadas para o 
servidor de licenças e ficarão esperando as solicitações dos clientes. Resulta deste bloco um pacote criptográfico de conteúdo para ser distribuído.

Além do conteúdo propriamente dito, o pacote criado pelo sistema também pode conter metadados, que podem armazenar várias informações. O mais comum é a inserção de algum tipo de informação de identificação, como algum tipo de número único para permitir o rastreamento pelo Distribuidor.

\section{Servidor de Licenças}

Servidores de licença são responsáveis por interpretar a lógica de negócios e aplicá-las conforme as solicitações dos clientes. Estes servidores são compostos pelos seguintes elementos:

- Gerador de Licenças: módulo responsável pela criação da licença que será entregue ao cliente. A licença consiste em um pacote criptográfico que contém a chave para acessar a mídia protegida e a declaração dos direitos, que descrevem a maneira como o cliente poderá usufruir dela.

- Chaves de Criptografia: repositório com as chaves criadas pelo empacotador. Uma chave pode ser resgatada quando o servidor precisar criar uma licença para a mídia vinculada a ela.

- Repositório de Direitos: aqui são mantidos os direitos que foram gerados pelo empacotador.

- Identificação: contém o cadastro para identificar os clientes pertencentes ao sistema.

A licença encontra analogia em um ingresso de cinema, por exemplo. Nesse caso, uma pessoa compra um ingresso que garante permissão para acessar determinado filme (conteúdo) em um único horário (obrigação). Essa licença poderia ser mais específica ainda, no caso do usuário ser idoso e ganhar desconto mediante apresentação de documento que ateste sua identidade. Este é apenas um exemplo de como a migração de todas as nuances da venda tradicional para a digital pode ser uma tarefa complexa. 


\section{Cliente}

O bloco do cliente recebe do sistema o pacote de conteúdo e a licença de uso, ambos criptografados. Os dois pacotes podem ser - e em muitos casos serão entregues pelo mesmo meio. De fato, o servidor de conteúdo e o servidor de licenças podem representar uma mesma entidade física. Adiante tem-se a exposição de seus elementos:

- Identidade: forma pela qual o usuário pode se autenticar no sistema. Existem diversas formas para tanto: senha, smart cards, token e biometria são os métodos mais comuns (O'GORMAN, 2003).

- Apresentação: compreende as aplicações habilitadas pelo DRM para apresentação do conteúdo. Tipicamente são aplicações desenvolvidas para uso específico nesses sistemas, ou nos casos em que são usadas modificações em aplicações tradicionais.

- Controlador DRM: é a unidade central do bloco do cliente. O controlador deve garantir que o pacote do conteúdo só seja aberto mediante a licença correspondente, além de reforçar os direitos descritos na licença.

Um grande desafio na implementação de uma plataforma DRM é garantir que uma vez que o usuário possua a chave para abrir o conteúdo, ele não a use indevidamente. Vale lembrar que a plataforma deve ser flexível, possibilitando ao usuário executar a mídia em diversos dispositivos, como, por exemplo: set-top boxes, celulares, computadores pessoais, PDAs, etc.

\subsection{Principais sistemas DRM comerciais}

Já existem vários sistemas DRM disponíveis no mercado (FLEURY, 2005), cada qual com escopo particular, nem sempre exercendo todas as funções para uma solução DRM completa. Seguem as caracterizações dos principais plataformas disponíveis atualmente. 


\subsubsection{Microsoft Windows Media Rights Manager}

A solução de DRM da Microsoft, o Windows Media Rights Manager (WMRM), oferece distribuição segura para provedores de conteúdo e distribuidores (MICROSOFT, 200-?). A Microsoft disponibiliza kit de desenvolvimento de software (SDKs) tanto para servidor, quanto para cliente. Versões mais recentes do produto possibilitam que dispositivos portáteis adquiram licenças e acessem conteúdo protegido. A Figura 3.2 ilustra o fluxo de dados dentro do sistema:

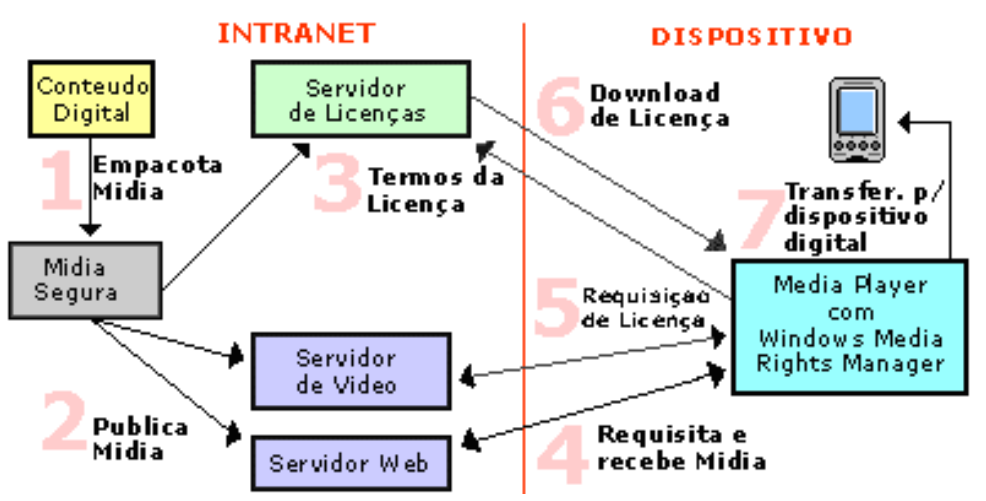

Figura 3.2 - Fluxo de dados do WMRM (MICROSOFT, 2006).

Segue a descrição dos elementos que compõem o sistema, de acordo com sítio institucional:

- Empacotamento: o processo aqui ocorre da mesma forma que no modelo do início do capítulo. O arquivo gerado é salvo no formato Windows Media de áudio (extensão .wma) ou vídeo (.wmv).

- Distribuição: o arquivo pode ser distribuído como qualquer outro: pela Internet, em CDs, etc. Em alguns casos é permitido que usuários enviem arquivos para outros usuários.

- Estabelecimento do servidor de licenças: o provedor de conteúdo define qual será o servidor de licenças usado e implementa o WMRM license services. O resto do processo é análogo ao modelo.

- Aquisição da licença: a licença deve ser adquirida para habilitar a execução do conteúdo. O processo é iniciado automaticamente quando o usuário baixa o conteúdo ou tenta executá-lo de um CD pela primeira vez. O WMRM pode direcionar o cliente para uma página de requisição da licença ou de forma 
"silenciosa" baixá-la automaticamente em casos em que o cliente não tenha que arcar com nenhum gasto.

- Execução da mídia: a execução da mídia requer necessariamente a utilização de um tocador que suporte o WMRM. Algumas licenças conferem ao cliente o direito de copiar a mídia para um dispositivo portátil, porém em nenhum caso as licenças são transferíveis. Caso um usuário copie a mídia para outro, esse segundo deverá comprar uma licença própria.

Uma das vantagens dessa solução é a disponibilidade do kit de desenvolvimento de software $(S D K)^{26}$ para personalização da implementação. A Microsoft também conta com a vantagem competitiva de ter um sistema operacional que domina o mercado de usuários domésticos, além de boa parte dos desktops em geral. Vale ressaltar que já existe suporte para diversos dispositivos como: set-top boxes, celulares, DVD players, entre outros.

Por outro lado, os formatos de áudio e vídeo disponíveis ficam limitados aos desenvolvidos pela própria fabricante (ASF, WMA e WMV). A princípio, o suporte a tocadores parece ainda estar limitado ao próprio Media Player, restringindo a plataforma-base utilizada.

Da mesma forma, as licenças tendem a ser abusivas e restringem o uso a um único computador ou dispositivo, ficando presas a dispositivos ao invés de usuários. Essa restrição de uso é algo pouco conveniente para os clientes, geralmente causando bastante descontentamento.

\subsubsection{Real Networks Helix DRM}

Criado pela Real Networks, o Helix DRM é o sistema proposto pela empresa como solução para distribuição de formatos-padrão áudio e vídeo (RealAudio, RealVideo, MP3, MPEG-4, AAC, H.263 e AMR) (HELIX, 2006). Além de computadores, o Helix DRM também pressupõe o uso em outros tipos de dispositivos móveis.

Este sistema é desenvolvido sobre a plataforma de transmissão de mídia da Real Networks (também conhecida como Helix). Uma diferença interessante em

\footnotetext{
${ }^{26}$ Atualmente a Microsoft não cobra pelo SDK.
} 
relação ao WMRM é o cuidado que a Real tem com a distribuição de mídia contínua em tempo real. Justamente por ser uma plataforma de distribuição de áudio e vídeo, - Helix DRM é configurado como uma camada que se sobrepõe à plataforma existente a fim de manter as mesmas funcionalidades que já existiam: distribuição de fluxo de canal de TV, VoD, aluguel e compra de mídia.

O Helix DRM utiliza uma estrutura muito similar ao modelo de Rosenblatt, mantendo os blocos funcionais. Assim como o proposto pela Microsoft, o Helix DRM precisa de tocadores habilitados para decriptar a mídia adquirida, estando por enquanto restrito ao Real Player $^{27}$, desenvolvido pela própria fabricante. O Helix DRM, assim como o WMRM, ainda está limitado a poucas plataformas de software devido à restrição do tocador.

O ponto positivo do Helix DRM é ser uma plataforma que conta com diversas funcionalidades que tratam distribuição de mídia, principalmente em tempo real. É assim que a plataforma Helix da Real já é uma importante solução no mercado de servidores de vídeo. A adição de mecanismos de DRM, por sua vez, colabora para agregar valor ao produto.

\subsection{Plataformas abertas de IPTV}

Mesmo que ainda predominantemente proprietário, o IPTV também possui iniciativas abertas para implementação. Algumas empresas vêm desenvolvendo sistemas que se integram através de padrões abertos, a fim de evitar estruturas muito rígidas que obriguem os clientes a adotar uma única solução. Além dessas iniciativas, alguns grupos foram formados para incentivar a utilização de protocolos já existentes e, conseqüentemente, sistemas mais transparentes.

\footnotetext{
${ }^{27}$ Real Player: <http://www.real.com/realplayer.html>.
} 


\subsubsection{Internet Streaming Media Alliance}

A Internet Streaming Media Alliance (ISMA) ${ }^{28}$ é um grupo formado por empresas de desenvolvimento de tecnologia audiovisual e provedores de serviço. $O$ escopo da ISMA é o desenvolvimento de um sistema de IPTV fim-a-fim baseado principalmente em padrões abertos já existentes, além da possibilidade de propor novos padrões caso necessário.

O padrão proposto pela ISMA (ISMA, 2005) se baseia fortemente em protocolos já conhecidos para transporte nas redes IP, como o Real-time Transport Protocol (RTP) (SCHULZRINNE et al., 2003). Um dos diferenciais está no fato dela propor o transporte da mídia diretamente acima do RTP, sem o uso do MPEG-2 Transport Stream (ISO/IEC 13818-1, 1995), ao contrário do que é feito em outros sistemas de transmissão de TV, como o Digital Video Broadcasting (DVB) ${ }^{29}$ (DVBIPI, 2002).

Retirar o MPEG-2 TS traz vantagens técnicas a partir do momento em que se está diminuindo o overhead causado pela complexidade do protocolo e, possivelmente, flexibilizando e dando maior capacidade escalar ao sistema. Porém é uma alternativa arriscada, visto que o MPEG-2 TS já é amplamente utilizado na indústria há muitos anos. Com isso a ISMA aposta em um sistema que precisa de um custo maior de implementação, entretanto, dando a contrapartida de serviços que utilizam menos banda e são mais flexíveis. Fica difícil prever se o mercado estará suficientemente motivado a investir um alto custo para a troca dos sistemas.

\subsubsection{Arquitetura}

De forma resumida, a arquitetura para transmissão no sistema de IPTV da ISMA pode ser visto na Figura 3.3 a seguir:

\footnotetext{
${ }^{28}$ Internet Streaming Media Alliance (ISMA): <http://www.isma.tv>.

${ }^{29}$ Digital Video Broadcasting (DVB): <http://www.dvb.org/>.
} 
Formatos de Midia

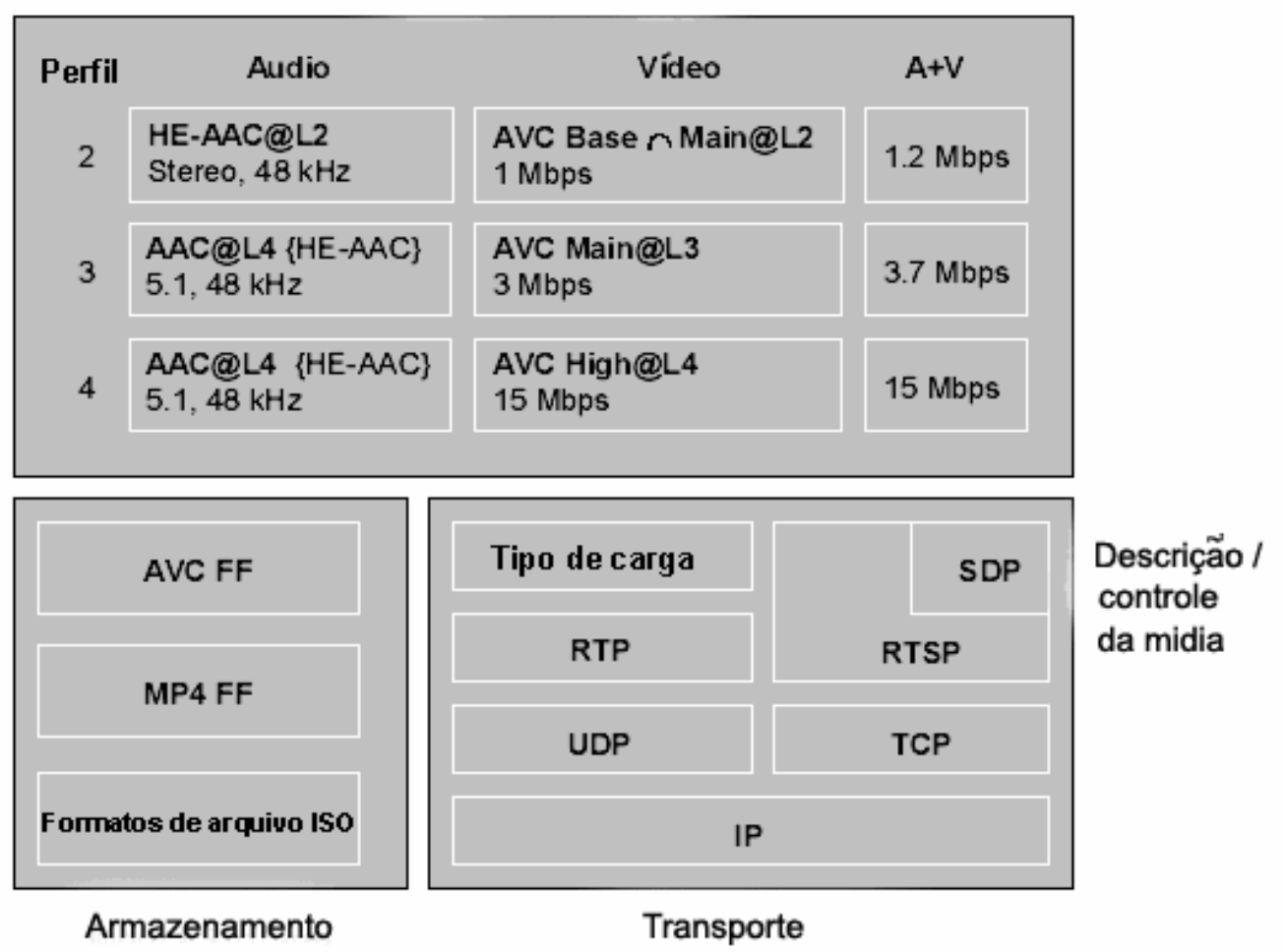

Figura 3.3 - Arquitetura de transporte ISMA (ISMA, 2005).

O modelo é composto por três elementos principais: o primeiro deles é o armazenamento do sistema, onde são definidos os tipos de arquivos que poderão ser utilizados no sistema. O ISMA utiliza o formato de arquivo do MPEG-4 (ISO/IEC 14496-1, 2001), que é um container genérico para vários tipos de codificação. $O$ segundo elemento é o transporte, que está subdividido na parte de transmissão do conteúdo propriamente dito (sobre UDP/RTP) e no controle de reprodução e descrição (sobre TCP). Na parte superior da imagem se encontra o último elemento, que descreve os formatos de mídia que poderão ser utilizados. É possível observar que são definidos 3 tipos de perfis (profiles), que vão desde definições menores para sistemas com restrições de banda, até o perfil 4 , que trabalha com HDTV.

\subsection{Trusted Platform Module (TPM)}

O Trusted Computing Group (TCG) ${ }^{30}$ foi formado com o intuito de criar mecanismos que possibilitem operações seguras em diversos dispositivos. Trata-se

\footnotetext{
${ }^{30}$ Trusted Computing Group: <http://www.trustedcomputinggroup.org>
} 
de uma corporação internacional que conta com mais de uma centena de representantes na indústria, criada com o propósito de desenvolver padrões abertos para tecnologia de segurança e computação confiável (Trusted Computing). O grupo vem desenvolvendo a tecnologia conhecida como Módulo de Plataforma Confiável, ou Trusted Platform Module (TPM) (TCG, 2006), que é considerada a base para a computação confiável. O TPM consiste em um chip estrategicamente ligado a um dispositivo, que permite armazenar de forma segura chaves criptográficas, certificados e senhas.

De acordo com o TCG (TCG, 2005), as principais capacidades do TPM incluem a criação de chaves assimétricas para o armazenamento seguro de informações. Como as chaves nunca deixam o módulo, a operação de criptografar e decriptar se torna mais segura. Outra importante funcionalidade é o armazenamento de valores de Hash que representam estados de configuração da plataforma, mecanismo que garante a integridade da configuração do sistema. Há também a possibilidade de inicialização e gerenciamento do chip TPM, que possibilita o controle da sua ação no sistema.

O TPM já está sendo usado no mercado, estando disponível em placas-mãe para PCs de fabricantes como: Asus, Gigabyte, Intel, entre outros ${ }^{31}$. Nota-se que a crescente adoção desta plataforma é uma aposta significativa na tecnologia.

O TPM pode vir a ser a tecnologia chave para que sistemas DRM virem realidade, pois pode atuar justamente no ponto fraco do sistema: a casa do usuário. Uma vez que as mídias que são distribuídas estarão criptografadas, o problema reside em garantir que o usuário final não fará uso indevido quando estiver em posse da mesma. O TPM resolve esse problema tornando os dispositivos do usuário "confiáveis".

Há casos em que é especialmente interessante para os Produtores de conteúdo que haja algum tipo de mecanismo de controle sobre o consumo da mídia distribuída. Dessa forma é interessante conseguir monitorar o que acontece no elemento de distribuição do sistema. A utilização de TPM neste elemento permite que ele seja considerado confiável pelo Produtor, podendo gerar relatórios de

\footnotetext{
${ }^{31}$ Exemplos de placas-mãe: Asus P5WDG2-WS <http://www.asus.com>; Gigabyte GA-K8N51PVM9$\mathrm{RH}<\mathrm{http}: / /$ www.gigabyte.com.tw $>$ e Intel D865GRH < http://www.intel.com>.
} 
consumo no sistema. Isso pode gerar formas de bilhetagem entre Produtor e Distribuidor mais flexíveis com a demanda do sistema.

Este processo de criar um elemento distribuído com garantias de confiabilidade é inspirado na proposta do distribuidor de Cinema Digital ( $\mathrm{DCl}, 2004)$, onde o servidor de distribuição fica instalado fisicamente nas salas de exibição dos cinemas, controlando rigidamente tudo é que exibido e reportando aos distribuidores e produtores. Na proposta da $\mathrm{DCl}$ são especificadas as interfaces deste elemento de distribuição, sendo que o funcionamento interno é deixado a cargo de protocolos proprietários como "garantia" de segurança e o elemento de distribuição deverá ser atestado pelos produtores antes de ser utilizado para exibição.

\subsection{Criptografia de mídia e esteganografia}

O controle de distribuição de conteúdo em um sistema IPTV deve permitir algum mecanismo de criptografia de fluxo de dados para assegurar a confidencialidade do conteúdo durante a distribuição e armazenamento.

Os fluxos contínuos de áudio e vídeo possuem características que os diferenciam da criptografia tradicional em alguns pontos: primeiramente, fluxos de áudio e vídeo permitem a perda de informação sem comprometer a reprodução do conteúdo, diferente do que acontece com arquivos criptografados que não podem perder dados. Em segundo lugar, estes fluxos deverão ser exibidos durante sua recepção. Para isto, são necessários algoritmos que permitam criptografar durante a transmissão e recepção, chamados de cifras de mascaramento (ou stream cipher).

Para viabilizar a criptografia do conteúdo em um sistema de fluxos contínuos, alguns mecanismos diferenciados de criptografia são sugeridos a seguir.

\section{Criptografia de canal}

A criptografia do canal de dados permite a criação de um canal seguro de comunicação entre dois pontos utilizando criptografia simétrica para transmissão dos dados e assimétrica para negociação inicial de chaves criptográficas entre as partes (STALLINGS, 2002). Exemplos desse mecanismo são: IP Security (IPSEC) e Transport Layer Security (TLS) (STALLINGS, 2002). 
O ponto negativo desses protocolos é a complexidade que inserem tanto no Distribuidor como no Cliente, além de dificultarem a comunicação 1-para-n necessária para a escalabilidade do sistema. Dessa forma, estes protocolos são mais indicados para transações secundárias do sistema, como a venda de uma licença de uso para um Cliente.

\section{Criptografia de payload}

Uma tecnologia mais indicada para transmissão do fluxo de dados é o Secure Real-time Transport Protocol (SRTP) (BAUGHER et al., 2004). O SRTP permite criptografar apenas o campo de dados (payload) do fluxo (Figura 3.4), possibilitando que a rede enxergue o tipo de tráfego e consiga utilizar algumas informações sobre o próprio tráfego, marcação de tempo e ordenação de pacotes (semelhante ao RTP, explicado adiante).

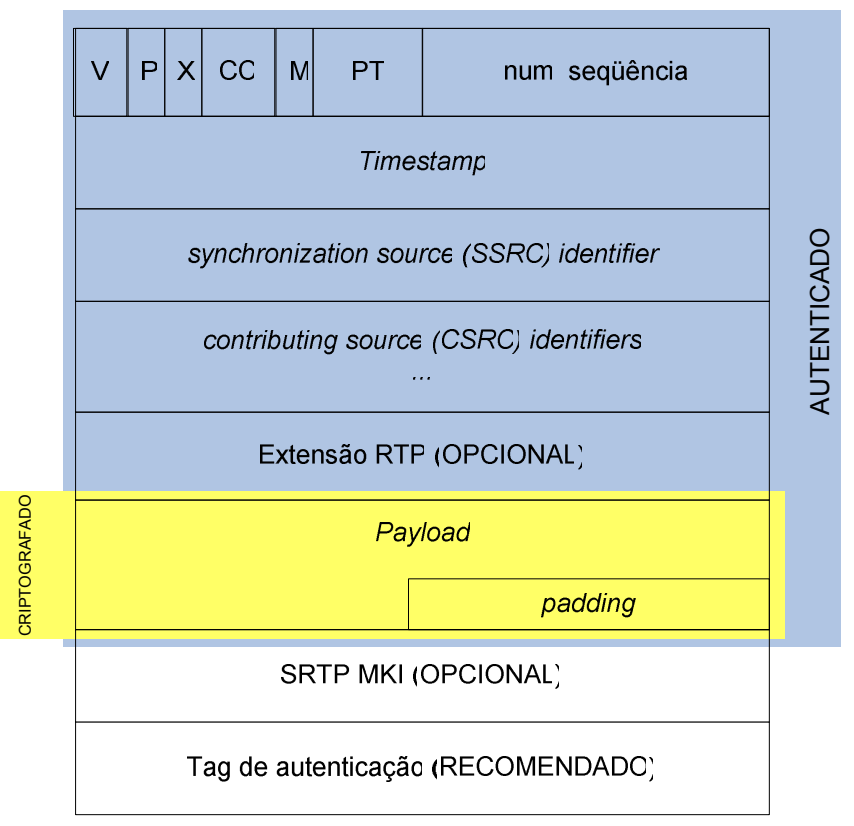

Figura 3.4 - Pacote SRTP.

Conforme ilustrado, recomenda-se ao Distribuidor também autenticar parte do cabeçalho e enviar o resumo criptográfico resultante no campo "Tag de autenticação" ao final do pacote. Este mecanismo garante a integridade dos dados. 


\section{Criptografia seletiva de vídeo}

Uma terceira forma de se aplicar segurança ao fluxo seria através da criptografia seletiva de vídeo (MARGI; BRESSAN; RUGGIERO, 2000), em que mecanismos criptográficos específicos para sigilo do conteúdo multimídia são aplicados. A grande vantagem deste tipo de solução é utilizar criptografia na menor parte possível do conteúdo, mantendo cabeçalhos de protocolos abertos. Isso possibilita que a mídia seja corretamente identificada por todos os equipamentos no sistema, podendo inclusive ser armazenada assim.

A vantagem oferecida por este método é crucial para facilitar a utilização de dispositivos já existentes para manipulação do conteúdo. Boa parte dos servidores de transmissão de vídeo, por exemplo, poderiam ser utilizados, visto que a única parte afetada pela criptografia, neste caso, é o estágio de apresentação. Este mecanismo é interessante para ser utilizado no Produtor, pois permite a manipulação da mídia nas próximas etapas de forma transparente.

\section{Distribuição de chaves criptográficas para grupos}

Seja qual for o mecanismo de criptografia utilizado, a distribuição das chaves entre clientes é um tópico que merece atenção especial. O processo de criação de chaves para grandes grupos de usuários é custoso, e no cenário de IPTV a questão do chaveamento é ainda mais crítica, pois é necessário que novos usuários ingressem e saiam dos grupos com certa freqüência, exigindo o rechaveamento.

Cada vez que um usuário entra no grupo de clientes do Distribuidor, este deve receber uma chave criptográfica para acesso ao conteúdo. Gerar chaves individuais seria a melhor maneira de controlar o acesso, porém isso implicaria em distribuir conteúdo especificamente criptografado para cada usuário, acabando com a possibilidade de distribuição para grupos. Infelizmente isso acarreta no Distribuidor ter que criptografar individualmente cada fluxo que transmite, fato que impossibilita esta técnica. Por outro lado a distribuição de chaves comuns ao grupo de usuários simplifica o processo de criação de chaves, porém introduz o problema de ter que criar novas chaves para todos no grupo cada vez que um sai.

Existem algoritmos em estudo (SHERMAN, 2003) para otimizar o processo de criação de chaves diferentes para integrantes de um grupo que recebe o mesmo 
fluxo criptográfico. Os referidos algoritmos ainda estão em desenvolvimento, contudo, faltam resultados concretos para comprovar a eficiência em larga escala.

De forma a simplificar esta questão, pode-se assumir a distribuição de chave única para o grupo de usuários recebendo o mesmo fluxo criptográfico, evitando o problema do novo chaveamento através da cobrança adiantada pelos serviços prestados, prática comum nas operadoras atualmente. Tecnologias mais avançadas para a estrutura de distribuição de chaves podem vir a ser consideradas em futuras implementações.

\section{Técnicas de esteganografia}

Além da criptografia de mídia, outros mecanismos podem ser utilizados para ajudar na proteção dos sistemas de IPTV. Uma técnica comum é a inserção de mensagens escondidas na mídia, conhecida como esteganografia. Estes mecanismos podem ser utilizados para identificação de autoria do conteúdo ou para rastreamento do mesmo.

\section{Marca d'água}

A técnica mais difundida de esteganografia é a marca d'água ou watermarking (DWA, 200-?). Sua aplicação pode ser visível ou invisível, dependendo do contexto. A figura a seguir apresenta um exemplo de marca d'água visível:

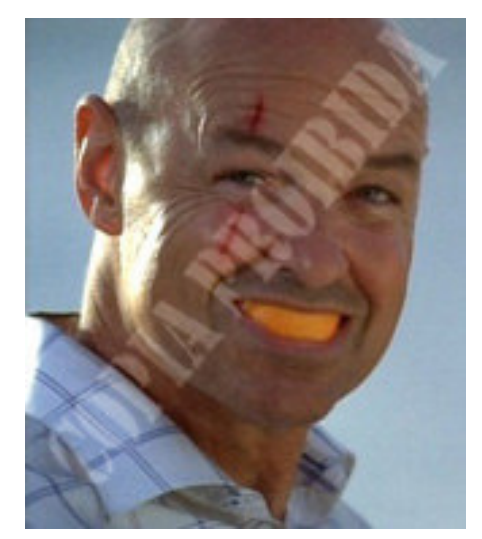

Figura 3.5 - Imagem com marca d'água visível.

Este tipo de marca serve para coibir a cópia de conteúdo sem autorização. São casos de marca d'água os logotipos das emissoras de TV sobrepostos na exibição do vídeo. Este é o uso mais comum atualmente, mas esta técnica não está restrita a isso. De fato, o uso das marcas invisíveis pode ser muito útil para identificar mídias 
adquiridas irregularmente. Mensagens escondidas na mídia permitem a certificação da autoria do conteúdo, além de também poderem garantir a integridade do mesmo.

\section{Footprint}

Uma variação deste mecanismo é utilizada para rastreamento (footprint ou forensic tracking) do conteúdo quando deixa um sistema. Este mecanismo consiste em identificar o conteúdo de forma invisível, podendo identificar individualmente cada conteúdo em relação ao usuário que o adquiriu.

Este mecanismo é muito utilizado atualmente em cinemas que tentam coibir a cópia amadora durante a exibição. Uma mensagem de autoria é inserida no filme e fica invisível durante a exibição, porém ao ser gravada com uma filmadora comum a marca aparece, prejudicando a cópia.

\subsection{Estratégias de difusão de conteúdo em IPTV}

A motivação para criação de sistemas IPTV é a necessidade de novos serviços para empresas que possuem uma infra-estrutura IP já instalada. Essas redes normalmente possuem características bem distintas de uma infra-estrutura para difusão televisiva. Nas redes IP as transmissões ponto-a-ponto predominam, sendo que a distribuição como na TV (broadcast) é, sempre que possível, evitada por causa do consumo excessivo de banda.

Nesta seção serão apresentadas tecnologias que possibilitam dar vazão ao conteúdo através da rede de acesso aos clientes. Dentre estas tecnologias estão inclusos mecanismos de distribuição para grupos, além de protocolos para transporte multimídia. Estas tecnologias formarão o conjunto que possibilitará modelar a pilha de protocolos para distribuição do conteúdo no cenário desenvolvido. 


\subsubsection{Protocolos de apoio ao transporte}

O grupo de protocolos descritos a seguir é principalmente formado por recomendações da Internet Engineer Task Force (IETF) ${ }^{32}$, órgão responsável por boa parte dos padrões utilizados na Internet. Dessa forma espera-se vincular a distribuição com mecanismos já existentes, facilitando a implementação do sistema proposto.

\section{RTP e SRTP}

Tradicionalmente a transmissão de mídias contínuas como áudio e vídeo é realizada sobre User Datagem Protocol (UDP) para minimizar latência e aumentar vazão. Todavia, este protocolo não possui garantia de entrega e seu controle pode ser um tanto quanto limitado. Para solucionar esta questão, é proposta a utilização do Real-time Transport Protocol (RTP) (SCHULZRINNE et al., 2003). O RTP insere cabeçalhos de para ajudar no controle pelo receptor, dentre eles, pode-se citar:

- Número de seqüência: os pacotes enviados são numerados de acordo com a sessão. Estes números ajudam o receptor a verificar se existe alguma perda na rede.

- Timestamp: cada pacote enviado recebe uma marcação de tempo. Esta marcação pode ser usada no receptor para verificar $\mathrm{Jitter}^{33}$, por exemplo.

- Tipo de payload: o tipo de conteúdo que está sendo transmitido vai marcado em um cabeçalho. Este pode ser utilizado para priorização ao passar pelos elementos da rede.

O RTP pode ser utilizado diretamente em conjunto com a criptografia seletiva de vídeo, permitindo o transporte pela rede com os mesmas características de transmissão de uma mídia comum. O processo de encapsulamento está ilustrado abaixo:

\footnotetext{
${ }^{32}$ Internet Engineer Task Force (IETF): <http://www.ietf.org>.

${ }^{33}$ Fenômeno que ocorre em uma rede IP definido pela chegada fora de ordem dos pacotes no destino. Nos casos de áudio e vídeo esta perturbação pode gerar diversos problemas e deve ser evitada pela rede e tratada pela aplicação quando possível.
} 


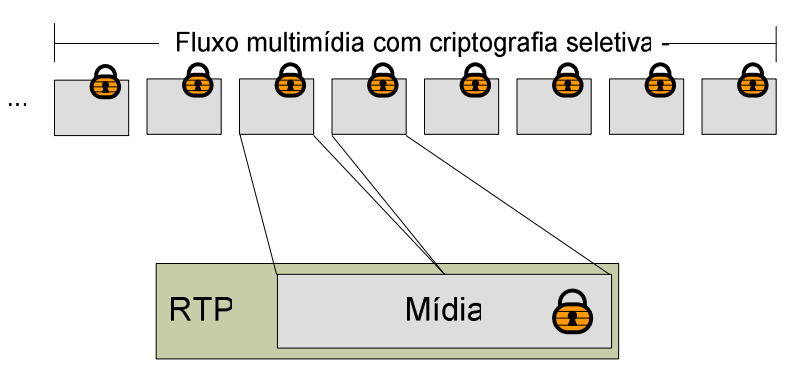

Figura 3.6 - Encapsulamento RTP.

Existe a possibilidade da mídia estar sem criptografia enquanto dentro do Distribuidor. No entando, esta deve ser criptografada para que possa ser passada para a Rede de Acesso. Neste caso, indica-se o uso do SRTP, proporcionando os mesmos cabeçalhos que o RTP além da criptografia do campo de dados.

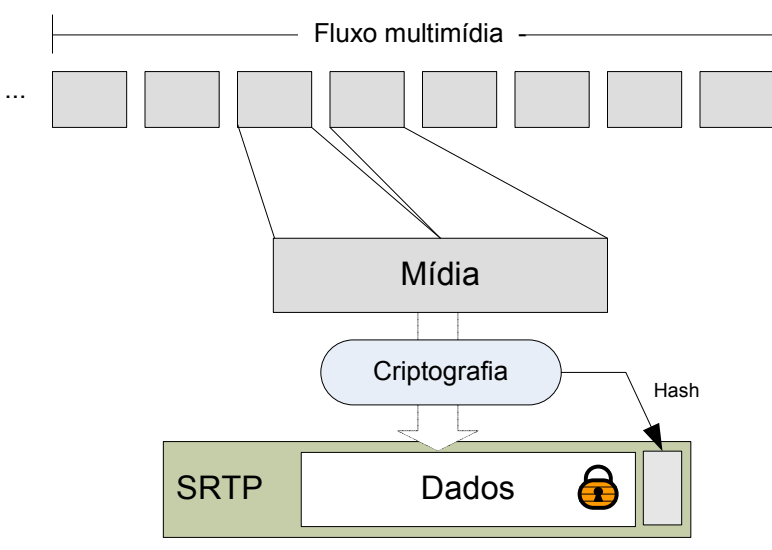

Figura 3.7 - Encapsulamento SRTP.

Fora o mecanismo de criptografia, estes protocolos funcionam de forma idêntica, melhorando a transmissão através de algumas características que estão disponíveis apenas no TCP (porém, com menor overhead).

\section{RTCP e SRTCP}

O RTP Control Protocol (RTCP) (SCHULZRINNE et al., 2003) permite que o Distribuidor tenha um canal de retorno com o Cliente para informações acerca de qualquer perturbação na Rede de Acesso (altas latências, Jitter, perda de pacotes, congestionamento, etc.) percebidas com a ajuda do RTP ou SRTP. O RTCP ajuda o Distribuidor a mapear estes problemas e contê-los. De acordo com o padrão, os pacotes de controle RTCP devem ser multiplexados pelo mesmo canal de transmissão dos dados (Figura 3.8). 


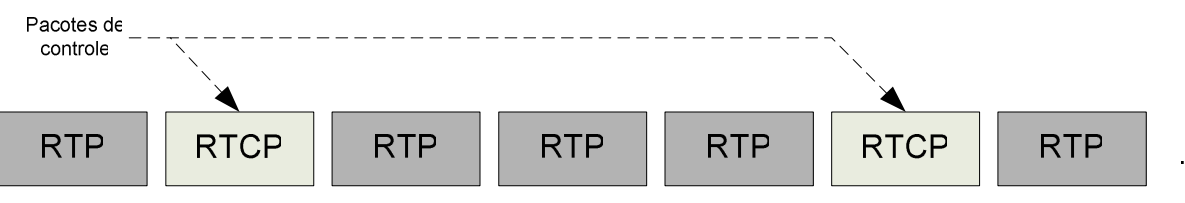

Figura 3.8 - Multiplexação de pacotes RTCP em uma Transmissão UDP.

Os receptores nos clientes também devem implementar o RTCP. Cada receptor envia periodicamente alguns pacotes de relatório (Sender reports) de volta para a fonte. A fração de tráfego que os pacotes de controle ocupam durante a transmissão é ínfima comparada ao fluxo de dados - usualmente se prevê a ocupação de no máximo 5\% em relação ao envio de dados.

No caso de transmissões SRTP, o Secure RTP Control Protocol (SRTCP) deve ser utilizado. Seu funcionamento é idêntico ao RTCP.

\section{RTSP}

O Real Time Streaming Protocol (RTSP) (SCHULZRINNE; RAO; LANPHIER, 1998) é um protocolo da camada de aplicação para controle sobre a entrega de dados com propriedades de tempo real. Este protocolo se aplica a conteúdos do tipo áudio e vídeo que estejam armazenados em um servidor, bem como fontes ao vivo. O RTSP tem capacidade de controlar diversas sessões simultâneas de dados, provendo habilidade para escolha do canal de entrega como UDP, multicast UDP ou mesmo TCP; além disso possibilita a utilização conjunta com mecanismos de entrega baseados em RTP.

O protocolo utiliza mensagens HTTP/1.1 para comunicação cliente-servidor, entretanto, segundo a norma que define o RTSP, não existe a noção de conexão RTSP, sendo invés disso mantida uma sessão rotulada por um identificador (identifier). Essa sessão não é vinculada a uma conexão de camada de transporte como o TCP. Na verdade, durante uma sessão RTSP, um cliente pode abrir e fechar diversas conexões de transporte com o servidor para fazer RTSP requests.

O RTSP é sugerido para utilização em conjunto com outros protocolos para complementar funcionalidades na distribuição de conteúdo VoD. 


\subsubsection{Multicast}

Mecanismos de distribuição para grupos em redes com o serviço de IPTV são necessários devido ao alto consumo de banda por conta dos canais HDTV. Esses canais podem chegar facilmente a consumir, cada um, de 8 a 10Mbps. Este valor, multiplicado por alguns milhares de usuários recebendo o fluxo simultaneamente, poderia fazer com que apenas um canal fosse suficiente para congestionar a rede de distribuição. Dessa forma, faz-se necessário o uso de mecanismos que otimizem essas transmissões individuais e as agrupem, acabando com a redundância dos fluxos nos enlaces da rede de distribuição. Adiante são apresentadas as estratégias de maior destaque para utilização de distribuição para grupos em sistemas IPTV.

Para atender a grupos de usuários com interesse na mesma informação foi criado um modelo de transmissão chamado de multicast (DEERING; CHERITON, 1985), um modelo de transmissão de dados $n$-para-n. A Figura 3.9 a seguir ilustra a diferença entre os tipos clássicos de distribuição em uma rede IP.
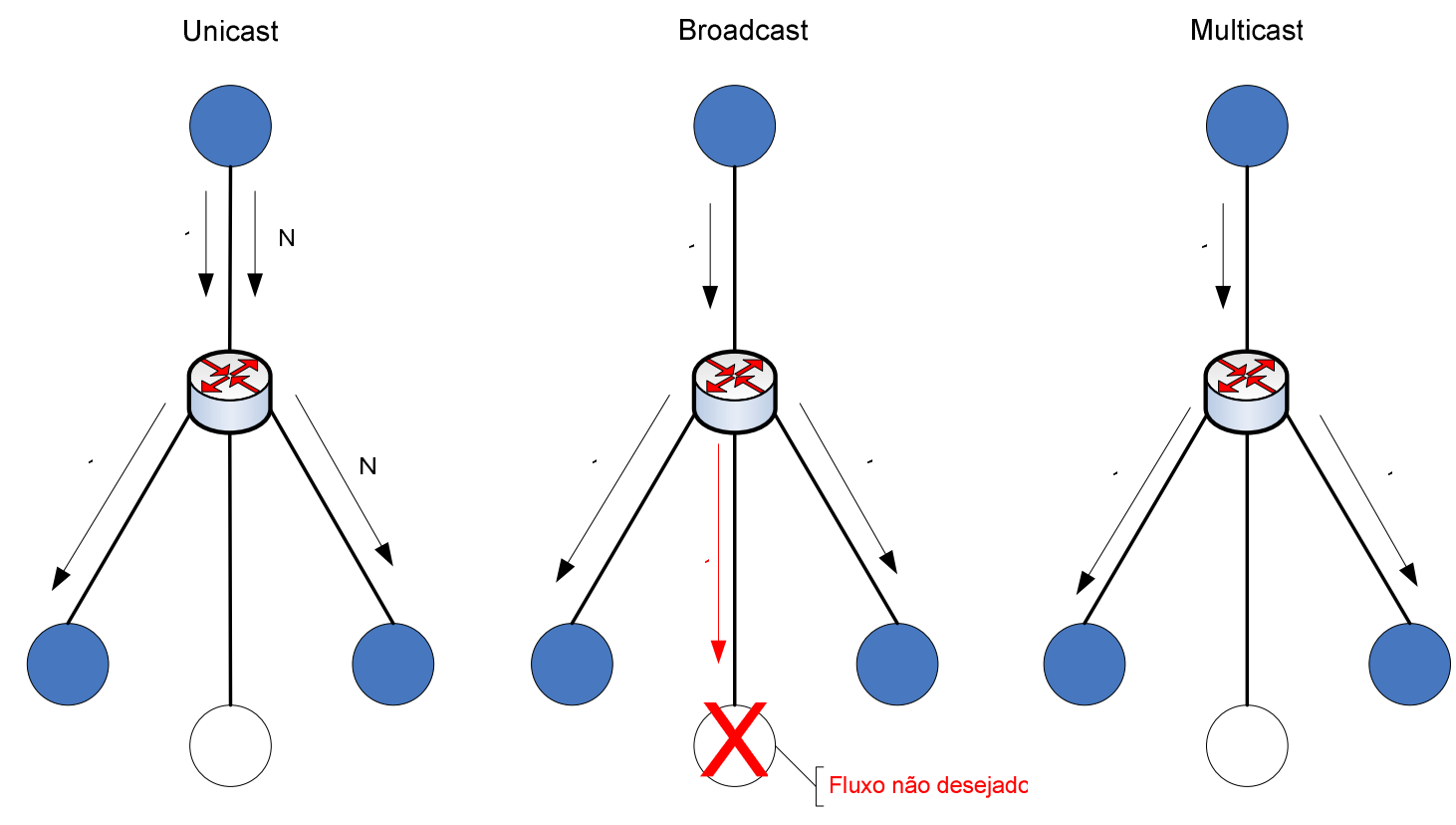

Figura 3.9 - Modelos de distribuição.

Quando uma determinada fonte deseja realizar a transmissão de um dado em unicast para mais de um usuário, esse transmissor deve criar uma cópia do dado e transmitir individualmente para cada receptor (este é o mecanismo utilizado na Internet). No broadcast o dado não tem um único destino especificado, mas sim o 
endereço de broadcast, que representa todos os equipamentos em uma sub-rede; o dado é enviado uma única vez e copiado pelos nós da rede em todos os enlaces, inundando a rede e quase sempre ocupando enlaces em que não é desejado. No caso do multicast, a transmissão é feita uma única vez e os nós da rede se preocupam em propagar os dados apenas para os enlaces que possuam receptores interessados, evitando a ocupação indesejada da rede.

No caso do multicast, diversos protocolos de roteamento estão disponíveis, sendo que os mais populares já se encontram disponíveis em roteadores comerciais há anos. Merecem destaque os protocolos Protocol Independent Multicast - Sparse Mode (PIM-SM) (ESTRIN et al., 1997) e Source Specific Multicast (SSM) (HOLBROOK; CAIN, 2006), utilizados atualmente pelos grupos de pesquisa da Internet $2^{34}$, entre outros. Estes protocolos possuem melhor desempenho em relação aos protocolos mais antigos baseados em inundação e poda ${ }^{35}$, como o Distance Vector Multicast Routing Protocol (DVMRP) (WAITZMAN; PARTRIDGE; DEERING, 1988).

Conforme dito anteriormente, o modelo multicast tradicional possibilita uma distribuição n-para-n, porém o SSM simplifica essa característica, tornando-o 1-paran. Do ponto de vista do modelo IPTV, essa simplificação não impacta por se caracterizar como um sistema 1-para-n. A segunda simplificação feita no SSM é a retirada do Rendezvous Point (RP), um tipo de nó centralizador dos grupos multicast em uma rede. O papel do RP era dado a um determinado roteador na rede, fazendo com que o mesmo tenha a responsabilidade receber e re-rotear o tráfego multicast, além de controlar todas as requisições. Como um cliente só tinha o endereço multicast, ele precisava se conectar ao RP para descobrir o endereço da fonte e então começar a receber os fluxos. Estas responsabilidades acarretavam, muitas vezes, uma perda de performance na máquina RP, além de criar um gargalo na rede. O SSM resolve isso pressupondo que o cliente que pretende ingressar em um grupo multicast saberá o endereço do transmissor e pode fazer a requisição diretamente.

\footnotetext{
${ }^{34}$ Internet 2: < http://www.internet2.edu/>.

${ }^{35}$ Inundação e poda (flood and prune) é o nome dado ao mecanismo em que o protocolo faz o broadcast (Flood) dos dados na rede e em seguida os nós de rede impedem (Prune) a passagem dos dados nos enlaces que não possuem receptores conectados.
} 
Além da utilização do protocolo de roteamento, o multicast também prevê que os equipamentos de rede devam implementar o Internet Group Management Protocol (IGMP) (HOLBROOK; CAIN; HABERMAN, 2006), protocolo responsável pelo controle dos clientes em um grupo multicast. Independente do protocolo de roteamento utilizado, o IGMP ${ }^{36}$ será mandatório na rede.

Apesar de antigo, o multicast não é popular, principalmente devido à falta de aplicativos que justificassem sua implantação nas redes comerciais. Já em redes públicas, como é o caso da Internet, o uso de multicast não é indicado por motivos como a falta de controle de uso para os endereços multicast (IANA, 2006), falta de escalabilidade em redes muito amplas e questões de segurança, como ataques de Denial of Service (DoS) (XU; SANDHU, 2002).

Para o escopo dos sistemas IPTV, a distribuição multicast é indicada (SIEMENS, 2006), sendo extremamente eficiente para reduzir a redundância do conteúdo dos canais transmitidos na rede.

\subsubsection{Overlay e Peer-to-peer}

Visto que diversas redes não implementam diretamente mecanismos de distribuição para grupos como o multicast - seja devido à limitação do multicast em alguns cenários (ex. Internet) ou mesmo de aplicações que justificassem a implementação destes esquemas -, outros mecanismos foram desenvolvidos para evitar esse problema. Esse é o caso das redes Overlay e P2P (EL-SAYED; ROCA; MATHY, 2003).

Em (LAO et al., 2005), uma possível diferenciação entre essas redes seria que as redes Overlay utilizam servidores distribuídos na rede para controlar as rotas de distribuição, eliminando tráfego repetido; enquanto as redes P2P utilizam os próprios clientes distribuídos na rede como nós para distribuição.

Na Figura 3.10 é apresentada a distribuição Overlay, com dois servidores intermediários, localizados na parte superior da figura. Após estes servidores receberem os fluxos do servidor de vídeo, eles criam novas transmissões com os clientes interessados. Este método retira a carga do servidor central, no entanto, as

${ }^{36}$ O SSM, por ser mais recente, pressupõe o uso da versão 3 do IGMP (IGMPv3). 
redes de acesso aos usuários continuam com tráfego excessivo, além de que novos pontos de falha são inseridos no sistema.

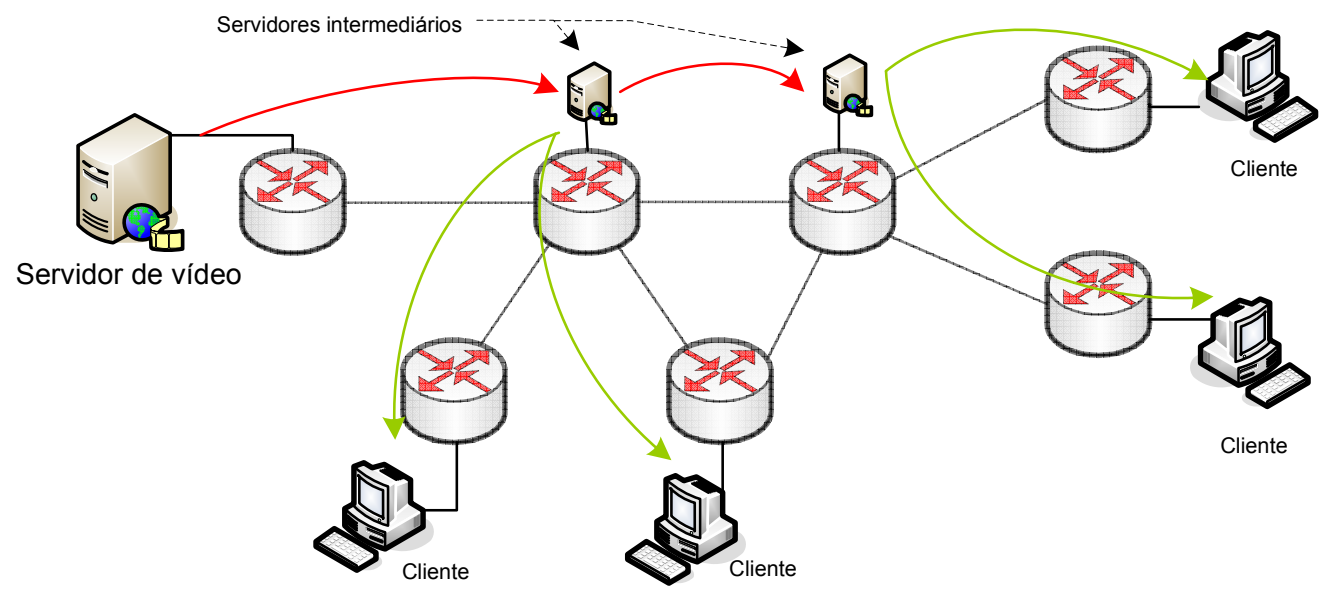

Figura 3.10 - Distribuição Overlay.

No caso do P2P (mostrado na Figura 3.11), a conexão com o servidor pode acontecer enter clientes (peers) que estejam logicamente próximos da fonte (servidor de vídeo); ou ainda no caso de conteúdos que nenhum outro cliente tenha, restando apenas recorrer àquela fonte. Uma vez que o conteúdo esteja disponível no sistema, grupos de clientes com o mesmo interesse são criados e novas conexões são feitas diretamente entre os clientes.

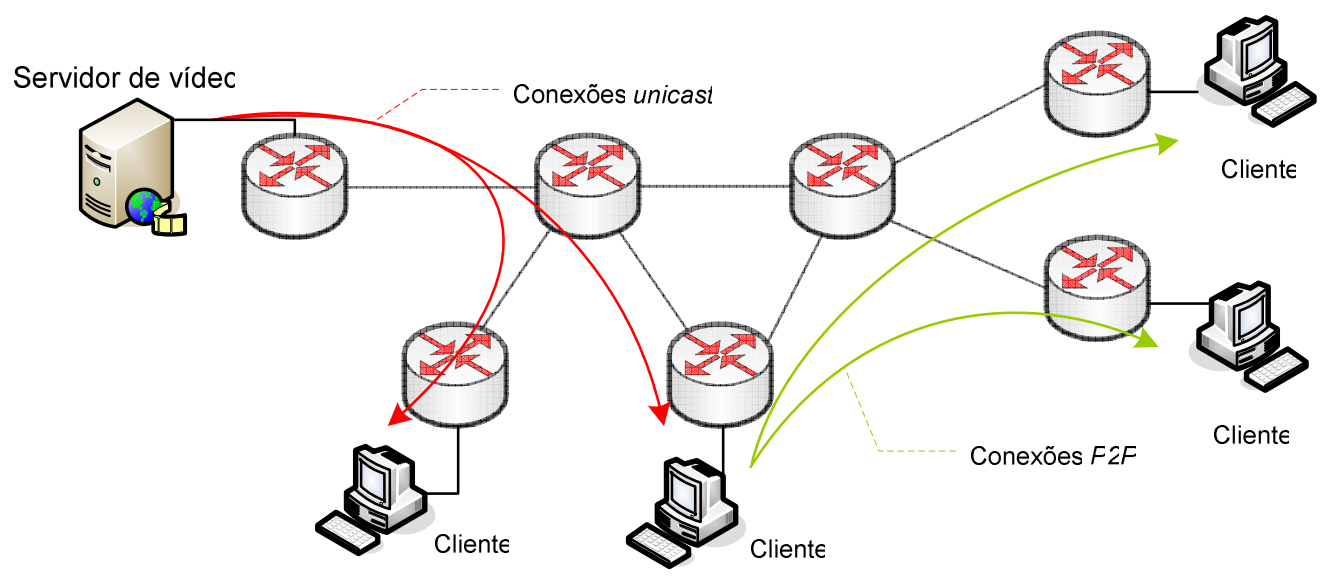

Figura 3.11 - Distribuição peer-to-peer.

As redes P2P também minimizam a carga do servidor, entretanto, passam a responsabilidade da transmissão para os próprios clientes. Este mecanismo se mostra muito custoso em uma rede onde os clientes têm limitações de banda, fluxos 
densos e, principalmente, se tem que contar com clientes que estão mudando de canal constantemente (zapping). A mudança constante de canais torna o grupo de usuários que compartilha o conteúdo extremamente volátil.

Estes dois modelos nasceram justamente da falta de esquemas de distribuição para grupos em redes públicas, utilizando a camada de aplicação para implementar funções ausentes na camada de rede. Apesar de ter seu valor de pesquisa, as plataformas baseadas em Overlay e P2P ainda possuem inúmeras limitações quando aplicadas à distribuição de vídeo com alta definição.

Além de algumas características citadas em cada distribuição, um importante motivo para descarte da utilização dessas distribuições em IPTV se dá em razão da falta de garantia de entrega do conteúdo - ausência de QoS eficiente - e da dificuldade para gerenciar o grupo de usuários devido à natureza volátil da audiência de um canal de TV.

\subsubsection{Multicast sobre Multi-Protocol Label Switching}

O Multi-Protocol Label Switching (MPLS) (ROSEN; VISWANATHAN; CALLON, 2001) é um esquema de distribuição de dados que emula características de uma rede comutada em redes de pacotes. MPLS provê um protocolo orientado à conexão para a rede IP, ao mesmo tempo em que confere a velocidade da comutação em camada 2.

O MPLS aloca recursos na rede quando um novo fluxo é iniciado. Usualmente esta operação é realizada através do Resource ReSerVation Protocol (RSVP) (POLK; DHESIKAN, 2006). Uma vez que os recursos estejam assegurados, o MPLS associa uma etiqueta (Label) aos pacotes e cria uma rota para entregar todos os pacotes que possuam esta etiqueta (Label Switched Path - LSP). O roteamento é feito utilizando-se o Label, em um campo de identificação de camada de enlace, evitando que roteadores tenham que analisar endereços de camada 3.

Uma grande vantagem do MPLS é ser independente das tecnologias de camada 2 e 3 , podendo ser utilizado em redes ATM e SONET, por exemplo; permitindo, portanto, integração com diversos protocolos. 
Apesar do MPLS ser caracterizado principalmente pela distribuição ponto-aponto de dados, o próprio grupo de trabalho responsável pelo seu desenvolvimento começou a desenvolver estudos para aplicação de multicast sobre o MPLS (OOMS; LIVENS, 2000) (OOMS et al.; 2002). Estes documentos encontram-se em fase inicial de especificação, e por isso não fornecem detalhes do funcionamento do protocolo. Fora o grupo de trabalho do IETF, existem alguns trabalhos na Academia que já apresentam resultado, como será visto a seguir.

\section{MPLS Multicast Tree (MMT)}

A proposta do MPLS Multicast Tree (MMT) (BOUDANI; COUSIN, 2005) é a de maior importância no estudo sobre encapsular a árvore multicast em LSPs MPLS. O autor utiliza as mesmas premissas da especificação do IETF citadas no item anterior.

O MMT concentra-se em reduzir os estados multicast nos roteadores e aumentar a escalabilidade do sistema. Isto é feito a partir da construção de uma árvore multicast considerando apenas os nós sem ramificações desta árvore. Dessa maneira, ele utiliza apenas trechos que se comportam como distribuições unicast e cria as LSPs, conforme ilustrado na Figura 3.12. Esta árvore irá restringir os estados multicast apenas aos roteadores ramificados (por exemplo, o roteador $\mathrm{R} 4$ da figura).
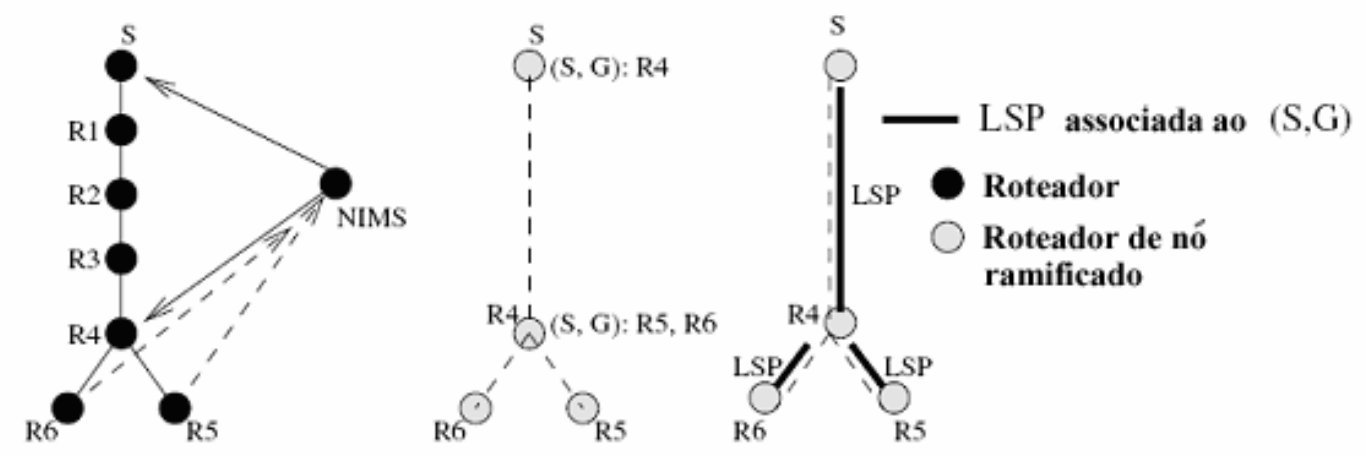

$-->$ mensagem de Join(S,G)

$\longrightarrow$ mensagem de ramificaçāo enviada pelo NIMS

( $\mathrm{S}, \mathrm{G})$ estados de roteamento que contém o próximo roteador ramificado

Figura 3.12 - Construção da árvore MMT.

As árvores são montadas através da entidade definida no estudo, chamada de Network Information Manager System (NIMS). Ela é responsável por coletar 
mensagens de ingresso e saída dos grupos multicast (Joins e Leaves) para criar as árvores de distribuição. Próximos passos incluem alguns mecanismos de agregação de diferentes árvores com a finalidade de reduzir o número de labels utilizados.

Apesar dos esforços de co-existência do MPLS e multicast em redes IP, não existe padronização e os resultados apresentados em (BOUDANI; COUSIN, 2005) mostram benefícios em redes na ordem de milhares de grupos multicast, sendo que a redução do número de estados dos roteadores é a principal vantagem indicada. Estes resultados aplicados a redes menores, como é o caso do IPTV, não necessariamente constituem benefício sobre o multicast tradicional.

Multicast sobre MPLS é uma solução possível para futuras redes IPTV, porém, ainda que existam benefícios, estes podem ser subjugados pela complexidade existente para implementação da solução.

Este capítulo apresentou diversas tecnologias que dão subsídio à especificação do Broker. O estudo realizado aqui se ateve a recomendações de padrões abertos, com intuito de facilitar implementações e a reutilização futura. 


\section{Capítulo 4 - Especificação do Elemento de Distribuição}

No modelo de referência IPTV apresentado no segundo capítulo foi sugerido um elemento de distribuição chamado Broker. O elemento, foco principal deste trabalho, está situado no Distribuidor e é responsável por gerar as licenças de uso para os conteúdos e distribuí-las aos clientes.

Neste capítulo será proposta a arquitetura do Broker para o sistema IPTV. Dentro desta arquitetura, será dada especial ênfase à geração de licenças e à transmissão do conteúdo através da Rede de Acesso.

\subsection{Políticas para manipulação da mídia no sistema}

A especificação é iniciada através do levantamento das políticas para uso do sistema. Esta análise é crucial para ajudar a visualização do cenário de especificação do Broker. Estas políticas definem as principais funções do sistema como um todo, sem levar em conta aspectos técnicos para sua implementação. Este é o grau mais alto da análise, servindo de base para a especificação do objeto do trabalho. Segue a listagem das políticas, subdivididas nos atores que interagem com o sistema:

\section{Produtor}

P1.1 - Deve ser capaz de distribuir seu conteúdo a um ou mais Distribuidores. Esta distribuição pode ocorrer de forma segura.

P1.2 - Deve poder estabelecer certas restrições de uso ao seu conteúdo.

\section{Distribuidor}

P2.1 - Deve ser capaz de receber conteúdo provenientes dos Produtores.

P2.2 - Deve ser capaz de transmitir os conteúdos dos Produtores para sua rede de clientes.

P2.3 - Deve respeitar restrições do Produtor. 
P2.4 - Pode armazenar os conteúdos localmente.

P2.5 - Deve aplicar sua lógica de negócios para distribuição do conteúdo.

P2.6 - Deve ser capaz de controlar o acesso ao conteúdo por cliente.

P2.7 - Deve possuir mecanismos que garantam confidencialidade do conteúdo durante o envio aos clientes.

P2.8 - Deve ser capaz de cobrar pelos conteúdos transmitidos.

P2.9 - Deve ser capaz de gerar informações de bilhetagem aos Produtores.

\section{Cliente}

P3.1 - Deve ter conhecimento dos conteúdos disponíveis no Distribuidor.

P3.2 - Deve ser capaz de solicitar conteúdos ao Distribuidor.

P3.3 - Deve respeitar restrições do Distribuidor e do Produtor para execução dos conteúdos recebidos.

P3.4 - Deve ser capaz de reproduzir os conteúdos recebidos.

P3.5 - Pode armazenar conteúdo recebido do distribuidor.

P3.6 - Pode copiar conteúdo para outros dispositivos.

P3.7 - Deve possuir mecanismos para pagar pelos conteúdos consumidos.

As políticas serão utilizadas amplamente durante toda a especificação, servindo como diretivas durante as tomadas de decisão. Este grupo de políticas forma o conjunto amplo e genérico no caso de manipulação do conteúdo no sistema. No próximo item são apresentados os serviços oferecidos pelo sistema de IPTV.

\subsection{Serviços}

Conforme vem sendo apresentado ao longo deste trabalho, a plataforma de IPTV deve oferecer aos seus usuários mais do que canais de programação, indo desde os conteúdos sob demanda até serviços interativos de videoconferência e jogos on-line. A intenção do modelo aqui proposto é fornecer uma interface no Broker para que esses serviços sejam interpretados e políticas de uso sejam criadas 
a partir dos mesmos. Portanto, o termo "serviço" é aqui definido como uma facilidade oferecida ao usuário mediante a observação de um conjunto de regras de execução. Em termos de implementação, o serviço deve ser visualizado como todas as ações passíveis de serem executadas pelos clientes através das licenças de uso obtidas do sistema.

Vale ressaltar, contudo, que nem todos os serviços oferecidos necessitam ser transformados em políticas. De fato, apenas serviços que utilizem o Broker seguem essa regra. Por exemplo: alguns serviços, como videoconferência, poderiam estar hospedados em servidores diferentes e não utilizar a interface do Broker para o controle de acesso. Certas informações (como o guia de canais) podem ser consideradas públicas e não terem necessidade de licenças de uso.

Diversos serviços oferecidos precisarão de algum grau de interatividade. Para a descrição dos serviços neste trabalho será usada a seguinte classificação:

- Interatividade local: uma vez acessado, o conteúdo possibilita interação com o usuário em um escopo local, ou seja, sem comunicação com o provedor ou outros clientes. Por exemplo, um jogo de quebracabeças.

- Interatividade com provedor: serviços que necessitam comunicação com o provedor durante a interatividade. Por exemplo, um bate-papo escrito (chat) durante um programa de entrevista.

- Interatividade com outros clientes: um serviço pode requerer que um usuário interaja com outro usuário através da rede de clientes do provedor, o que é muito comum em alguns tipos de jogos ou videoconferências.

De acordo com o modelo de descrição de serviços de IPTV apresentado pelo DVB (DVB-IPI, 2002), os serviços podem ser agrupados em categorias criadas a partir da percepção do cliente. Dessa forma, cada categoria pode ser detalhada para descrever que tipos de mecanismos tecnológicos ela necessitará. Segue a descrição das categorias:

\section{S01 - Entretenimento}

Descrição: serviços de lazer em geral, como notícias de esporte e jogos online. Compostos por: 
- TV por assinatura (vídeo/áudio);

- Vídeo sob Demanda (vídeo/áudio);

- Música (áudio);

- Download de fotos;

- Jogos.

Interatividade: a interatividade nesta categoria de serviços é obrigatória. O VoD necessita de interatividade com o provedor no instante de compra do serviço, além de interatividade (pelo menos local) para as funções de pause, forward e rewind, entre outras. Além disso, os jogos podem utilizar os três tipos de interatividade definidos acima.

Requisitos operacionais: os serviços de entretenimento utilizam distribuição de áudio e vídeo, tanto ao vivo, como sob demanda. O serviço de fotos pode utilizar ainda download unicast de arquivos JPEG, PNG ou similares.

Requisitos de direitos: esta categoria pode contar com diversas políticas diferentes dependendo de como o serviço é oferecido. Dentre os mais comuns, pode-se citar restrição por cliente, restrição por tempo, quantidade de vezes tocadas, validade da licença e permissão de empréstimo ${ }^{37}$ para outros clientes.

\section{S02 - Informações gerais}

Descrição: distribuição - na maioria dos casos, para grupos - de conteúdo informativo, incluindo os seguintes temas:

- Informações sobre viagens;

- Câmbio e bolsa de valores;

- Informativos de esportes;

- Propaganda;

- Jornais televisivos.

Interatividade: esta categoria de serviços raramente utiliza mecanismos interativos pois tem uma natureza dinâmica e informativa.

\footnotetext{
${ }^{37}$ Necessidade comum no caso de arquivos de música, por exemplo.
} 
Requisitos operacionais: distribuição de áudio e vídeo. Trata-se basicamente de difusão do conteúdo. Canais de informação sobre bolsa de valores e mercado podem ter formato de páginas HTML, diferente dos canais televisivos.

Requisitos de direitos: as licenças para esta categoria de serviço estão usualmente relacionadas com a forma como o valor da informação decai com o passar do tempo. Licenças de uso podem limitar o uso do conteúdo apenas por um intervalo de tempo (por exemplo, cotação da bolsa de valores), liberando-o depois disso para cópia e afins.

\section{S03 - Educacional}

Descrição: conteúdo educacional pode ser separado dos outros serviços (como - "informações gerais") devido ao seu perfil muito direcionado e à maior possibilidade de interação com o usuário. São listados a seguir os de maior destaque dentro dessa área:

- Ensino à distância;

- Programas de saúde.

Interatividade: pelo menos a interatividade local deve ser considerada obrigatória para este serviç ${ }^{38}$. Além disso, interatividade com o servidor e entre outros clientes também é recomendada.

Requisitos operacionais: distribuição de áudio e vídeo, além de texto e imagens, como suporte para as aulas. Mecanismos de bate-papo e videoconferência podem ser acrescentados.

Requisitos de direitos: os principais requisitos de direitos para esta categoria estão vinculados com a autoria do conteúdo e permissões para redistribuição.

\section{S04 - Mensagem}

Descrição: serviços de mensagens são basicamente esquemas de troca de mensagens e conteúdos multimídia pelos usuários do sistema. São eles:

- E-mail;

- Mensagens multimídia.

\footnotetext{
${ }^{38}$ A obrigatoriedade neste item ocorre em parte pela necessidade de diferenciação em relação ao serviço de informações gerais. Operacionalmente, existem programas educativos sem nenhum tipo de interatividade já na TV tradicional.
} 
Interatividade: estes serviços requerem interatividade entre usuários do sistema e, algumas vezes, com o próprio provedor.

Requisitos operacionais: transmissões de mensagens e texto ou HTML; imagens; trechos de vídeo em geral. Transmissões ponto-a-ponto.

Requisitos de direitos: este tipo de serviço requer mecanismos de privacidade e não-repúdio para os usuários. Neste caso, as licenças não são necessariamente a melhor solução, podendo criar uma complexidade desnecessária ao serviço. Uma possível solução é o uso de criptografia ponto-a-ponto pelos clientes.

\section{S05 - Comunicação}

Descrição: conexões em tempo-real entre usuários, com conteúdo geralmente criado por um dos usuários e enviado aos outros. Entre eles, tem-se:

- Videoconferência;

- Voz sobre IP (VoIP).

Interatividade: necessita de interatividade entre usuários (com especial cuidado com atrasos na rede).

Requisitos operacionais: esta categoria de serviços requer um canal de conexão com baixa latência e maior largura de banda para as conexões P2P de vídeo, podendo utilizar, em contrapartida, maior compressão de vídeo, uma vez que a qualidade de imagem é menos importante que para um canal de TV.

Requisitos de direitos: analogamente a categoria anterior, esta também se beneficia de mecanismos de criptografia para assegurar privacidade entre usuários. Porém, alguns casos como salas de videoconferência de grupo poderiam utilizar licenças que inibam a reutilização do conteúdo gerado no evento para outros fins, garantindo os direitos de imagem dos envolvidos.

\section{S06 - Informações do Sistema}

Descrição: serviço que informa o usuário sobre os outros serviços disponíveis no sistema. Pode servir como um portal de acesso a eles. A principal aplicação atualmente é:

- Guia Eletrônico de Canais (Electronic Program Guide - EPG). 
Interatividade: a única interatividade necessária aqui é a local, pois o serviço apenas dá acesso aos demais serviços oferecidos pelo sistema.

Requisitos operacionais: distribuição para grupos em fluxo de canal de TV.

Requisitos de direitos: não existe nenhum requisito explícito nesta categoria, uma vez que a informação divulgada deve ser considerada pública.

A lista apresentada visa categorizar todos os possíveis tipos de serviços que podem ser disponibilizados em um sistema IPTV, porém, novas categorias podem vir a ser acrescentadas com o tempo, visto que o sistema é recente.

\subsection{Requisitos do sistema}

Até este ponto foram analisadas as políticas de uso e mapeados os serviços que estão sendo considerado no cenário em que o sistema de IPTV se situa. Estes levantamentos possibilitam a passagem para uma análise mais voltada para a tecnologia, como acontece com o levantamento de requisitos. Os requisitos funcionais considerados $^{39}$ partem da necessidade de manter 0 sistema suficientemente flexível para inserção de novos serviços.

A Tabela 4.1 apresenta as atividades específicas do Produtor.

\begin{tabular}{llc}
\hline Produtor & \multicolumn{1}{c|}{ Atividade } & Categoria \\
\hline Ref \# & \multicolumn{1}{c}{ Evidente } \\
\hline RP.1 & $\begin{array}{l}\text { Transmissão de conteúdo de canal de TV para Distribuidores } \\
\text { Devem existir meios de transmissão entre Produtor e Distribuidor com } \\
\\
\text { capacidade para transmissão de canais de TV em tempo real. }\end{array}$ & \\
\hline RP.2 & $\begin{array}{l}\text { Transmissão de conteúdo sob demanda para Distribuidores } \\
\text { Deve existir meio de transmissão para conteúdo VoD entre Produtor e }\end{array}$ & Evidente \\
& $\begin{array}{l}\text { Distribuidor. (Este meio de transmissão não tem requisitos de baixa } \\
\text { latência como no item anterior). }\end{array}$ & \\
\hline
\end{tabular}

\footnotetext{
${ }^{39}$ Os requisitos funcionais podem ser "evidentes", no caso de atividades que devem ser executadas com o usuário a par da execução, ou "ocultos", para atividades executadas sem a necessidade de conhecimento explícito pelo usuário. (LARMAN, 2000)
} 


\begin{tabular}{llc}
\hline RP.3 & $\begin{array}{l}\text { Descrição dos direitos para Distribuição e consumo do conteúdo } \\
\text { O sistema deve permitir mecanismos para que o Produtor possa descrever } \\
\text { inequivocamente os direitos sobre o conteúdo que está distribuindo } \\
\text { através de licenças. }\end{array}$ & Evidente \\
\hline RP.4 & Distribuição das licenças & Evidente \\
& O Produtor deve distribuir as licenças para os interessados. & \\
\hline RP.5 & $\begin{array}{l}\text { Criptografia de conteúdo } \\
\text { O Produtor pode criptografar o conteúdo antes do envio para os }\end{array}$ & \\
& $\begin{array}{l}\text { Distribuidores. O Conteúdo só deve ser acessado mediante observação da } \\
\text { descrição de direitos. }\end{array}$ & \\
\hline
\end{tabular}

Tabela 4.1 - Requisitos funcionais para manipulação de mídia - Produtor

A segunda tabela (Tabela 4.2) levanta os requisitos funcionais para 0 Distribuidor, onde se situa o Broker.

\section{Distribuidor}

\begin{tabular}{llc}
\hline Ref \# & \multicolumn{1}{c}{ Atividade } & Categoria \\
\hline RD.1 & Recepção de fluxos de canal de TV & Evidente \\
& O Distribuidor deve ser capaz de receber a transmissão linear de canais & \\
& de TV dos Produtores. Esta recepção pode se dar através de diversos & \\
& meios como: satélite, redes de computadores, mídia removível, entre & \\
& outros. Estes fluxos podem estar criptografados. &
\end{tabular}

\begin{tabular}{lll}
\hline RD.2 Recepção de arquivos VoD & Evidente
\end{tabular}

O Distribuidor deve ser capaz de receber arquivos de conteúdo sob demanda de Produtores. Estes arquivos podem estar criptografados.

\begin{tabular}{lll}
\hline RD.3 Transcodificação de mídia & Oculto
\end{tabular}

O Distribuidor deve ser capaz de transcodificar o conteúdo proveniente dos Produtores para formatos mais adequados tanto para armazenamento, bem como para retransmissão à Rede de Acesso.

RD.4 Armazenamento do conteúdo recebido de Produtores Evidente

Deve ser possível armazenar em repositórios do Distribuidor todo conteúdo que pode ser transmitido posteriormente ao sistema.

\section{RD.5 Distribuição de fluxos de canal de TV para rede de Clientes Evidente}

Os fluxos recebidos devem poder ser retransmitidos para a rede de Clientes. Devem ser previstas distribuição 1-para-1 e 1-para-n. Deve ser observado que estes fluxos usualmente possuem requisitos de entrega com baixa latência ao usuário. 


\begin{tabular}{|c|c|c|}
\hline RD.6 & $\begin{array}{l}\text { Distribuição de arquivos de VoD para rede de Clientes } \\
\text { O Distribuidor deve ser capaz de transmitir conteúdo VoD perante } \\
\text { requisição dos clientes. (Requisições de VoD são usualmente 1-para-1, } \\
\text { no entanto Near-VoD permite 1-para-n). }\end{array}$ & Evidente \\
\hline RD.7 & $\begin{array}{l}\text { Recepção de licenças dos Produtores } \\
\text { O sistema deve permitir o recebimento e armazenamento das licenças } \\
\text { enviadas pelos Produtores. }\end{array}$ & Evidente \\
\hline RD.8 & $\begin{array}{l}\text { Descrição de direito para distribuição do conteúdo pela rede de } \\
\text { clientes } \\
\text { O sistema deve permitir mecanismos para que o Distribuidor possa } \\
\text { descrever inequivocamente os direitos sobre o conteúdo que esta } \\
\text { distribuindo através de licenças. }\end{array}$ & Evidente \\
\hline RD.9 & $\begin{array}{l}\text { Distribuição das licenças } \\
\text { Distribuidor deve ser capaz de distribuir licenças para a rede de clientes e } \\
\text { atender solicitações por novas licenças. }\end{array}$ & Evidente \\
\hline RD.10 & $\begin{array}{l}\text { Criptografia de conteúdo } \\
\text { O Distribuidor deve }{ }^{40} \text { criptografar o conteúdo antes do envio para os } \\
\text { clientes pela rede de acesso. }\end{array}$ & Evidente \\
\hline
\end{tabular}

Tabela 4.2 - Requisitos funcionais para manipulação de mídia - Distribuidor

A Tabela 4.3 exibe o caso de um Cliente genérico do sistema.

\section{Cliente}

\begin{tabular}{llc}
\hline Ref \# & \multicolumn{1}{c}{ Atividade } & Categoria \\
\hline RC.1 & Recepção de fluxos de canal de TV & Evidente \\
& O Cliente deve ser capaz de receber a transmissão linear de canais de TV & \\
& pela Rede de Acesso. Este tipo de transmissão tem requisitos altos quanto \\
& à latência.
\end{tabular}

\begin{tabular}{lll}
\hline RC.2 Recepção de arquivos VoD Evidente &
\end{tabular}

O Cliente deve ser capaz de receber arquivos de conteúdo sob demanda pela Rede de Acesso. Estes arquivos podem estar criptografados.

\begin{tabular}{lll}
\hline RC.3 Navegação por Guia de programação (EPG) Evidente &
\end{tabular}

O sistema deve prover o Cliente com um guia de programação com intuito de agilizar a navegação pelo conteúdo.

\begin{tabular}{lll}
\hline RC.4 Interpretação de direitos & Oculto \\
& O Cliente deve ter um mecanismo para interpretar as licenças & \\
& provenientes de Produtor e Distribuidor antes do consumo do conteúdo.
\end{tabular}

\footnotetext{
${ }^{40}$ Diferente do Produtor, o Distribuidor deve criptografar o conteúdo pois a Rede de Acesso é um meio muito mais suscetível a questões de segurança.
} 
RC.5 Reforço dos direitos

Oculto

O Cliente deve respeitar as condições impostas nas licenças de uso. Estas

condições podem limitar funções do sistema para a mídia em questão.

$\begin{array}{lll}\text { RC.6 Requisição de informação de direitos Oculto } & \end{array}$

Caso o Cliente não possua a licença para uma determinada mídia, este deve ser capaz de requisitá-la ao Distribuidor. A obtenção de novas licenças pode requerer algum tipo de contrapartida do Cliente.

$\begin{array}{lll}\text { RC.7 Acesso a conteúdo criptografado Oculto } & \end{array}$

O software do Cliente deve ser capaz de abrir o conteúdo criptografado para exibição. (de acordo com RC.5)

\begin{tabular}{lll}
\hline RC.8 Exibição do conteúdo Evidente &
\end{tabular}

O Cliente deve ser capaz de decodificar o conteúdo recebido para exibição em tempo-real. (de acordo com RC.5)

RC.9 Armazenamento das mídias

Evidente

O Cliente pode contar com algum dispositivo de armazenamento para a mídia recebida. (de acordo com RC.5)

RC.10 Transferência e cópia entre dispositivos Evidente

O Cliente pode realizar cópia ou transferência do conteúdo para outros dispositivos. (de acordo com RC.5)

Tabela 4.3 - Requisitos funcionais para manipulação de mídia - Cliente

A última tabela (Tabela 4.4) levanta os principais pontos para o transporte de mídia na Rede de Acesso.

\section{Rede de Acesso}

\begin{tabular}{lll} 
Ref \# & Atividade & Categoria \\
\hline
\end{tabular}

\begin{tabular}{lll}
\hline RR.1 Alta taxa de transmissão & Evidente
\end{tabular}

A Rede de Acesso entre Distribuidor e Clientes deve possuir capacidade adequada para transmissão do conteúdo. Mecanismos de distribuição para grupos devem ser observados.

\begin{tabular}{lll}
\hline RR.2 Priorização de tráfego & Evidente
\end{tabular}

A Rede de Acesso deve implementar mecanismos de priorização de tráfego para os fluxos de vídeo.

\begin{tabular}{lll}
\hline RR.3 & Gerência & Evidente \\
& Devem existir mecanismos de gerência para monitoramento de recursos & \\
& na Rede de Acesso. &
\end{tabular}

RR.4 Canal seguro de cobrança

Evidente

A Rede de Acesso deve permitir o uso de canais seguros para transações entre Distribuidor e Cliente.

Tabela 4.4 - Requisitos funcionais para manipulação de mídia - Rede de Acesso 
Esta listagem dos requisitos funcionais é suficiente para detalhamento de interfaces e aprofundamento das funcionalidades do elemento de distribuição.

\subsection{Interfaces}

O Broker representa um servidor de distribuição de mídias seguras dentro de um sistema IPTV. O conceito geral da distribuição do conteúdo se baseia em licenças de uso que podem ser distribuídas para os usuários, em paralelo com o conteúdo, pelo próprio Broker.

A Figura 4.1 apresenta as interfaces de entrada e saída do Distribuidor em alto nível. De acordo com esta representação, o Broker recebe os conteúdos disponíveis no sistema e é responsável por encaminhá-los à rede de clientes. Para isso, deve negociar diretamente com a base de licenças do sistema - formada pelas licenças vindas do Produtor de Conteúdo e pela base do próprio Distribuidor - e com a coleção de serviços que devem ser disponibilizados aos clientes. Como interface de saída, o Broker prevê uma interface que possibilita a geração de relatórios de informações do sistema.

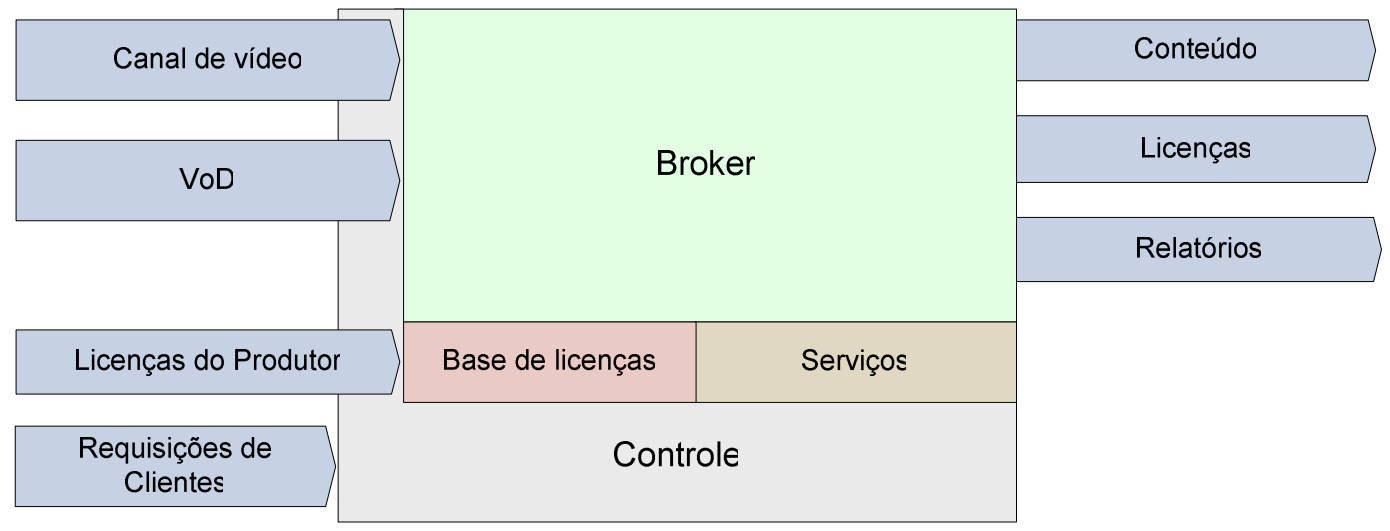

Figura 4.1 - Interfaces do Distribuidor.

Ainda neste diagrama (Figura 4.1) pode-se observar a camada de Controle, na parte inferior, responsável por controlar a chegada e a disponibilidade dos conteúdos no sistema. O Controle também recebe as licenças que acompanham o conteúdo, bem como as requisições dos clientes, que esta camada deve gerenciar e autenticar. 
Conforme o sistema recebe requisições dos clientes, os conteúdos são enviados ao Broker para distribuição. Em primeiro lugar é feita a análise dos pedidos para que sejam criadas as licenças de uso que darão direito de acesso ao conteúdo. A licença é gerada com base na descrição dos serviços na forma das políticas de uso armazenadas no sistema. Após a criação, o Broker deve enviar as licenças individualmente para os clientes.

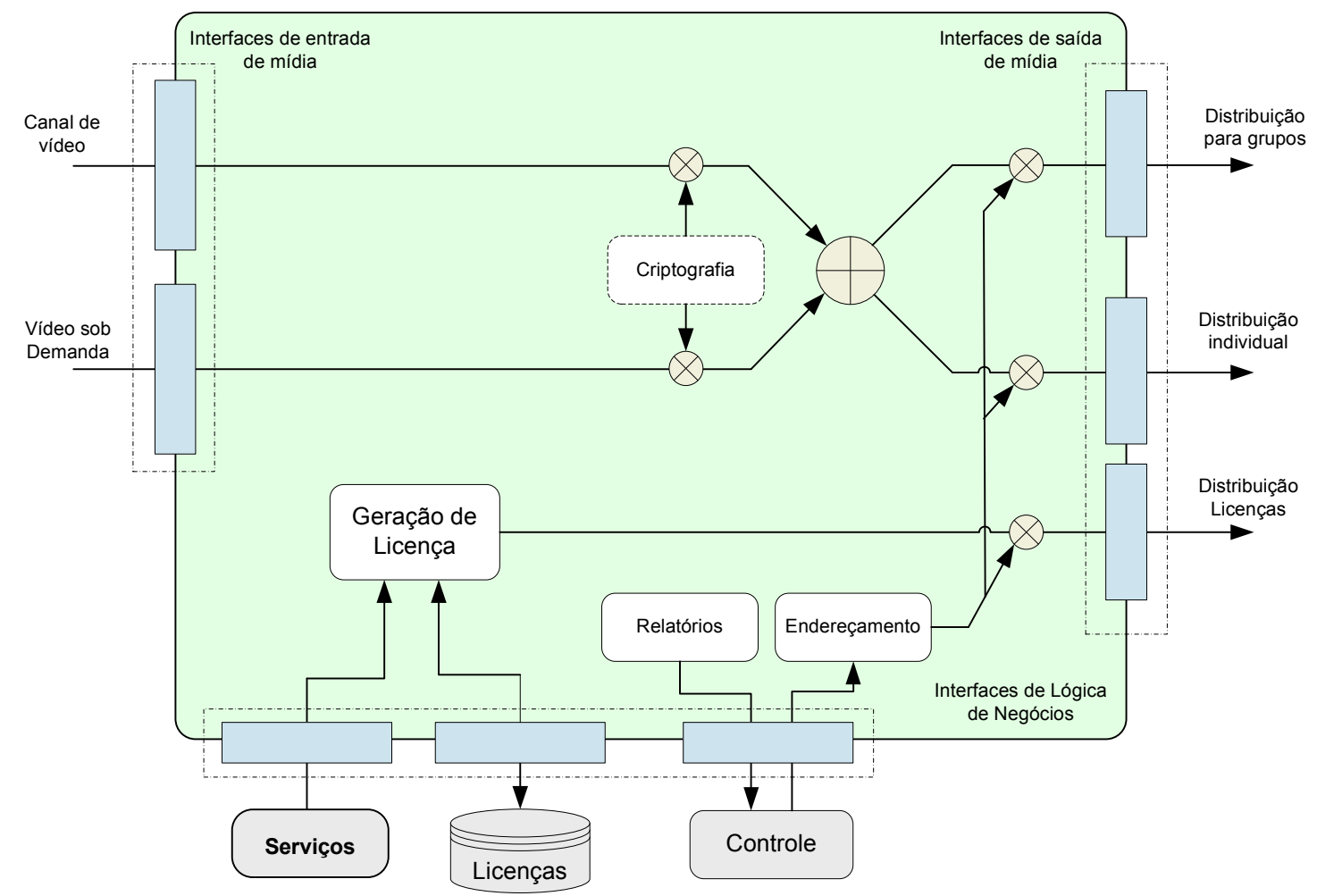

Figura 4.2 - Broker: Interfaces e lógica interna.

Após a criação da licença de uso, a mídia deve ser tratada para a distribuição. Neste estágio é aplicado o mecanismo de criptografia escolhido. Na seqüência, o controle do sistema fornece o endereçamento para que o Broker possa entregar as mídias.

Por último, o Broker deve ser capaz de gerar relatórios de utilização para ajudar no gerenciamento do consumo de conteúdo no sistema. Esta funcionalidade deve servir tanto para o Distribuidor quanto para o Produtor, como será descrito adiante neste capítulo.

O detalhamento das interfaces do Broker, em particular, bem como sua lógica interna, são apresentados na Figura 4.2. Nela são indicados os grupos de interfaces de entrada de mídia, de lógica de negócios e de saída para o conteúdo. Além das 
interfaces, a lógica de preparação do conteúdo e das licenças pelo Broker também está representada na figura pelos fluxos internos.

Seguem as descrições para cada grupo de interfaces, conforme os elementos que as compõem:

\section{Interfaces de Lógica de Negócios}

Serviços: os serviços disponíveis são definidos externamente ao Broker, sendo sua responsabilidade disponibilizar uma entrada de informações flexível para converter a semântica desses serviços em políticas de uso.

Licenças: as licenças são geradas internamente ao Broker e poderão ser armazenadas em um repositório do sistema. Elas são criadas a partir de uma base de políticas de uso que traduz os serviços para uma REL.

Controle: esta interface deve indicar o endereçamento para envio dos conteúdos aos clientes. Dessa forma, o Broker se limita a enviar os pedidos que são devidamente autorizados pela camada de controle do sistema. Esta interface pode ser utilizada para fornecer ao Distribuidor relatórios (logs) com estatísticas de consumo de recursos no sistema, entre outros parâmetros. Estes relatórios podem conter informações sobre consumo de recursos de rede (banda, QoS e perdas), recursos da máquina (processamento e memória) e bilhetagem do sistema.

\section{Interfaces de Entrada de Mídia}

Canal de Vídeo: depois de liberado pelo Controle do sistema, o conteúdo em fluxo contínuo de canal chega ao Broker para ser distribuído. A distribuição deve ocorrer com base no endereçamento provido pelo Controle através da interface de negócios.

Vídeo sob Demanda: análoga ao Canal de Vídeo, a interface de VoD trabalha com os fluxos de conteúdo sob demanda. Estes fluxos podem ser distribuídos tanto para grupos como individualmente, dependendo apenas dos serviços que são oferecidos no sistema.

\section{Interfaces de Saída de Mídia}

Distribuição para grupos: distribuição multicast ou outro mecanismo de distribuição para grupos em redes IP. 
Distribuição individual: distribuição unicast do conteúdo.

Nestes dois casos, mecanismos de criptografia da mídia devem ser analisados para garantir confidencialidade dos dados. Alguns empregos de criptografia serão analisados adiante.

\subsection{Geração de Licenças}

O Broker deve possuir um mecanismo para a criação das licenças de uso que são distribuídas aos clientes. Este processo se inicia pelo mapeamento dos serviços disponíveis no sistema em políticas de uso $^{41}$, como ilustrado na figura abaixo:

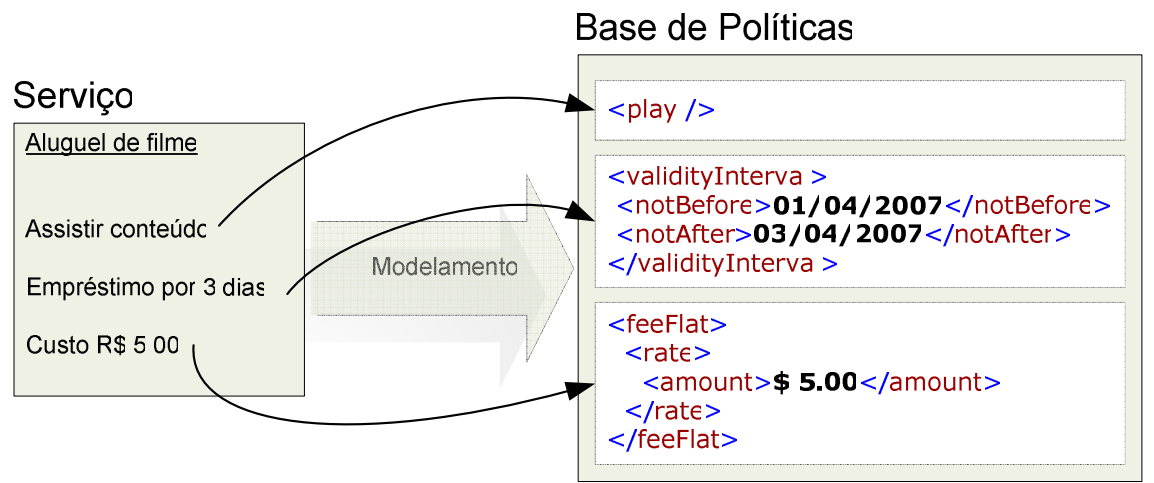

Figura 4.3 - Modelagem de serviços em políticas.

As políticas são estruturas de dados usadas para expressar cada uma das condições existentes nas licenças de uso. Cada condição do serviço deve ser mapeada em uma estrutura de política, e futuramente ser instanciada formando a licença com a descrição completa do serviço. O Broker prevê um repositório de dados para guardar essas estruturas, permitindo sua reutilização no rápido mapeamento de novos serviços.

O bloco para acesso às funcionalidades relacionadas à geração e interpretação das licenças de uso no sistema é apresentada na Figura 4.4. Nela é introduzido um maior grau de detalhamento aos blocos funcionais da REL a ser utilizada, além das operações com outros elementos do Distribuidor.

\footnotetext{
${ }^{41}$ Não confundir com as políticas de uso do início da especificação.
} 


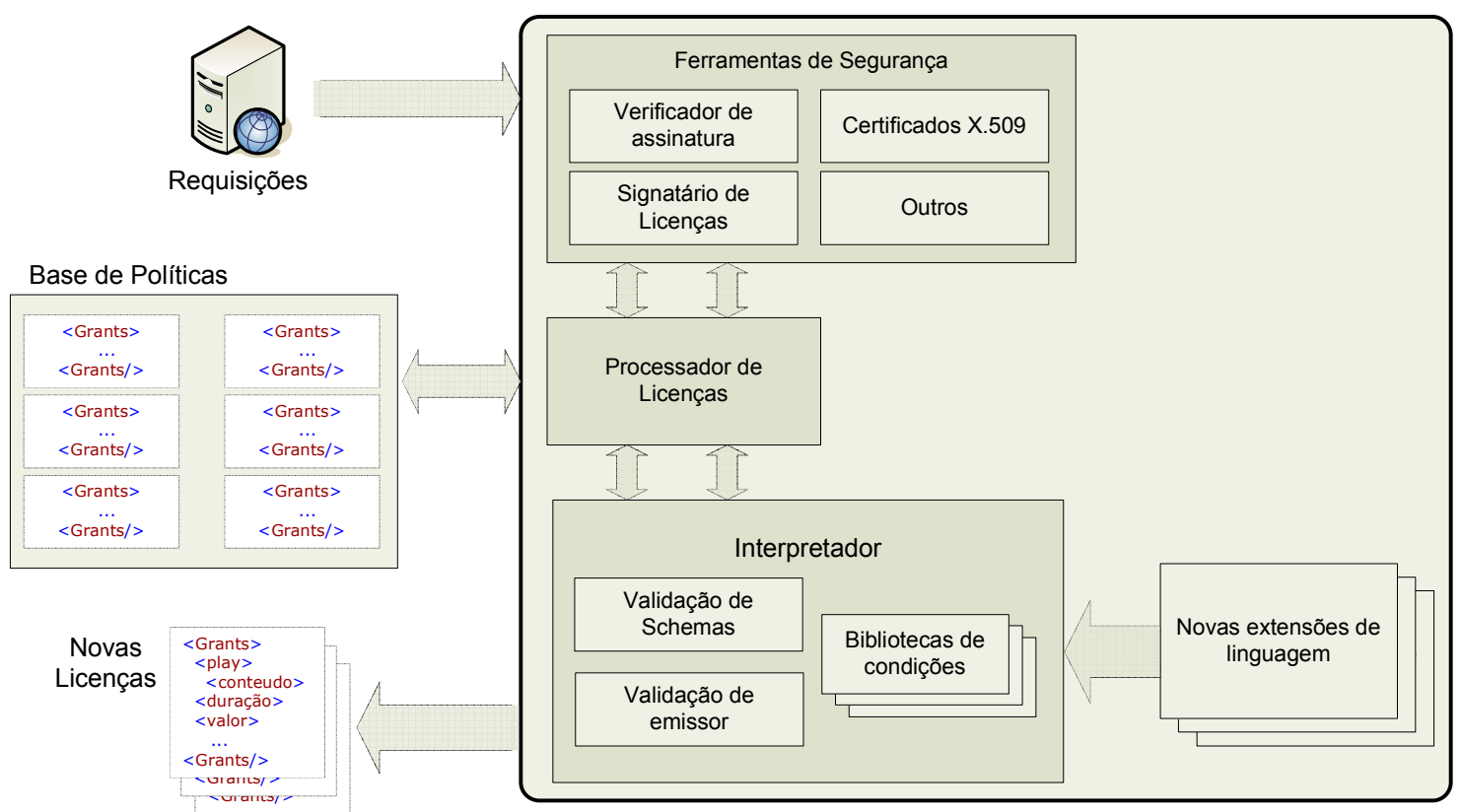

Figura 4.4 -Bloco de geração de licenças.

A principal função deste bloco é receber as requisições de novas licenças da camada de controle do Distribuidor e proceder com a criação das mesmas. Todavia, os módulos internos poderão ser utilizados separadamente para realização de tarefas menores como, por exemplo, a validação das licenças do Produtor.

\section{Processador de Licenças}

Este elemento é responsável por se conectar diretamente com a base de políticas do Distribuidor para obter os blocos estruturais necessários à montagem da licença requisitada. O Processador deve ainda se comunicar com os outros dois módulos internos que desempenham os papéis de validação da estrutura e assinatura antes do envio.

\section{Interpretador}

Este elemento deve possuir mecanismos para as funções de leitura, interpretação e validação da licença a ser criada. Também as novas extensões da linguagem devem poder ser incorporadas futuramente, sob demanda do sistema.

\section{Ferramentas de Segurança}

As ferramentas de segurança compõem um bloco funcional responsável por todas as tarefas vinculadas à integridade e confidencialidade das licenças. Estes 
mecanismos prevêem: verificação de assinatura, assinatura das licenças e verificação de certificados X.509, entre outros.

Com estes três blocos funcionais disponíveis, tem-se o processo completo para criação das licenças de uso conforme a Figura 4.5. A montagem da licença depende de todos os elementos, além de informações de identificação de conteúdo e destinatário do próprio Distribuidor.

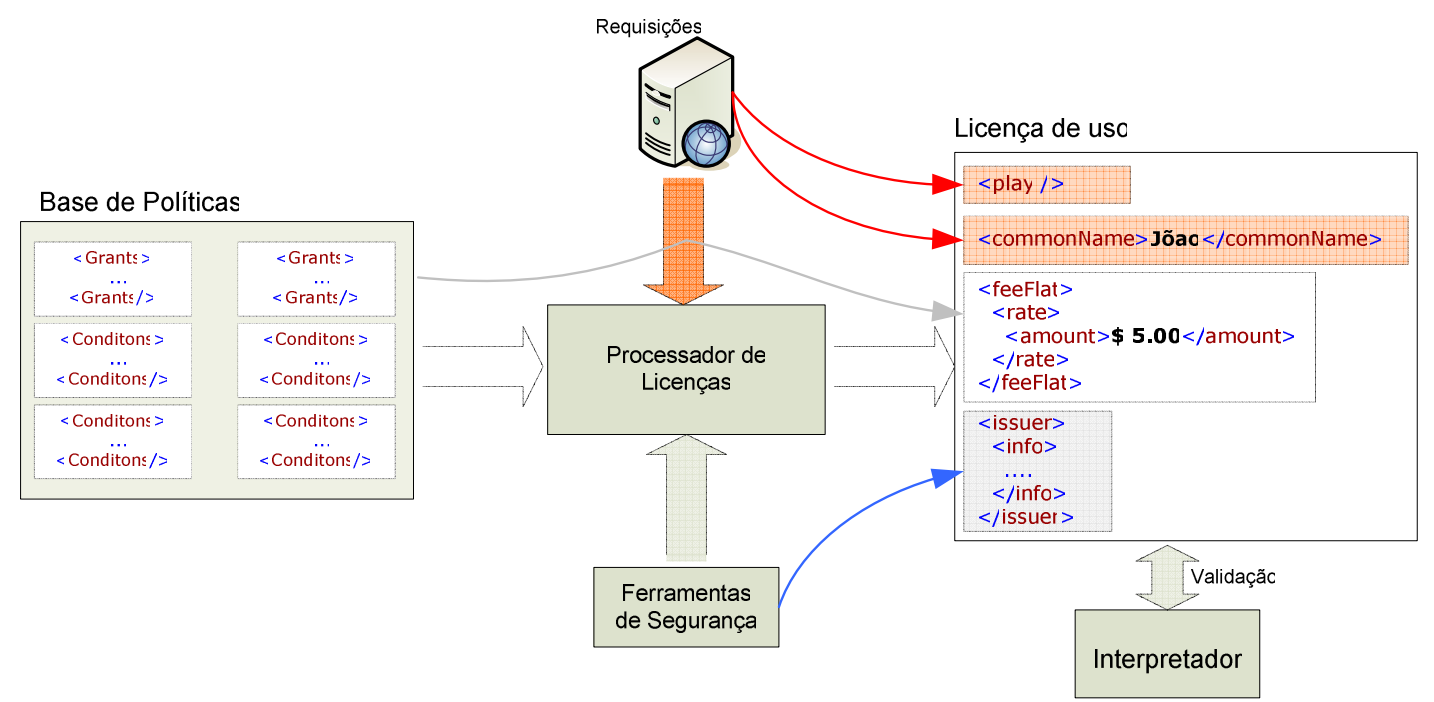

Figura 4.5 - Processo de criação de Licenças de uso.

De acordo com a figura acima, o Processador de Licenças centraliza a maioria das operações realizadas na criação, acionando os outros blocos funcionais conforme tenha necessidade. A partir de uma requisição do Distribuidor, o Processador acessa a base de políticas de uso do sistema em busca das estruturas que serão utilizadas na nova licença. Tendo montado todas as permissões e condições necessárias, o Processador insere os identificadores de destino e direito, fornecidos como parâmetros iniciais na requisição do Distribuidor.

Neste ponto, a licença já pode ser considerada funcional, tendo sua estrutura fundamental totalmente montada. O próximo passo é a inserção da estrutura de assinatura do emissor para garantir autenticidade e integridade à licença. Este processo consiste em fornecer como parâmetros de entrada as chaves privada e pública que serão usadas para "assinar" o documento. De posse desses parâmetros, o signatário calcula o resumo criptográfico (hash) de todo o documento e posteriormente insere este valor junto com a chave pública no campo <issuer>. 
O resumo criptográfico é o cálculo que gera um número de tamanho definido a partir de todas as informações da licença. Este valor é criptografado com a chave privada do emissor, podendo ser lido apenas a partir do processo inverso ${ }^{42} \mathrm{com}$ a chave pública que é distribuída na licença. Por menor que seja qualquer alteração na licença altera esse cálculo, evidenciando que o documento não é mais legítimo.

O último estágio da concepção da licença é a validação feita pelo Interpretador. Este passo serve para garantir que a licença está de acordo com a formatação XML correta e com os schemas da linguagem. A validação evita, assim, possíveis problemas de inconsistência em todas as etapas anteriores.

\section{Licenças de distribuição}

O processo de criação de licenças também prevê a criação das licenças de uso a partir das de distribuição, atividade realizada também no Processador de Licenças. Este será o mecanismo utilizado para criar as licenças de uso (distribuídas aos clientes) a partir das licenças de distribuição (feitas pelo Produtor e enviadas ao Distribuidor). Este processo é ilustrado na figura abaixo:

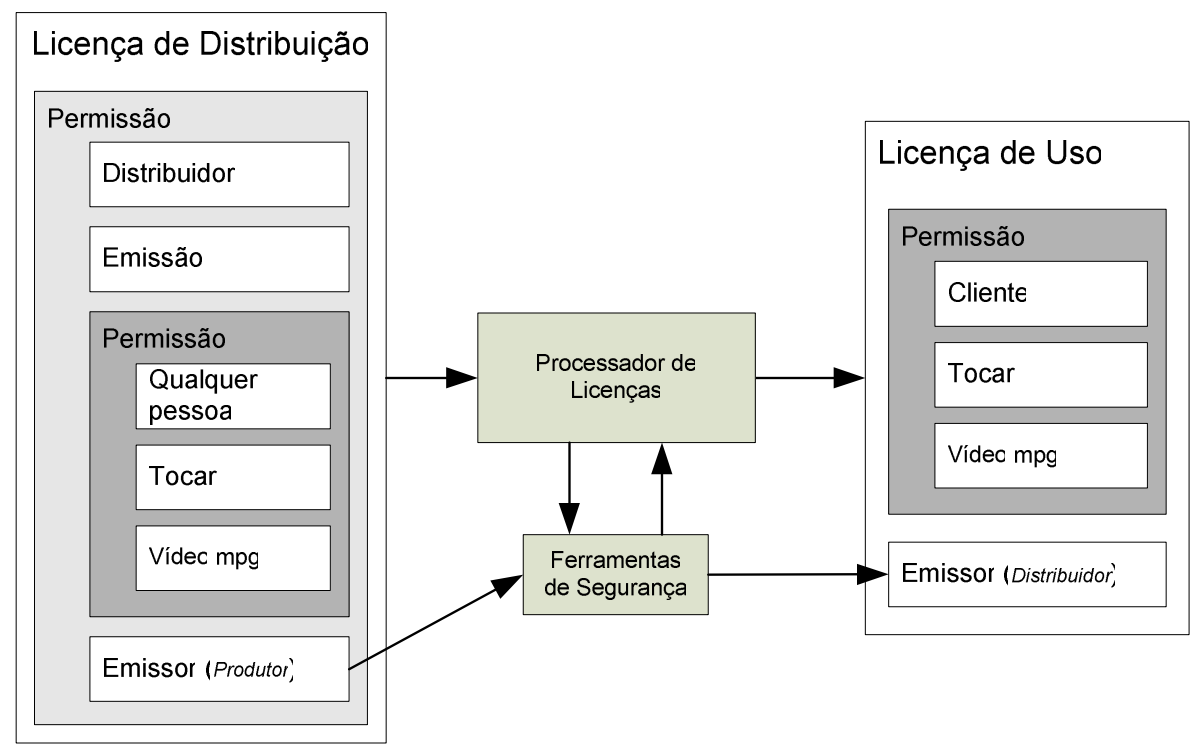

Figura 4.6 - Derivação de licença.

De acordo com o que é apresentado na figura, a licença de distribuição contém uma permissão de emissão, concedendo ao Distribuidor a possibilidade de criar uma

\footnotetext{
${ }^{42}$ A verificação da integridade é realizada durante a validação da licença pelo interpretador. Neste passo, o interpretador calcula o resumo criptográfico da licença e compara com o valor criptografado no campo do emissor. Se estes valores forem iguais, a licença está íntegra.
} 
nova licença, chamada de licença de uso. Esta nova licença permite ao Cliente, por exemplo, tocar a mídia Video.mpg.

O Processador de Licenças deve verificar o certificado do Emissor na Licença de Distribuição perante uma lista de emissores certificados que pode estar presente no sistema, ou mesmo através de uma Entidade Certificadora (Certification Authority - $\left.C A^{43}\right)$. Uma vez que o Emissor tenha sido aprovado, o Gerador pode gerar a licença e assinar - digitalmente, através das chaves criptográficas que possui - para a futura distribuição aos seus clientes.

Vale ressaltar que estas ferramentas podem ser utilizadas também no software do Cliente, uma vez que as atividades exercidas serão apenas um subconjunto do que está sendo especificado para o Broker.

\subsection{Estrutura de Transmissão}

Aqui serão definidos os mecanismos necessários de transmissão que devem ser oferecidos pelo sistema de IPTV para a geração dos pacotes de serviços. Estes mecanismos devem ser amplos o suficiente não apenas para mapear os serviços de TV existentes no sistema proposto, como também para prever os novos serviços que podem ser incorporados futuramente. Para tanto, são apresentadas a seguir as principais categorias dos mecanismos. Finalmente, é apresentada uma pilha de protocolos para suportar as necessidades de transmissão, levando em conta os estudos realizados no terceiro capítulo da dissertação.

\section{Transmissão de fluxo de canal de TV}

A transmissão do sinal de um canal de TV é o principal serviço do sistema. A fim de prover um mínimo de funcionalidades para esse tipo de serviço, observa-se a seguinte classificação:

- Transmissão de canal aberto: são considerados os canais em que não há necessidade de controle sobre o consumo pelos clientes.

\footnotetext{
${ }^{43}$ Entidades Certificadoras são entidades que emitem certificados digitais e que atestam a autenticidade de documentos gerados a partir desses certificados, através de uma estrutura de chaves criptográficas assimétricas.
} 
- Transmissão de canal protegido: em oposição aos canais abertos, todos os demais canais são considerados protegidos. Conforme dito anteriormente, o controle de acesso dar-se-á por conta de mecanismos de criptografia.

Vale ressaltar que a utilização de canais abertos ou protegidos não depende diretamente da categoria de serviços definida anteriormente, e sim do modelo de negócios estabelecido.

\section{Transmissão de conteúdo sob demanda}

Além da transmissão dos canais de TV tradicionais, outro serviço que deve ser tratado pelo Broker é a transmissão de conteúdo sob demanda para os clientes. Seguem as categorias em que se divide este serviço:

- Video on Demand (VoD): serviço no qual o Cliente possui um determinado grau de controle sobre o conteúdo, tanto de visualização quanto do instante em que deseja assistir. Caracteriza-se pela transmissão de um determinado conteúdo (ex.: filme) ponto-a-ponto entre Distribuidor e Cliente. É recomendada a implementação de características adicionais de controle da mídia, como "avançar", "retroceder", "pausar", etc. (ATM FORUM, 1995)

- Near-VoD: são distribuições para grupo (1-para-n) com intuito de garantir disponibilidade de conteúdo semelhante ao VoD, sem necessitar de transmissões ponto-a-ponto com cada Cliente. O Near-VoD pode possuir características simplificadas de controle de exibição em relação ao VoD. (DAVIC, 1998).

Sistemas de distribuição de conteúdo utilizam-se de recursos de Near-VoD para diminuir a quantidade de conexões ponto-a-ponto do sistema. Tradicionalmente, o mecanismo de otimização é a transmissão do mesmo conteúdo em intervalos regulares de tempo (SITARAM; DAN, 2000). Este processo fica mais claro na Figura 4.7, onde um usuário faz a requisição para começar a assistir a um determinado filme no instante $15 \mathrm{~min}$. Em sistemas mais simples, o usuário tem que esperar até o início do próximo fluxo para poder começar a assistir ao conteúdo, ainda que algumas técnicas permitem eliminar este tempo de espera inicial. 


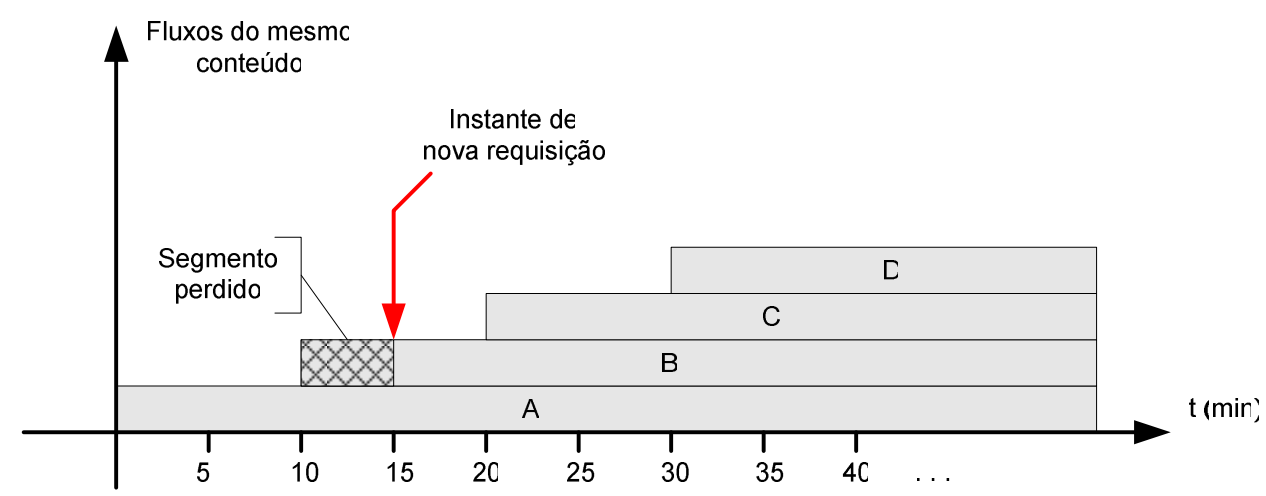

Figura 4.7 - Transmissão de fluxos periódicos.

Para não ter que esperar cinco minutos antes de começar a assistir ao fluxo $\mathrm{C}$, o segmento perdido do fluxo $B$ é enviado em unicast ao usuário e então começa a receber o fluxo B por multicast. Através deste processo, o usuário é atendido imediatamente após sua requisição, tendo a sensação de estar sendo atendido individualmente (técnica conhecida como Patching). Esta técnica se faz especialmente eficiente para conteúdos muito populares, que representam uma constante chegada de requisições. Quanto maior a freqüência com que o vídeo é requisitado, maior será a quantidade de fluxos periódicos do mesmo.

Em alguns casos, sistemas de Near-Vod conseguem simular os mecanismos de controle de exibição através da mudança do fluxo que o Cliente está assistindo ou através de funções do receptor. Por exemplo: um usuário "pausa" seu filme e recomeça a assistir 5 minutos depois. Este processo pode ser feito mudando 0 usuário para o próximo fluxo no tempo, ou nos equipamentos mais recentes, através das funções de time-shifting, que permitem que o usuário grave (buffer) o trecho que está sendo exibido para que possa retornar a assistir do mesmo ponto.

\subsubsection{Pilha de protocolos}

De acordo com as necessidades de transmissão, aliadas aos requisitos levantados no decorrer da especificação, é sugerida uma pilha de protocolos para a implementação da parte de transmissão do Broker, conforme a Figura 4.8. A estrutura sugerida tem três níveis : camada inferior de rede, constituída pela pilha TCP/IP; camada intermediária que contém os protocolos de transporte; e camada 
superior de controle de transmissão, contando com protocolos de QoS e autenticação das requisições do Distribuidor.

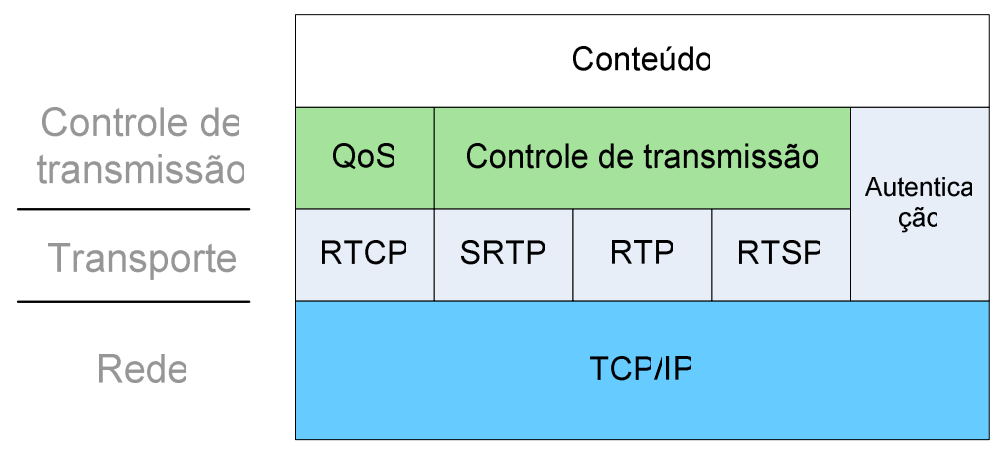

Figura 4.8 - Pilha de protocolos de distribuição.

O envio das mídias de áudio e vídeo no sistema deve ser sempre feito através de fluxos UDP, com o intuito de minimizar latência e maximizar a banda de passagem. Este é o mecanismo tradicional de transmissão de vídeo e áudio em redes IP, uma vez que a perda de alguns pacotes durante a transmissão - fato minimizado por ser uma rede controlada preferivelmente com QoS - não implica no comprometimento da experiência do cliente.

Os fluxos TCP são utilizados nos casos em que se necessita de uma conexão sem perdas com um cliente, como nos casos de envio de licenças. O TCP cria uma conexão entre dois pontos e garante a entrega do conteúdo fazendo verificações pacote a pacote.

Uma observação que vale ser feita é a situação em que o Distribuidor disponibiliza conteúdos que o usuário possa baixar e assistir depois; neste caso, utiliza-se TCP, pois a latência e banda passante não são requisitos.

Para a camada de transporte da mídia são indicados os protocolos RTP e SRTP, como visto no decorrer do terceiro capítulo. A escolha entre os dois depende de como a criptografia será aplicada ao conteúdo. Caso o conteúdo chegue criptografado pelo Produtor com criptografia seletiva, o Broker necessita apenas encapsular diretamente o fluxo multimídia em pacotes RTP para distribuí-lo. A segunda opção é a mídia chegar aberta ao Distribuidor, fazendo-se necessário a aplicação do SRTP para o transporte seguro até o Cliente. Nos dois casos os mecanismos possuem uma taxa de overhead baixa e devem ser suficientes para garantir um grau razoável de segurança à mídia enquanto trafega pela Rede de Acesso. 
Além destes protocolos para transportar o conteúdo, são indicados também o RTCP e o RTSP. O RTCP alimenta a camada de controle de transmissão com informações acerca do estado da rede, permitindo que esta faça as alterações necessárias. Finalmente, o RTSP permitirá a troca de mensagens para controle de exibição dos conteúdos VoD.

Para a camada de controle de transmissão, diferentes mecanismos tradicionais de QoS podem ser utilizados na pilha de protocolos como, por exemplo, o Differentiated Services (DiffServ) (GROSSMAN, 2002). O DiffServ utiliza um campo de 8-bits do datagrama IP entitulado Type of Service (ToS) para aproveitar os seis primeiros bits (denominados Differentiated Service Code Point ou DSCP) ${ }^{44}$ para classificação do conteúdo que está sendo enviado na rede.

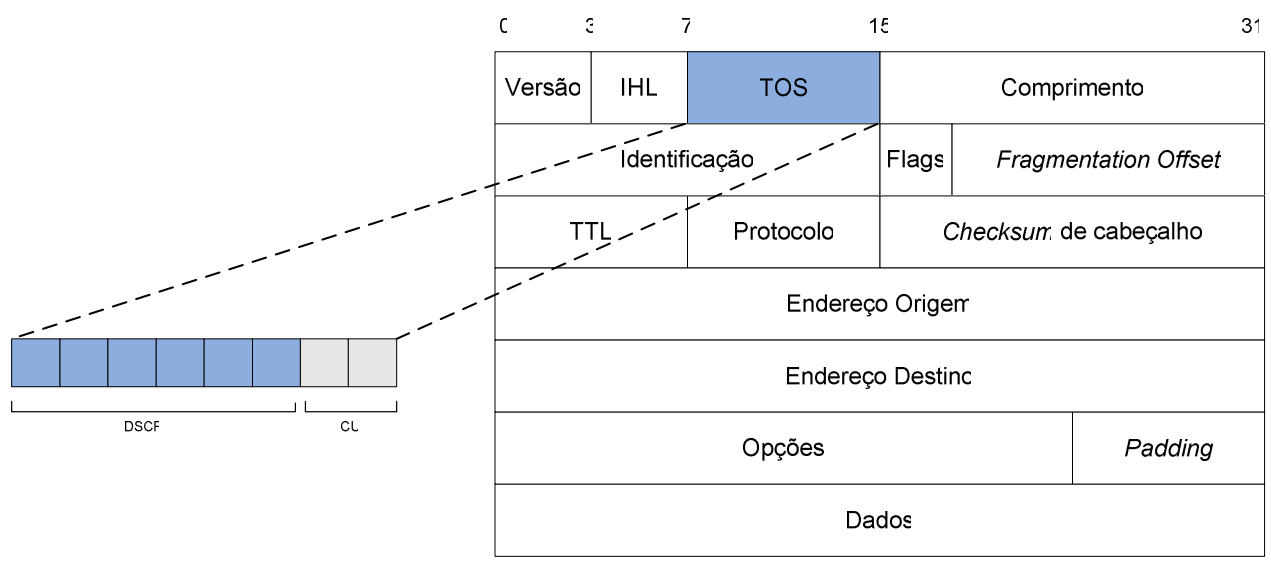

Figura 4.9 - Datagrama IP.

O DiffServ é tido como uma solução intermediária pois não faz a reserva de recursos na rede, apenas prioriza os pacotes de acordo com o valor do DSCP. Além da marcação feita nos pacotes, todos os equipamentos de rede devem implementar o protocolo para que ocorra a priorização nos enlaces.

Outros mecanismos mais complexos de QoS podem ser adicionados, dependendo apenas do suporte destes pelos equipamentos de rede disponíveis.

O Broker deve implementar um mecanismo para satisfazer a necessidade de comunicação segura com outros elementos do Distribuidor, além da geração de relatórios de utilização do sistema (Figura 4.10).

\footnotetext{
${ }^{44}$ Os dois últimos bits do campo são deixados para futuras extensões (Currently Unused).
} 


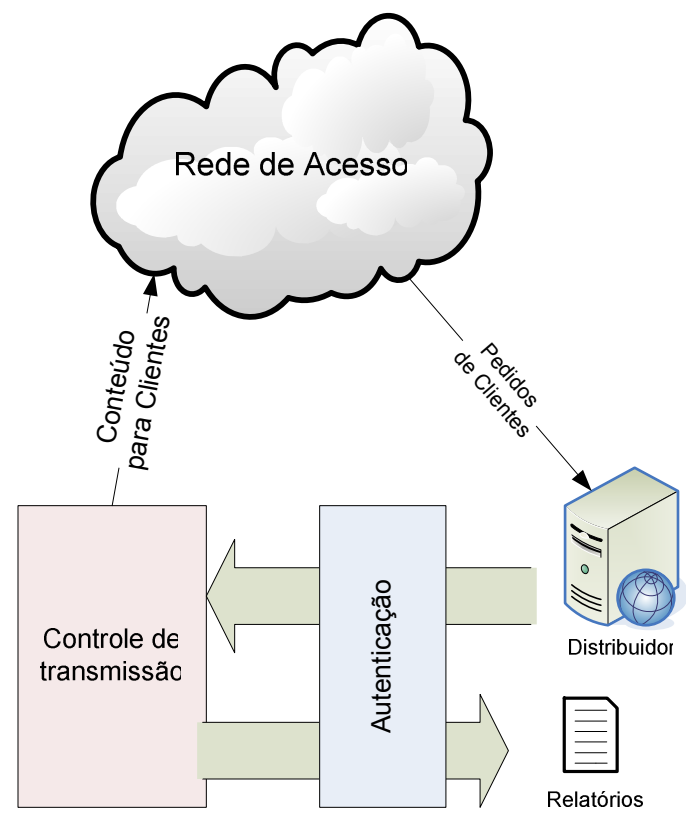

Figura 4.10 - Controle de transmissão.

Sugere-se o uso de TLS ou IPSEC para fazer as vezes deste canal de comunicação, porém outras tecnologias podem ser empregadas. Estas interfaces devem aceitar requisições para geração de relatórios a partir do Distribuidor e também dos Produtores.

\subsection{Escolha da Linguagem de Expressão de Direitos}

Um dos principais diferenciais do Broker é a utilização de uma linguagem de descrição de direitos para criar as licenças a partir das políticas de uso. Estas licenças são criadas para vincular um serviço - um determinado tipo de uso - a um conteúdo, descrevendo de forma rigorosa e precisa os direitos que serão interpretados por diferentes tipos de dispositivos.

Para o caso do IPTV, as licenças possuem um papel análogo aos Smart Cards, cartões de memória que armazenam as chaves para decriptografar o conteúdo em sistemas de TV a cabo. As licenças podem se destinar a um único usuário ou a um grupo, com o diferencial de poderem ser renovadas pelo canal de comunicação IP com o Distribuidor de forma rápida.

No que concerne a este ponto, a premissa do trabalho é escolher uma linguagem que seja flexível e possa se adaptar a diversos modelos de negócios. 
Com este intuito, será utilizada uma linguagem XML de padrão aberto, a fim de garantir também maior transparência ao modelo desenvolvido.

No segundo capítulo da dissertação já foi observado que o XML possui as características necessárias para ser usado como documento de intercâmbio entre os dispositivos envolvidos no sistema IPTV. Cabe considerar, contudo, que devido à complexidade atual das linguagens de descrição de direitos, mais de uma proposta poderia ser utilizada neste trabalho, uma vez que essas linguagens possuem semântica adequada para descrever os serviços aqui analisados.

Este trabalho utilizará a MPEG-21 REL (WANG et al., 2005) como linguagem de descrição de direitos. A MPEG-21 REL é uma evolução direta da XrML apresentada no segundo capítulo. $O$ uso deste padrão traz vantagens por ser voltado ao armazenamento e transmissão de mídia através de redes de computadores. Além disso, em trabalhos futuros, outras funcionalidades do MPEG poderão ser adicionadas ao sistema e trazer benefícios para codificação, descrição e gerenciamento das mídias.

Ainda que a escolha desta linguagem não tenha sido arbitrária, cabe ressaltar que a interoperabilidade entre RELs XML é possível (DELGADO; PRADOS; RODRIGUEZ, 2005) e mesmo a troca da linguagem poderia ser realizada futuramente nas implementações.

\subsubsection{Estrutura de Licença de uso}

De acordo com a MPEG-21 REL, a estrutura básica de licença de uso segue o modelo apresentado na Figura 4.11. 


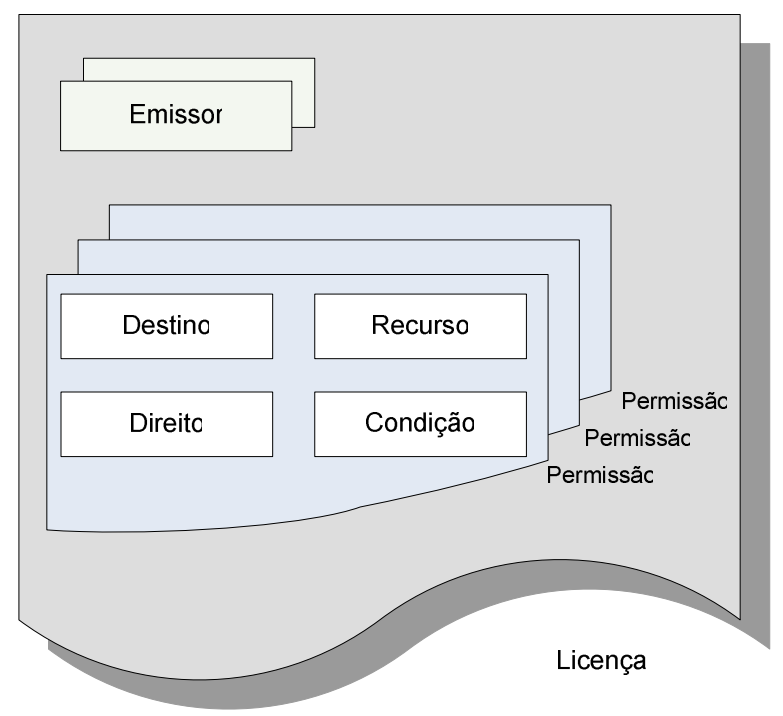

Figura 4.11 - Estrutura de Licença (WANG et al., 2005).

A figura mostra a estrutura de uma licença de acordo com os quatro elementos básicos da linguagem: Destino, Recurso, Direito e Condição, já apresentados no decorrer do trabalho. Estes quatro elementos constituem uma ou mais permissões (Grants); dentro dessas permissões ficam as estruturas principais de descrição da linguagem. Além disso, existe espaço para a inclusão de um ou mais emissores com intuito principal de verificação de legitimidade (não-repúdio).

Como já foi comentado, tradicionalmente os sistemas de TV a cabo utilizam mecanismos como Smart Cards ou Set-Top Boxes com senha para controlar o acesso ao sistema. Estes mecanismos são frágeis e uma vez que o aparelho seja violado, fica impraticável para o provedor do serviço fazer a troca de chaves de criptografia do sistema. As licenças de uso são mecanismos mais flexíveis por poderem ser renovadas (ou até mesmo revogadas) através do canal de retorno IP que o usuário possui com o Distribuidor. Por ter a possibilidade de tempo de validade limitado, a chave criptográfica do conteúdo pode ainda ser trocada a cada troca de licença, sem intervenção local no cliente.

De acordo com a cadeia de negócios apresentada ao longo do trabalho, o Distribuidor recebe uma licença que the garante o direito de distribuir determinado conteúdo ao seu grupo de clientes (licença de distribuição). Uma importante função que deve ser exercida no Broker é a derivação da licença de distribuição emitida pelo Produtor, criando, a partir desta, uma licença de uso para um ou mais clientes. 
Em certos casos, é necessário enviar para o cliente também a licença de distribuição para verificação, criando mais uma etapa de verificação. Este procedimento onera o cliente, aumentando o número de verificações que devem ser feitas, algumas vezes em mais de uma entidade certificadora. Neste ponto volta-se a falar no conceito de entidade confiável.

Uma vez que o Produtor de Conteúdo "confia" na entidade de distribuição, o Broker pode fazer esta derivação diretamente. Este procedimento permite que o cliente somente faça a checagem da licença do Distribuidor, diminuindo a complexidade da informação que deve ser interpretada e, conseqüentemente, o tempo gasto neste processo e o custo computacional para realizá-lo.

\subsubsection{Modelo de Licenças}

Neste item serão apresentados os principais exemplos para licenças que podem ser utilizadas no contexto de sistemas IPTV. Abaixo, tem-se um exemplo em XML de licença de uso:

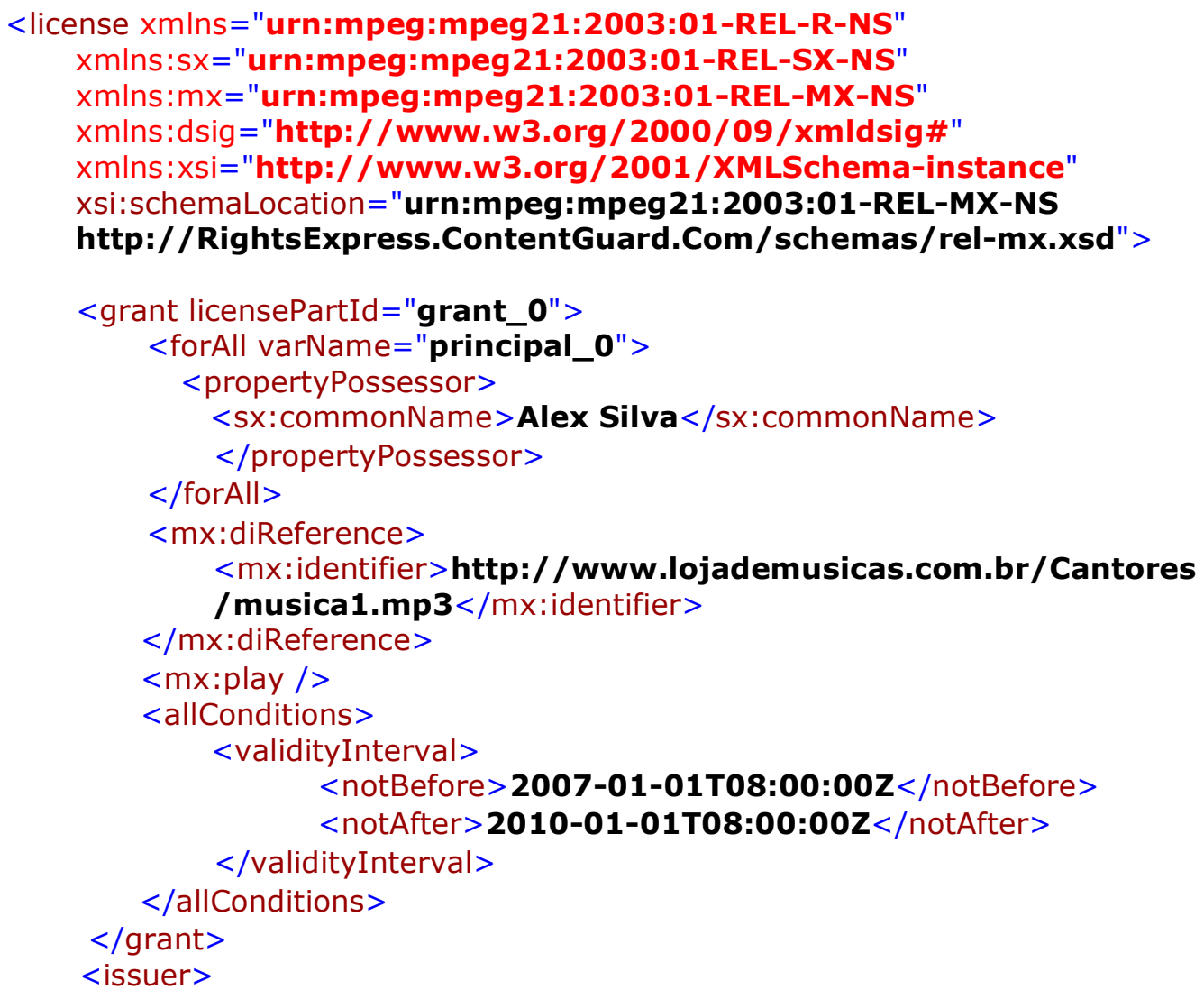




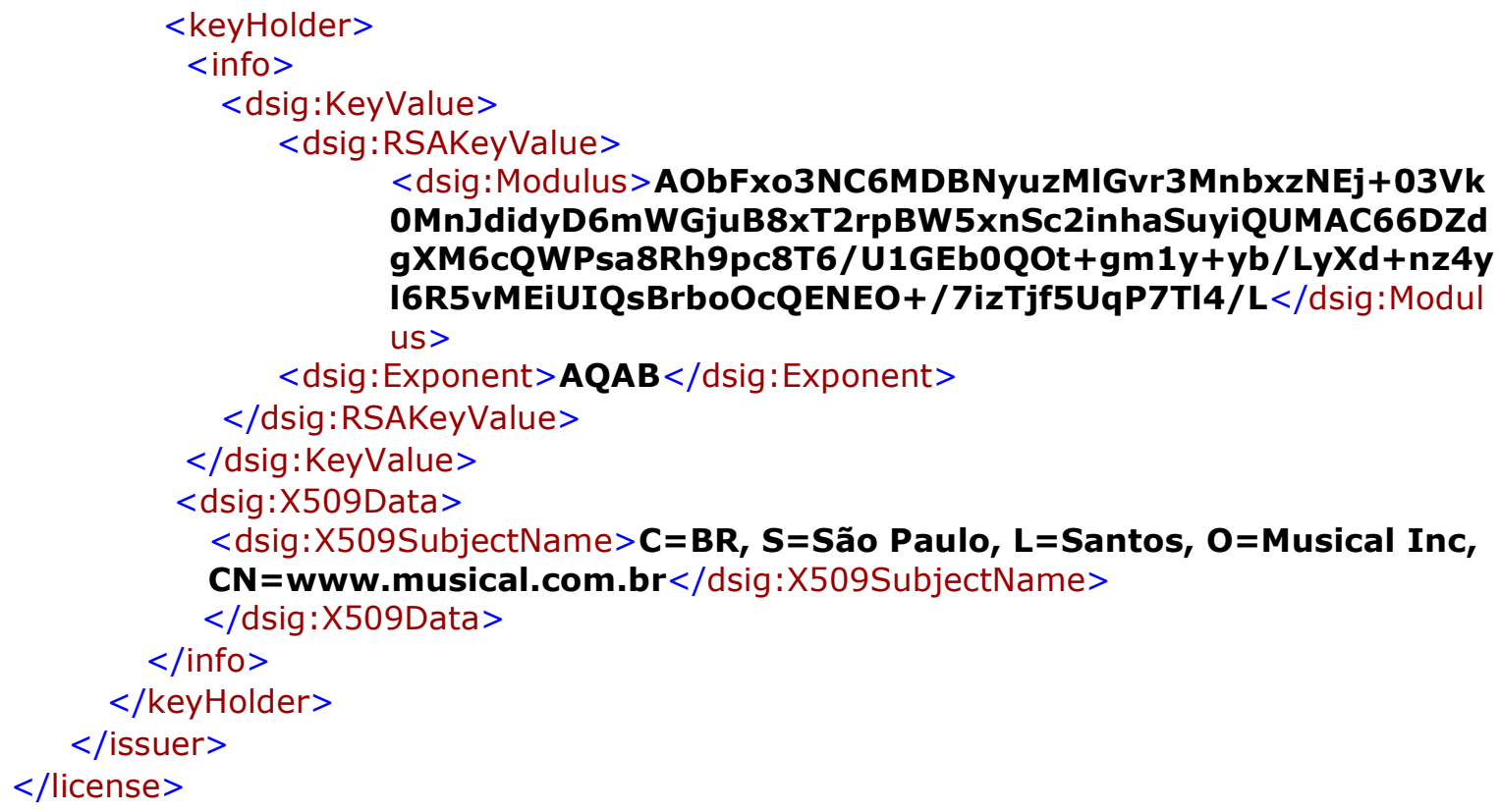

Esta licença deve ser interpretada como uma permissão gerada pela empresa $\underline{\text { Musical Inc., para que Alex Silva tenha direito de tocar (play) a música musica1.mp3 }}$ durante o período que compreende primeiro de Janeiro de 2007 até primeiro de Janeiro de 2010.

Os documentos XML em geral utilizam identificadores chamados de Uniform Resource Name (URN) e Uniform Resource Identifier (URI) para indicar ao interpretador quais tags está utilizando, ou mesmo identificar unicamente um recurso. Os URI são identificadores globais, que referenciam um recurso independente de onde ele esteja sendo utilizado. Este é o caso do URI que identifica a música que Alex pode tocar: http://www.lojademusicas.com.br/Cantores/musica1.mp3. Já os URNs são identificadores de escopo local, e no caso do XML são usados para identificar os domínios (namespaces - xmlns) em que são especificadas as tags criadas.

O último tag principal da licença, o <issuer>, contém a informação relativa ao emissor da licença, além de trazer sua assinatura digital e um resumo criptográfico (hash) para assegurar a integridade do documento. Este mecanismo será especialmente discutido no próximo capítulo.

De maneira a simplificar a leitura de uma licença, pode-se representá-la de forma resumida (WANG et al., 2005) como na Figura 4.12. Este formato condensado 
torna a leitura da licença muito mais fácil e será, tendo isso em vista, utilizado na ilustração dos exemplos de trechos de políticas de uso a seguir.

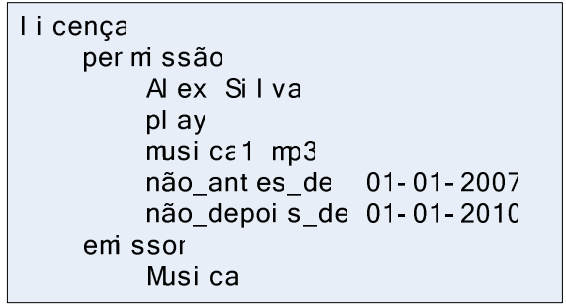

Figura 4.12 - Licença de uso.

\subsubsection{Exemplos de principais políticas no sistema IPTV}

Neste item serão apresentados os casos de maior importância no sistema IPTV e como as políticas de uso descrevem cada situação. Na Figura 4.13 é apresentado o exemplo de uma licença de distribuição:

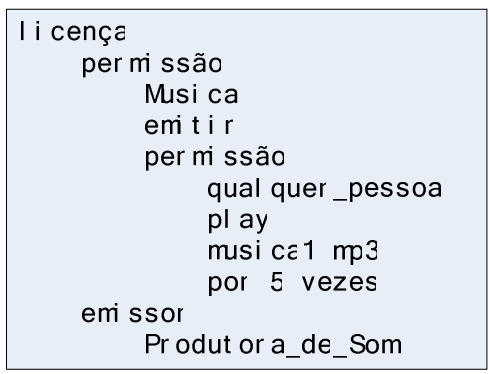

Figura 4.13 - Licença de distribuição.

Esta licença descreve a permissão que a empresa Musical tem de distribuir a música musica1.mp3 para que seja tocada no máximo 5 vezes. Segue o trecho de política de uso que representa essas novas condições:

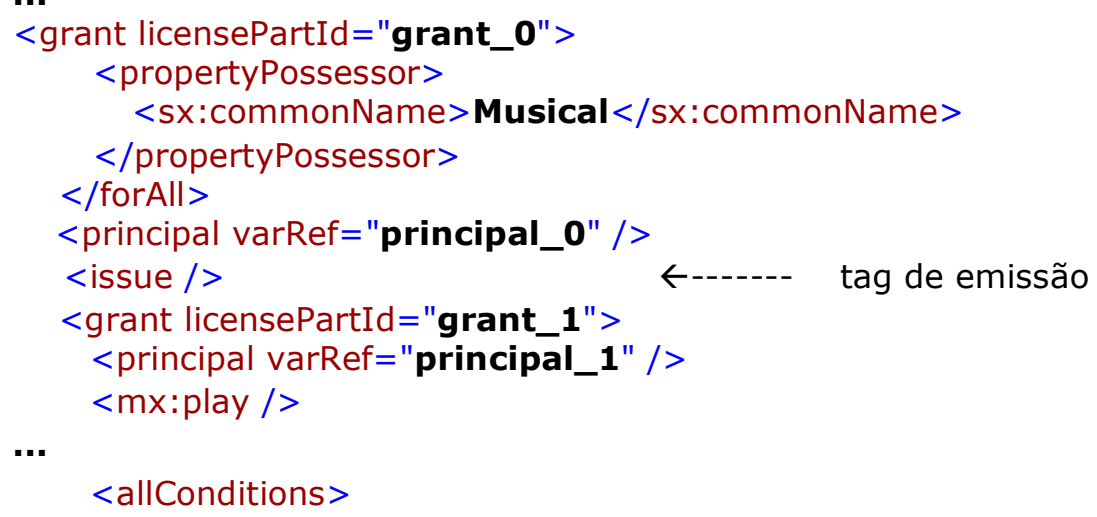


$<$ sx:exerciseLimit $>$

$<$ sx:count $>\mathbf{5}</$ sx:count $>\quad \leftarrow------\quad$ tag de limitação de reprodução

$</$ sx:exerciseLimit $>$

$</$ allConditions $>$

...

No próximo exemplo (Figura 4.14), tem-se uma licença de oferta, onde um cliente qualquer pode "alugar" a mídia video.mpeg por uma taxa pré-estabelecida de $\underline{\mathrm{R} \$ 5,00}$.

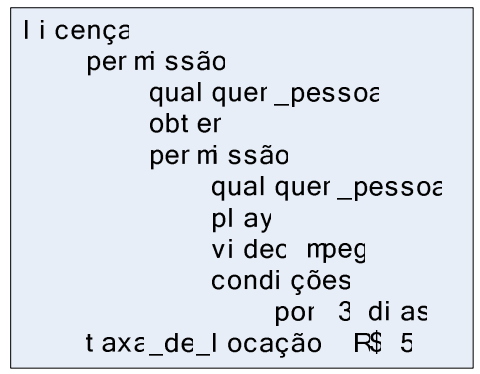

Figura 4.14 - Licença de oferta.

Estas condições são expressas da seguinte forma:

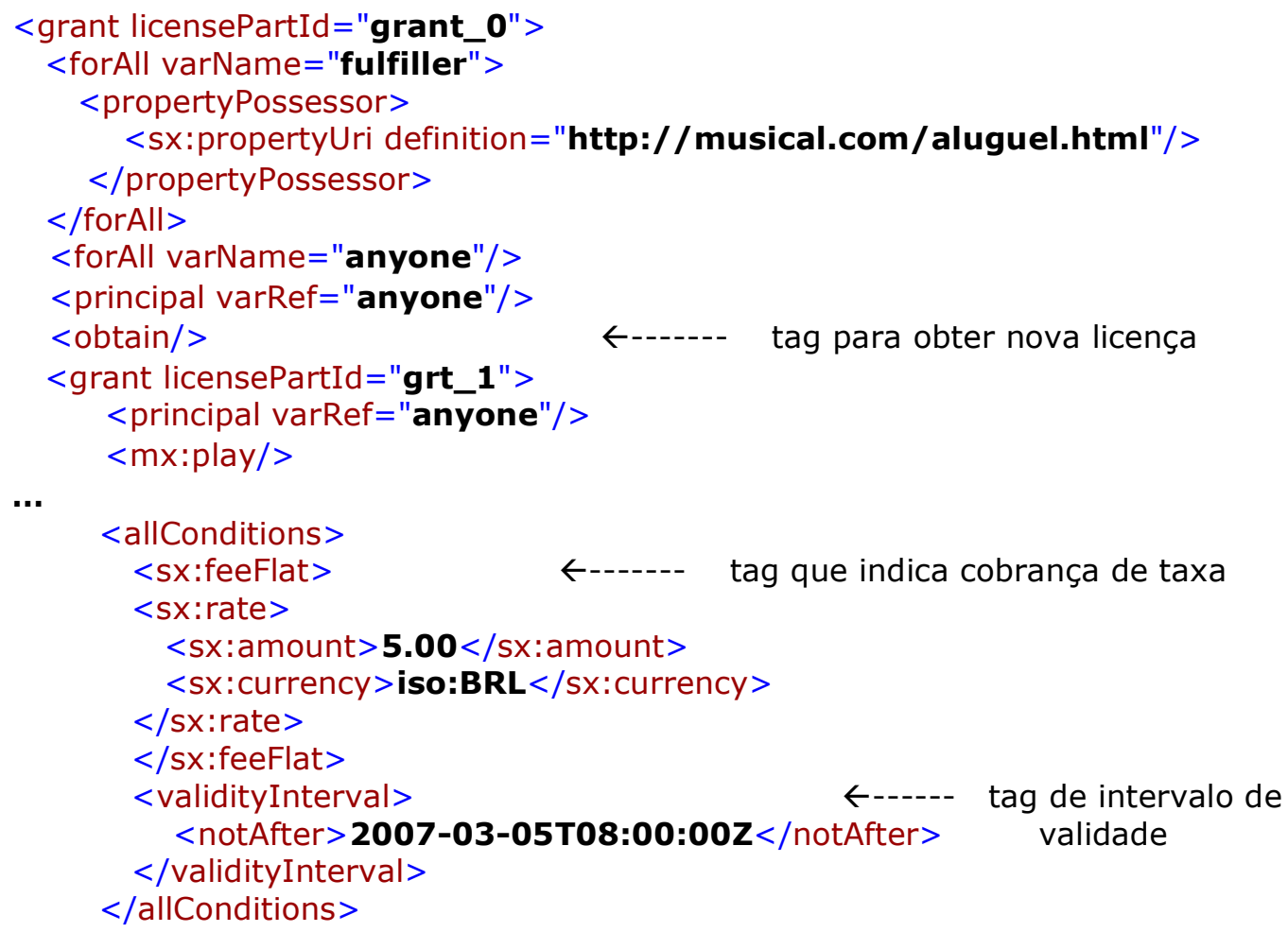

No início do código é possível observar que o URI da loja Musical.com é indicado. Este endereço é usado para apontar ao software cliente onde deve ser obtida a licença de uso. O campo de intervalo de validade será criado com base na data em que o usuário alugar a mídia. 
Por último, é apresentado um exemplo (Figura 4.15) onde o destinatário Alex Silva obtém o direito de assistir um vídeo por um período determinado, restrito a um dispositivo específico. Depois desse período, o usuário não terá mais restrição de dispositivo.

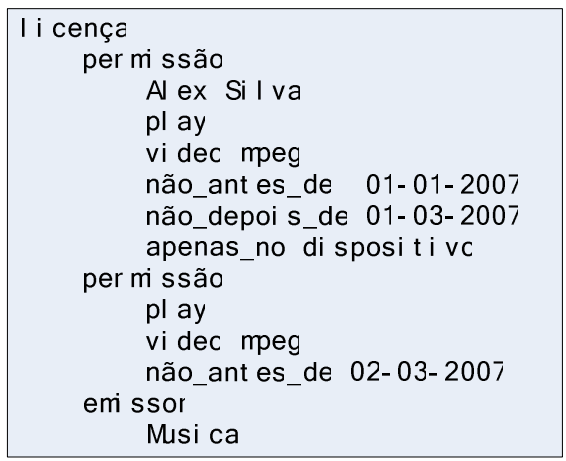

Figura 4.15 - Licença com restrição de dispositivo

Para este caso, seguem as estruturas de linguagem de destaque:

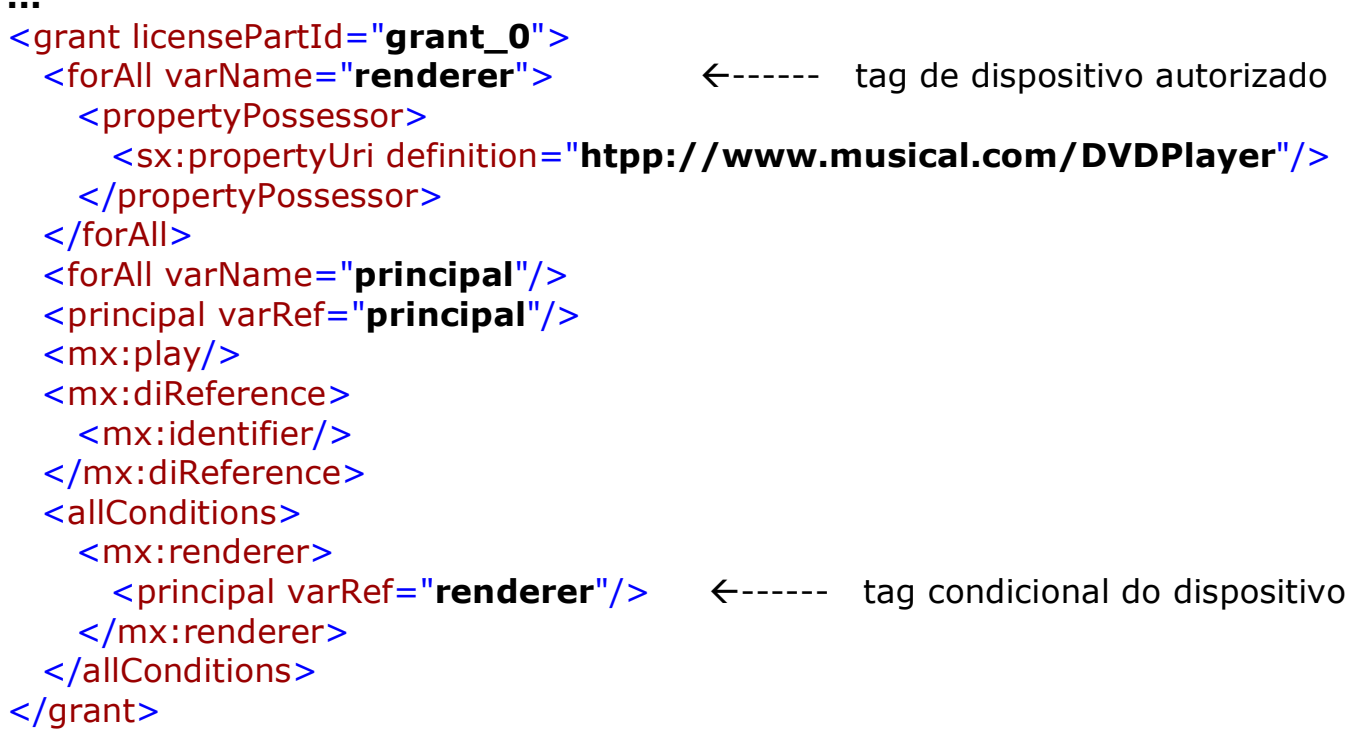

Este caso é importante para ilustrar que as licenças podem conter mais de uma permissão, podendo estar encadeadas. Um caso prático para o exemplo acima é a situação em que um cliente do sistema IPTV recebe um programa que só poderá ser assistido no seu Set-Top Box por um período de tempo. Após este período, o Produtor decide que o conteúdo não tem mais valor comercial e libera para que seja visto em outros aparelhos. 
Estes são apenas alguns dos tipos de licença que podem ser criados para uso em um sistema de IPTV. As possibilidades crescem à medida que novos serviços são desenvolvidos para o sistema. A REL utilizada prevê a ampliação da linguagem através de novos dicionários de dados que podem ser adicionados posteriormente.

A especificação permitiu a definição detalhada do Broker inserido no contexto do sistema de distribuição. Com base nisso, outros sistemas de distribuição de conteúdo podem generalizar este mesmo objeto para distribuir de forma segura conteúdo em redes de dados. O Broker tende a ficar mais elaborado conforme ocorre o amadurecimento das linguagens de expressão de direitos e sua integração com outras tecnologias de segurança. 


\section{Capítulo 5 - Caso de validação}

De acordo com as tecnologias apresentadas e a especificação do capítulo anterior, o escopo da implementação é reduzido e se propõe a validar este trabalho através da criação e utilização das licenças de uso dentro de um sistema de distribuição de conteúdo. Isso se dá com o desenvolvimento de um protótipo de gerador de licenças baseado no MPEG-21 REL e implementado em conjunto com um tocador de vídeo para o consumo do conteúdo.

Este capítulo descreve as etapas de desenvolvimento do protótipo partindo dos requisitos levantados anteriormente, além de apresentar as plataformas utilizadas na implementação. $O$ objetivo do protótipo é ser coerente com as necessidades do modelo discutido, devendo prever as interfaces com outros módulos do sistema para possível integração posterior.

\subsection{Descrição do protótipo}

Nesta seção será feita a descrição do protótipo implementado na validação do trabalho. Serão discutidos os requisitos do sistema e em seguida apresentados os diagramas essenciais para visualização das funções exercidas pelo software. A descrição aqui contida se baseará em diagramas do Unified Modeling Language (UML) (LARMAN, 2000) para ilustrar o cenário e principais fluxos do protótipo.

A implementação se divide em dois blocos funcionais. De um lado está a criação das licenças de uso para fluxos de vídeo baseados nos direitos (existentes ou não) vindos do Provedor de Conteúdo. O segundo módulo é responsável por interpretar estas licenças e, com base nas permissões nelas contidas, habilitar a execução do vídeo.

\subsubsection{Requisitos do sistema}

A listagem de requisitos funcionais utilizados para a implementação representa um subconjunto do que foi levantado no capítulo anterior, focando diretamente os 
mecanismos que serão implementados. Estes requisitos serão utilizados posteriormente nos diagramas UML.

O escopo de validação na implementação é a geração de licenças e utilização das mesmas pelos clientes. Vale ressaltar que este protótipo não pretende, a princípio, utilizar mecanismos de segurança elencados na especificação completa do elemento de distribuição.

\subsubsection{Casos de uso}

Este item apresenta e descreve os principais casos de uso para exibição das funções e atores do sistema em alto nível, possibilitando maior compreensão dos requisitos de projeto. Na Figura 5.1 é ilustrado o caso de uso com as principais operações que envolvem o Distribuidor e o Produtor de Conteúdo.

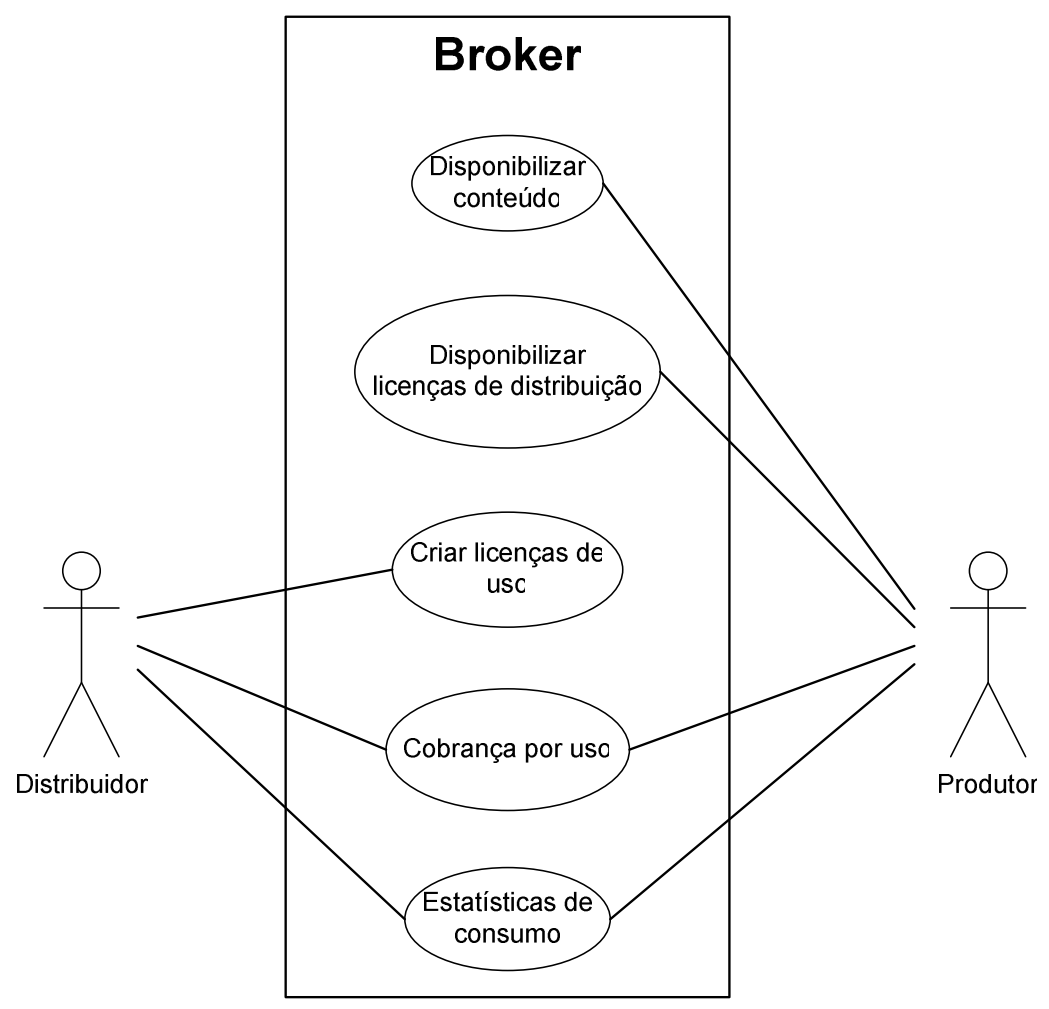

Figura 5.1 - Diagrama de caso de uso - Distribuidor e Produtor.

Segue a descrição dos casos levantados pelo diagrama acima:

\begin{tabular}{|ll|}
\hline Caso de uso & Disponibilizar conteúdo \\
\hline Atores & Distribuidor, Produtor (iniciador). \\
\hline
\end{tabular}




\begin{tabular}{|ll|}
\hline Finalidade & $\begin{array}{l}\text { Envio do conteúdo ao Distribuidor para que seja distribuído à } \\
\text { rede de clientes. }\end{array}$ \\
\hline Visão Geral & $\begin{array}{l}\text { O conteúdo do Produtor é enviado ao Distribuidor através de } \\
\text { fluxos de canal de TV ou VoD. Nesta etapa são negociados } \\
\text { mecanismos de transmissão e outros detalhes necessários } \\
\text { para entrega dos conteúdos. }\end{array}$ \\
\hline Tipo & Primário e essencial. \\
\hline $\begin{array}{l}\text { Referências } \\
\text { Cruzadas }\end{array}$ & RD.1, RD.4 \\
\hline
\end{tabular}

\begin{tabular}{|ll|}
\hline Caso de uso & Disponibilizar licenças de distribuição \\
\hline Atores & Produtor. \\
\hline Finalidade & Fornecer as licenças de distribuição ao sistema. \\
\hline Visão Geral & $\begin{array}{l}\text { As licenças de distribuição são fornecidas ao Broker de acordo } \\
\text { com os contratos entre Produtor e Distribuidor, ficando } \\
\text { disponíveis no sistema para serem posteriormente utilizadas } \\
\text { para geração das licenças de uso dos clientes. }\end{array}$ \\
\hline Tipo & Primário e real. \\
\hline $\begin{array}{l}\text { Referências } \\
\text { Cruzadas }\end{array}$ & RD.7, RD.8 \\
\hline
\end{tabular}

\begin{tabular}{|ll|}
\hline Caso de uso & Criar licenças de uso \\
\hline Atores & Distribuidor. \\
\hline Finalidade & $\begin{array}{l}\text { Criação das licenças de uso a partir das licenças de } \\
\text { distribuição. }\end{array}$ \\
\hline Visão Geral & $\begin{array}{l}\text { O distribuidor requisita ao sistema a criação de licenças de uso } \\
\text { a serem distribuídas para sua rede de clientes. Essas licenças } \\
\text { são derivações diretas das licenças de distribuição fornecidas } \\
\text { pelo Produtor. }\end{array}$ \\
\hline Tipo & Primário e real. \\
\hline Referências & RD.7, RD.8 \\
Cruzadas & \\
\hline
\end{tabular}

\begin{tabular}{|ll|}
\hline Caso de uso & Cobrança por uso \\
\hline Atores & Distribuidor, Produtor. \\
\hline Finalidade & $\begin{array}{l}\text { Pagamento ou outra imposição para habilitar o consumo do } \\
\text { conteúdo. }\end{array}$ \\
\hline Visão Geral & $\begin{array}{l}\text { Este caso levanta a necessidade do Distribuidor e/ou Produtor } \\
\text { requisitarem cobrança pelo consumo da mídia uma vez }\end{array}$ \\
\hline
\end{tabular}




\begin{tabular}{|ll|}
\hline & distribuída. \\
\hline Tipo & Secundário e essencial. \\
\hline $\begin{array}{l}\text { Referências } \\
\text { Cruzadas }\end{array}$ & RR.4 \\
\hline
\end{tabular}

\begin{tabular}{|ll|}
\hline Caso de uso & Estatísticas de consumo \\
\hline Atores & Distribuidor, Produtor. \\
\hline Finalidade & $\begin{array}{l}\text { Mecanismo para reportar as operações de distribuição tanto à } \\
\text { entidade distribuidora, como à produtora. }\end{array}$ \\
\hline Visão Geral & $\begin{array}{l}\text { Criação de documentos (logs) no sistema para que as } \\
\text { operações do Broker sejam transparentes aos envolvidos. }\end{array}$ \\
\hline Tipo & Opcional e essencial. \\
\hline $\begin{array}{l}\text { Referências } \\
\text { Cruzadas }\end{array}$ & RR.3 \\
\hline
\end{tabular}

O segundo caso de uso a ser descrito (Figura 5.2) apresenta o cenário existente entre Cliente e Distribuidor, explicitando operações mediadas pelo Broker.

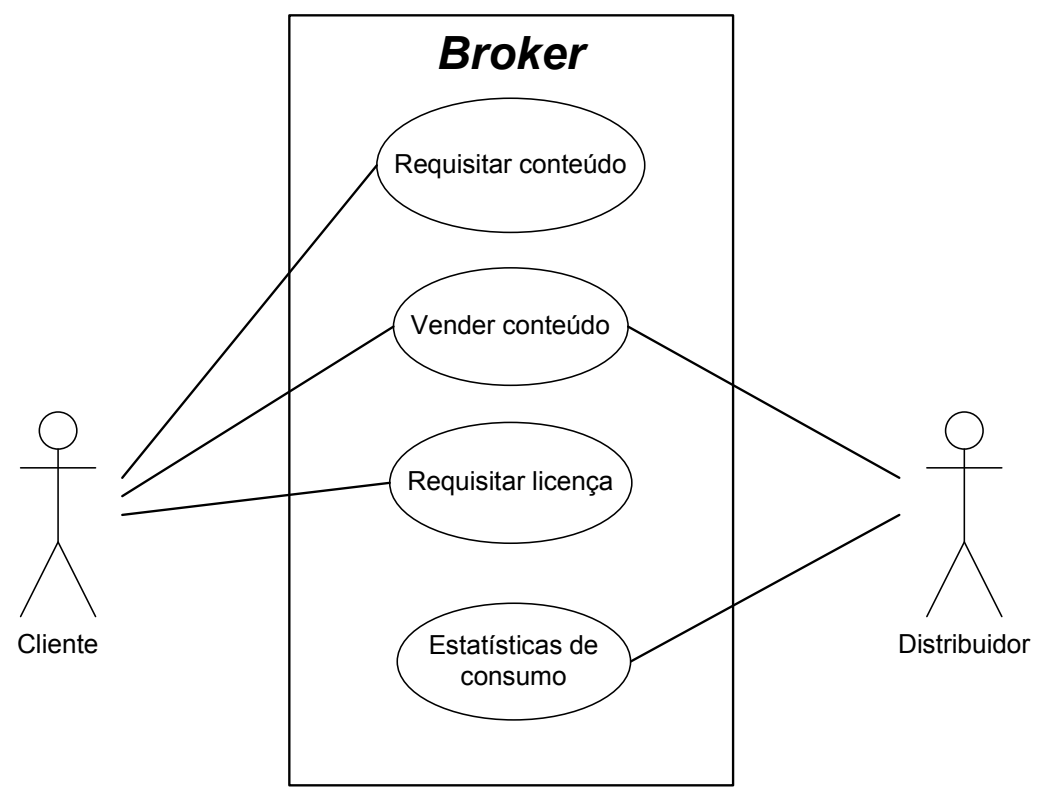

Figura 5.2 - Diagrama de caso de uso - Cliente e Distribuidor.

Segue a descrição dos casos levantados:

\begin{tabular}{|ll|}
\hline Caso de uso & Requisitar conteúdo \\
\hline Atores & Cliente. \\
\hline Finalidade & $\begin{array}{l}\text { Possibilitar ao Cliente uma interface de requisição do conteúdo } \\
\text { disponível no sistema. }\end{array}$ \\
\hline
\end{tabular}




\begin{tabular}{|ll|}
\hline Visão Geral & O sistema deve permitir a aquisição do conteúdo pelo Cliente. \\
\hline Tipo & Primário e real. \\
\hline $\begin{array}{l}\text { Referências } \\
\text { Cruzadas }\end{array}$ & RD.3, RD.5, RD.6 \\
\hline
\end{tabular}

\begin{tabular}{|ll|}
\hline Caso de uso & Vender conteúdo \\
\hline Atores & Cliente (iniciador), Distribuidor. \\
\hline Finalidade & Cobrança pelo conteúdo a ser consumido. \\
\hline Visão Geral & O Cliente pode ser cobrado por certos conteúdos que deseje \\
& $\begin{array}{l}\text { acessar. O sistema deve permitir a cobrança por estes } \\
\text { conteúdos de forma rápida e simples, de forma a interferir o } \\
\text { mínimo possível na experiência do Cliente. }\end{array}$ \\
\hline Tipo & Opcional e essencial. \\
\hline Referências & RR.4 \\
\hline
\end{tabular}

\begin{tabular}{|ll|}
\hline Caso de uso & Requisitar licença \\
\hline Atores & Cliente (iniciador). \\
\hline Finalidade & $\begin{array}{l}\text { Enviar licenças de uso ao Cliente conforme requisitado no } \\
\text { sistema. }\end{array}$ \\
\hline Visão Geral & $\begin{array}{l}\text { Um Cliente que tenha acesso a determinado conteúdo deve } \\
\text { poder requisitar uma licença de uso diretamente ao sistema. }\end{array}$ \\
& Este recurso pode, ou não, disparar o processo de compra. \\
\hline Tipo & Primário e real. \\
\hline $\begin{array}{l}\text { Referências } \\
\text { Cruzadas }\end{array}$ & RD.8, RD.9 \\
\hline
\end{tabular}

\begin{tabular}{|ll|}
\hline Caso de uso & Estatísticas de consumo \\
\hline Atores & Distribuidor. \\
\hline Finalidade & $\begin{array}{l}\text { Possibilitar ao distribuidor acesso a relatórios sobre o consumo } \\
\text { ocorrido no sistema. }\end{array}$ \\
\hline Visão Geral & Criação de documentos (logs) no sistema para que as \\
& operações do Broker sejam transparentes aos envolvidos. \\
\hline Tipo & Opcional e essencial. \\
\hline Referências & RR.3 \\
\hline
\end{tabular}

Os diagramas de caso de uso apresentados são suficientes para cobrir as principais funções necessárias durante a fase de implementação do protótipo deste 
trabalho. No detalhamento de cada caso encontra-se a informação do Tipo, que pode ser dividido em:

- Primário, secundário e opcional: os processos são classificados pela importância: os primários são os mais comuns; secundários acontecem com menos freqüência; e os opcionais representam processos que não necessariamente são considerados.

- Essencial e Real: os casos essenciais são descritos em mais alto nível, com maior abstração tecnológica; já os casos reais são mais específicos, enfatizando ações concretas.

\subsubsection{Diagramas de atividades}

Com os requisitos levantados e os casos de uso já desenvolvidos, um próximo passo na apresentação do programa são os diagramas de atividades, que oferecem uma visão do fluxo de ações durante a execução do programa. Seguem os diagramas que representam os dois casos principais do programa, a parte do Distribuidor e a parte do Cliente. 


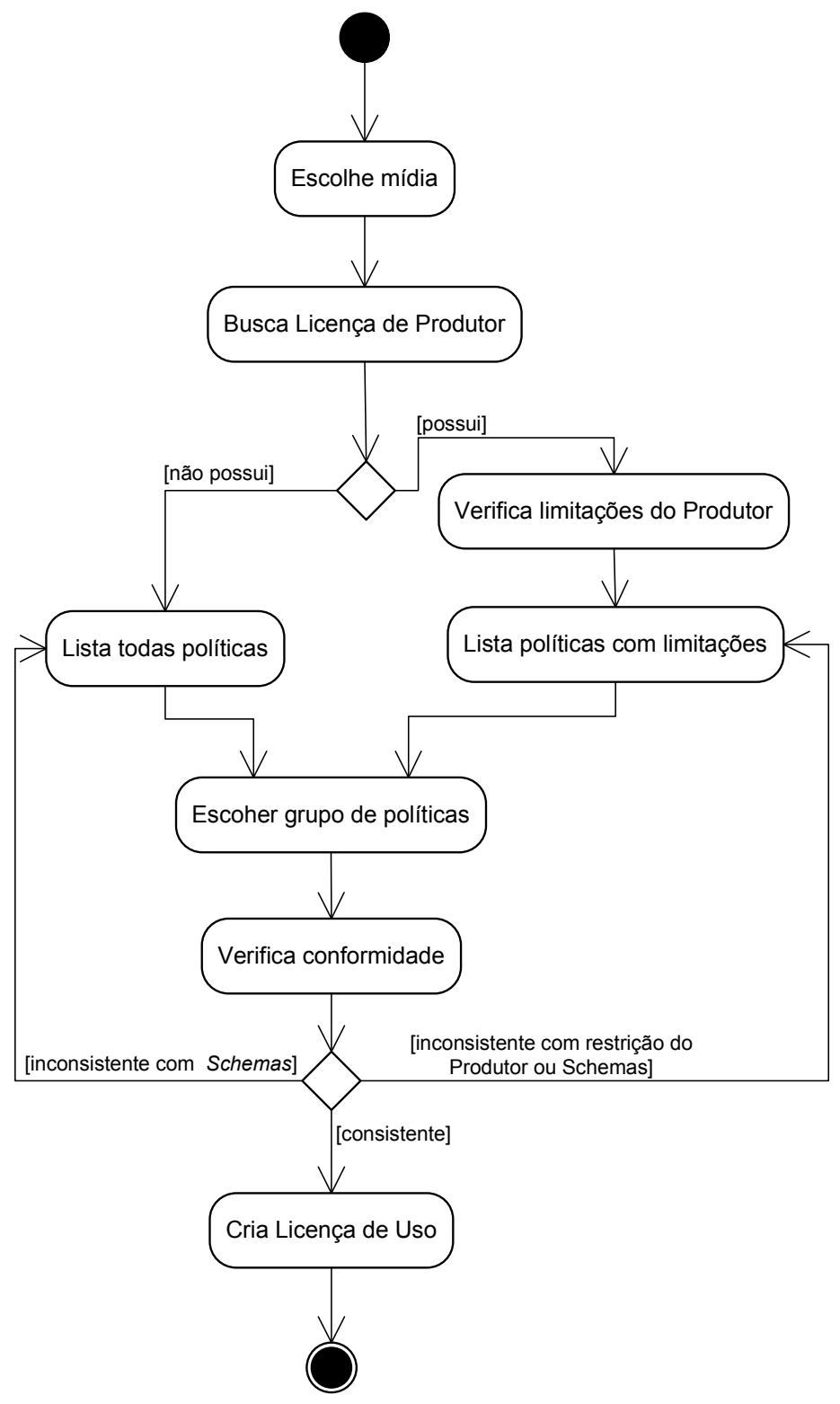

Figura 5.3 - Diagrama de Atividade para geração de licença de uso.

O diagrama da Figura 5.3 representa a primeira etapa do programa, a criação da licença de uso no Distribuidor. O usuário escolhe a mídia para qual pretende criar uma licença e seu repositório é verificado em busca da licença de produtor. As possibilidades para criação de licença de uso serão listadas de acordo com as limitações impostas pelo Produtor. Após a criação da licença é feita a verificação de conformidade com os schemas da linguagem e a licença está pronta para ser distribuída. 


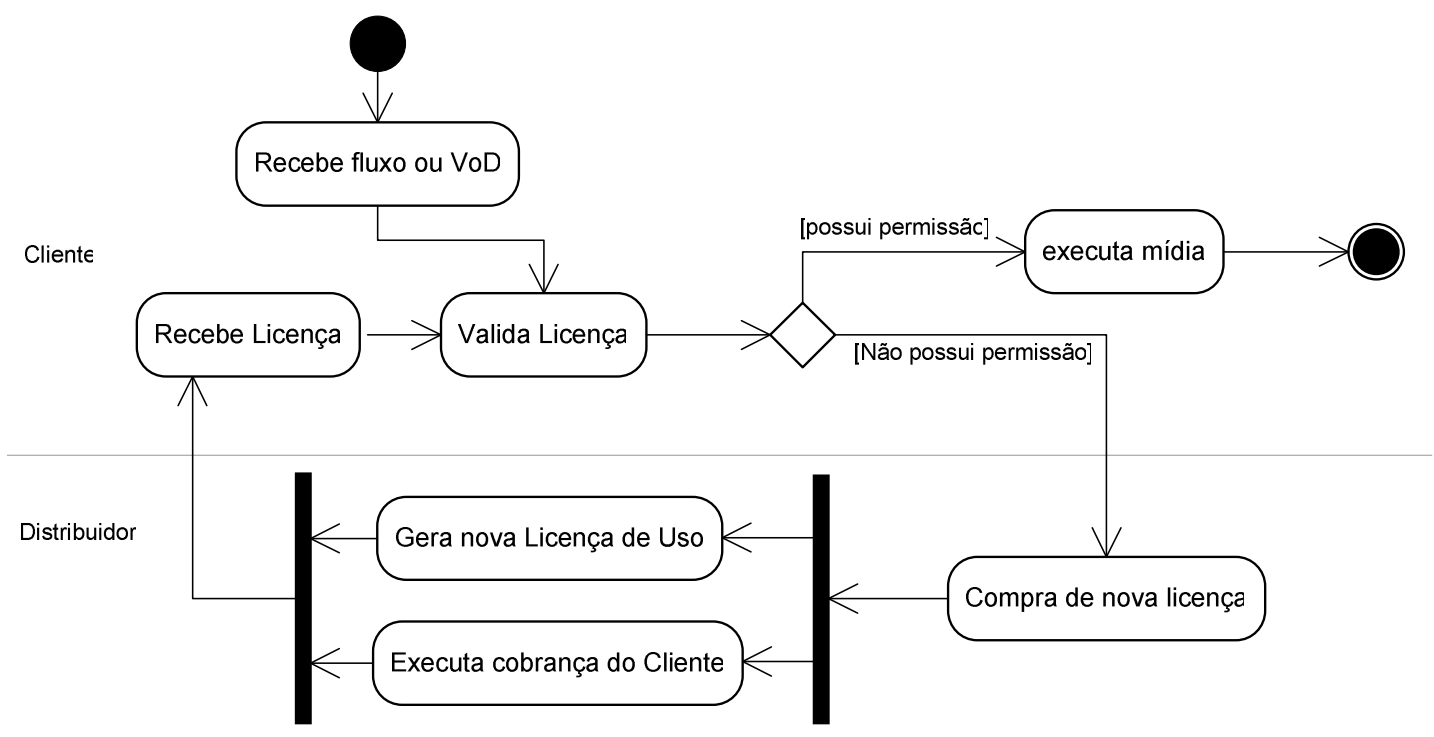

Figura 5.4 - Diagrama de Atividade para exibição de conteúdo.

A segunda etapa do processo está ilustrada na Figura 5.4. Neste procedimento, o conteúdo é recebido pelo cliente e é verificado se este possui as permissões necessárias para execução. Caso não possua, deve contatar o Distribuidor para fazer a transação necessária para habilitar a execução do conteúdo.

\subsubsection{Classes do protótipo}

Os diagramas de atividades possibilitaram uma visão geral dos procedimentos realizados pelo protótipo. Para aproximar este fluxo do código implementado serão apresentados inicialmente diagramas de seqüência, que contêm as principais interações entre as entidades definidas na implementação. Em seguida o modelo conceitual termina com a apresentação dos diagramas de classes resultantes do protótipo. É importante lembrar que os diagramas de seqüência e de classes não têm intenção de fazer um alto detalhamento, limitando-se a apresentar apenas os principais métodos utilizados.

O primeiro diagrama (Figura 5.5) representa o bloco implementado do Distribuidor. É feito o detalhamento sobre o processo de criação de uma licença de uso a partir do Processador de licenças, representado pela entidade Processador, mais à esquerda da figura. 


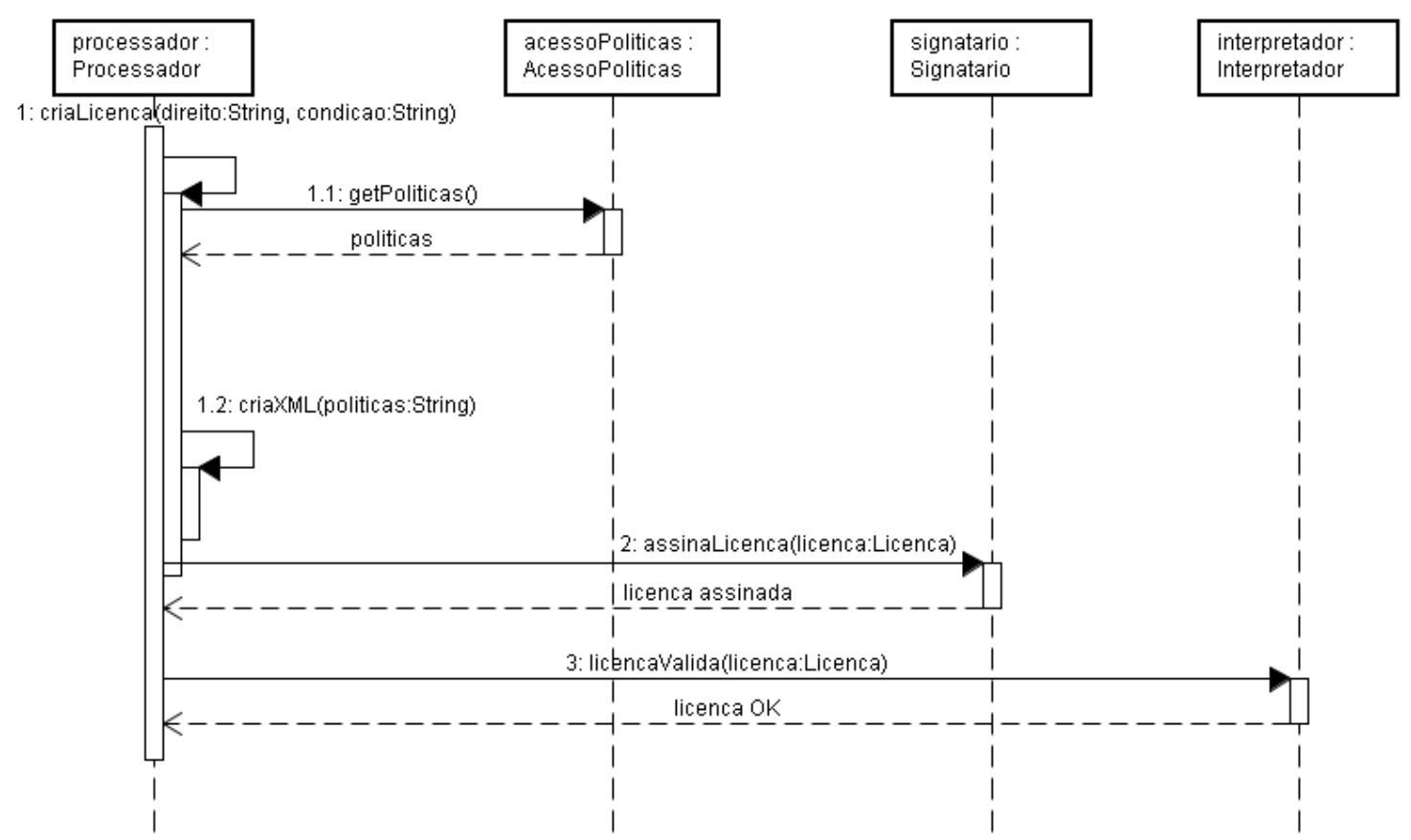

Figura 5.5 - Diagrama de seqüência para criação de licença no Distribuidor.

O processo inicia-se com a requisição para criação de licença; neste momento o Processador é informado dos detalhes da licença a ser criada. A primeira etapa é acessar o banco de políticas do sistema para resgatar os blocos de políticas que serão utilizados. Em seguida, o Processador cria o XML com a licença quase completa, faltando apenas a identificação de emissor. O Signatário recebe o XML e assina seu conteúdo, acrescendo o campo de emissor ao final da licença, campo este que contém a chave pública do distribuidor e o resumo criptográfico para verificação de integridade da licença. Um último passo é enviar a licença recémcriada para o Interpretador verificar se a estrutura está de acordo com o formato oficial. Com a verificação feita, o processo termina com uma licença completa, pronta para ser enviada aos clientes.

Como última instância, o diagrama de seqüência é mapeado em um diagrama com as classes utilizadas no Distribuidor (Figura 5.6). 


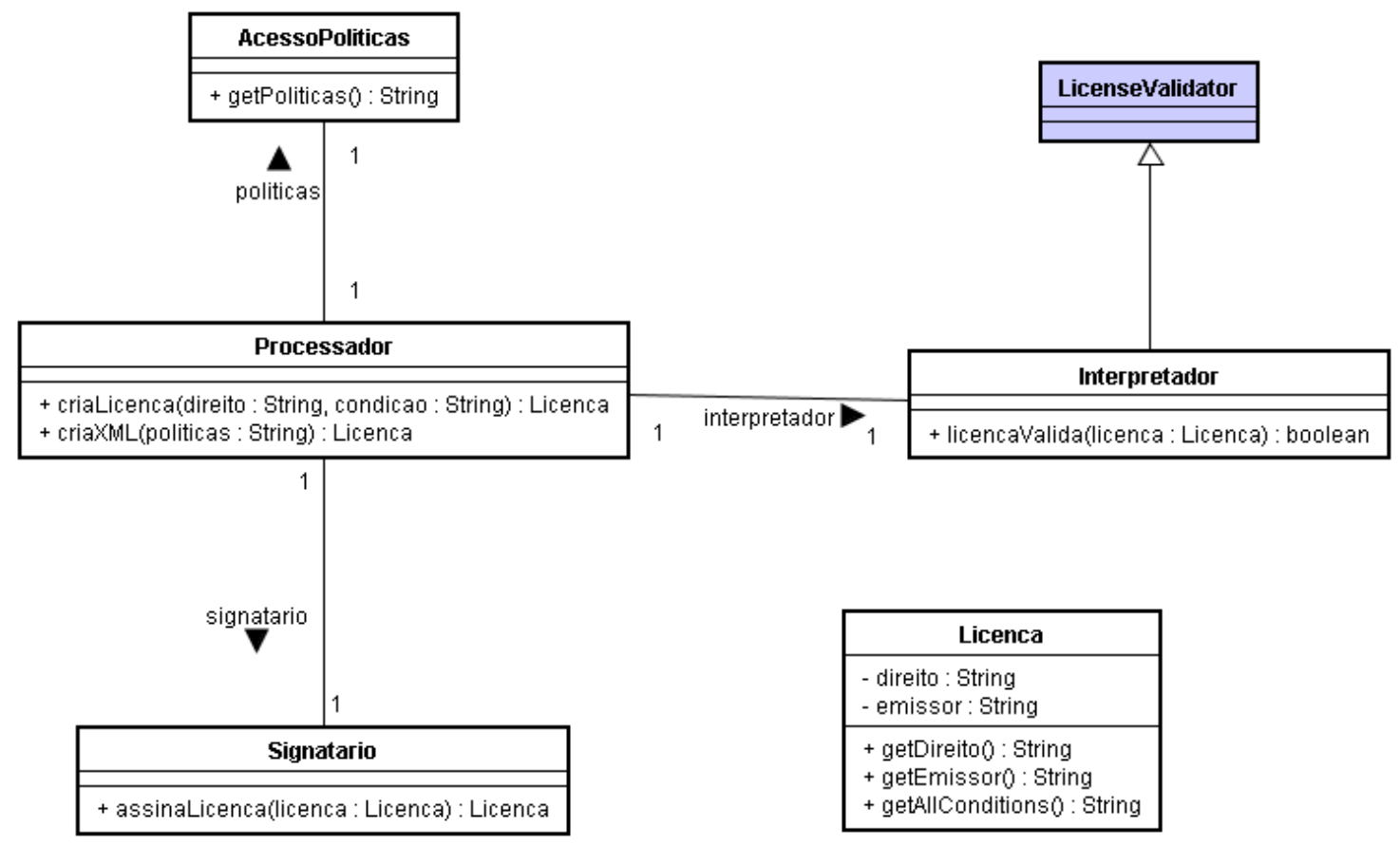

Figura 5.6 - Diagrama de classes do Distribuidor.

As classes Processador, Interpretador, Signatário, AcessoPolíticas e Licenca foram as classes criadas para o protótipo. A classe Licenca não possui associação direta com nenhuma outra classe do sistema, no entanto sua estrutura de dados é amplamente utilizada pelas outras classes no processo de criação. Vale ressaltar que a classe Interpretador é uma generalização do LicenseValidator pertencente ao framework MPEG REL utilizado para garantir a correta interpretação da linguagem.

Da mesma forma que no Distribuidor, o diagrama de seqüência também foi gerado para o Cliente (Figura 5.7). Neste caso é ilustrado o processo do software cliente para receber uma requisição de mudança de canal, iniciando a verificação e compra de licença.

Ao receber uma solicitação de mudança de canal, o aplicativo deve buscar o fluxo desejado na rede através do endereço IP (seja multicast ou unicast). Antes da exibição do fluxo, deve-se fazer uma busca no repositório pela licença de uso específica do conteúdo. No caso ilustrado pelo diagrama, esta licença não está disponível, portanto o aplicativo deverá requisitá-la ao Distribuidor. 


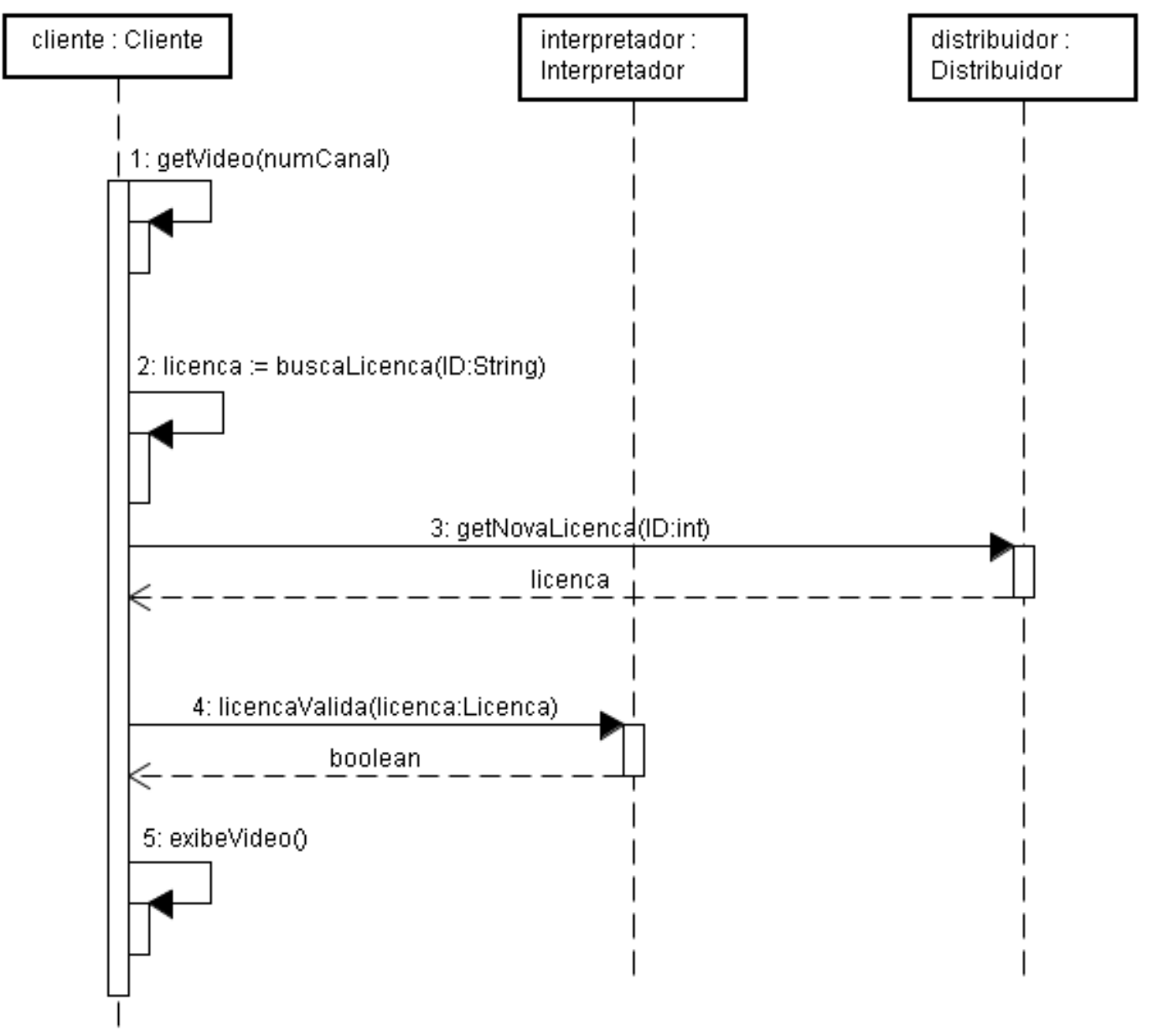

Figura 5.7 - Diagrama de seqüência para mudança de canal no Cliente.

A lógica de venda de licenças não é objetivo do trabalho e por isso não será detalhada neste protótipo.

Para esta validação, basta que o Cliente tenha acesso à nova licença perante uma requisição. Tendo recebido a licença, o cliente verifica sua integridade através do mesmo mecanismo utilizado no Distribuidor, em processo que garante a conformidade da linguagem no cliente. Uma vez validada, é liberada a exibição do vídeo para o usuário.

De acordo com o diagrama de seqüência são definidas as entidades transformadas em classes para o protótipo, como mostrado na Figura 5.8. 


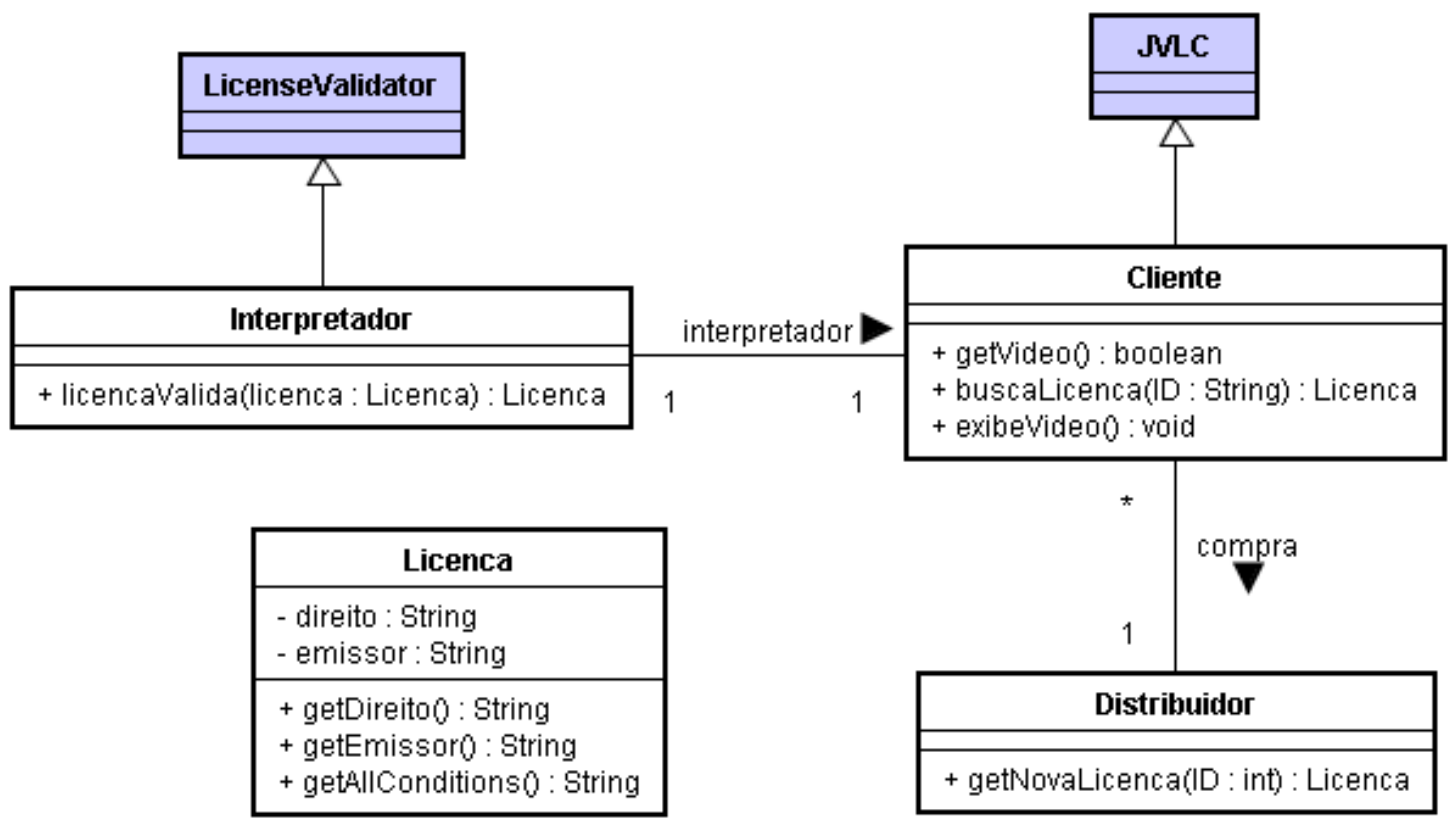

Figura 5.8 - Diagrama de classes do Cliente.

Da mesma forma que no Distribuidor, o Cliente também utiliza as classes Licenca, Interpretador e LicenseValidator. A outra classe externa utilizada no Cliente é o JAVA VideoLAN Client (JVLC), a fim de proporcionar os mecanismos para exibição de vídeo.

\subsubsection{Interfaces do protótipo}

Foram criadas interfaces gráficas em Java para facilitar a utilização do protótipo tanto para o Distribuidor quanto para o Cliente. Neste caso, as interfaces utilizam o pacote gráfico Java Abstraction Window Toolkit (AWT). O AWT é o pacote de interface gráfica tradicional da linguagem, disponível desde 1995, e conta com diversos gerenciadores de leiaute (layout managers) suficientes para o suporte à aplicação que está sendo desenvolvida.

\section{Interface de Distribuidor}

A primeira interface apresentada é a do Distribuidor, onde é possível acessar suas principais funções representadas na Figura 5.9: 


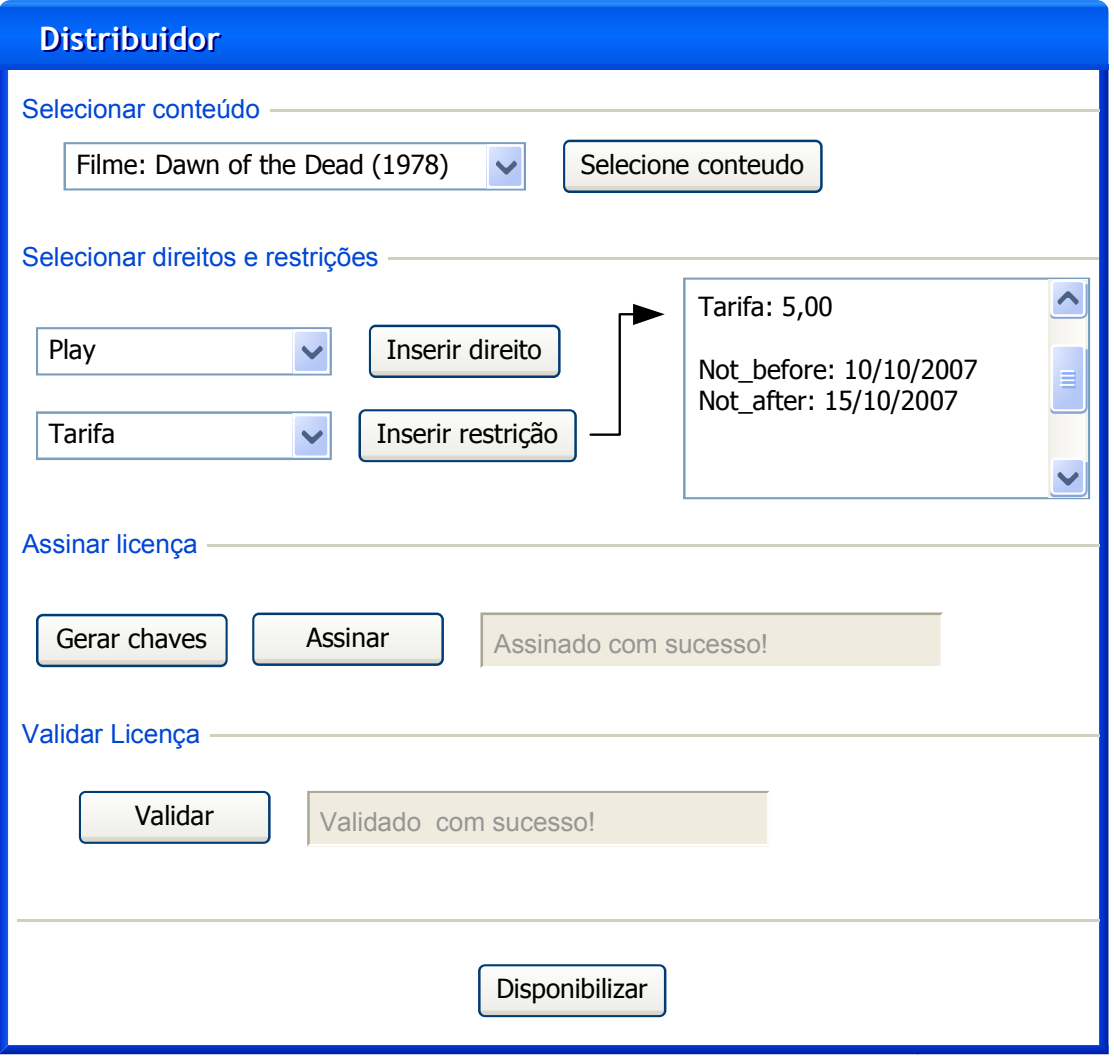

Figura 5.9 - Interface do Distribuidor.

Esta interface permite a criação de licenças de uso de forma completa. Segue a descrição de cada função:

\section{Seleção de conteúdo}

A primeira etapa para a criação da licença é selecionar o conteúdo que vai ser descrito. Esta primeira função lista identificadores dos conteúdos disponíveis na base do Distribuidor. Os identificadores estão vinculados aos descritores URI de cada conteúdo no sistema.

\section{Seleção de direitos e restrições}

Nesta etapa são selecionados os direitos que devem ser garantidos na licença, além de permitir a inserção de restrições. No exemplo da Figura 5.9, foram inseridas restrições de tarifação por uso, além de período de validade para a licença. 


\section{Geração de chaves e assinatura de licenças}

Aqui é possível gerar um par de chaves assimétricas para em seguida assinar a licença. $O$ processo de assinatura garante que a licença não possa ser modificada sem que o sistema perceba.

\section{Validar licenças}

Uma última função disponível é a validação de licenças. Este processo utiliza o interpretador do SDK MPEG REL, o mesmo que será utilizado no Cliente.

Após a validação da licença é possível disponibilizá-la aos clientes pela base de dados.

\section{Interface Cliente}

A interface de cliente prevê a integração com o guia de programação de canais (EPG) desenvolvido no projeto IPTV, realizado pelo LARC em parceria com a Ericsson. Esta integração confere maior flexibilidade ao protótipo pela capacidade de navegação. Por outro lado, a integração dos mecanismos de controle de consumo através das licenças também é uma vantagem que pode ser futuramente agregada ao projeto.

O guia possui duas interfaces principais, exibidas a seguir:

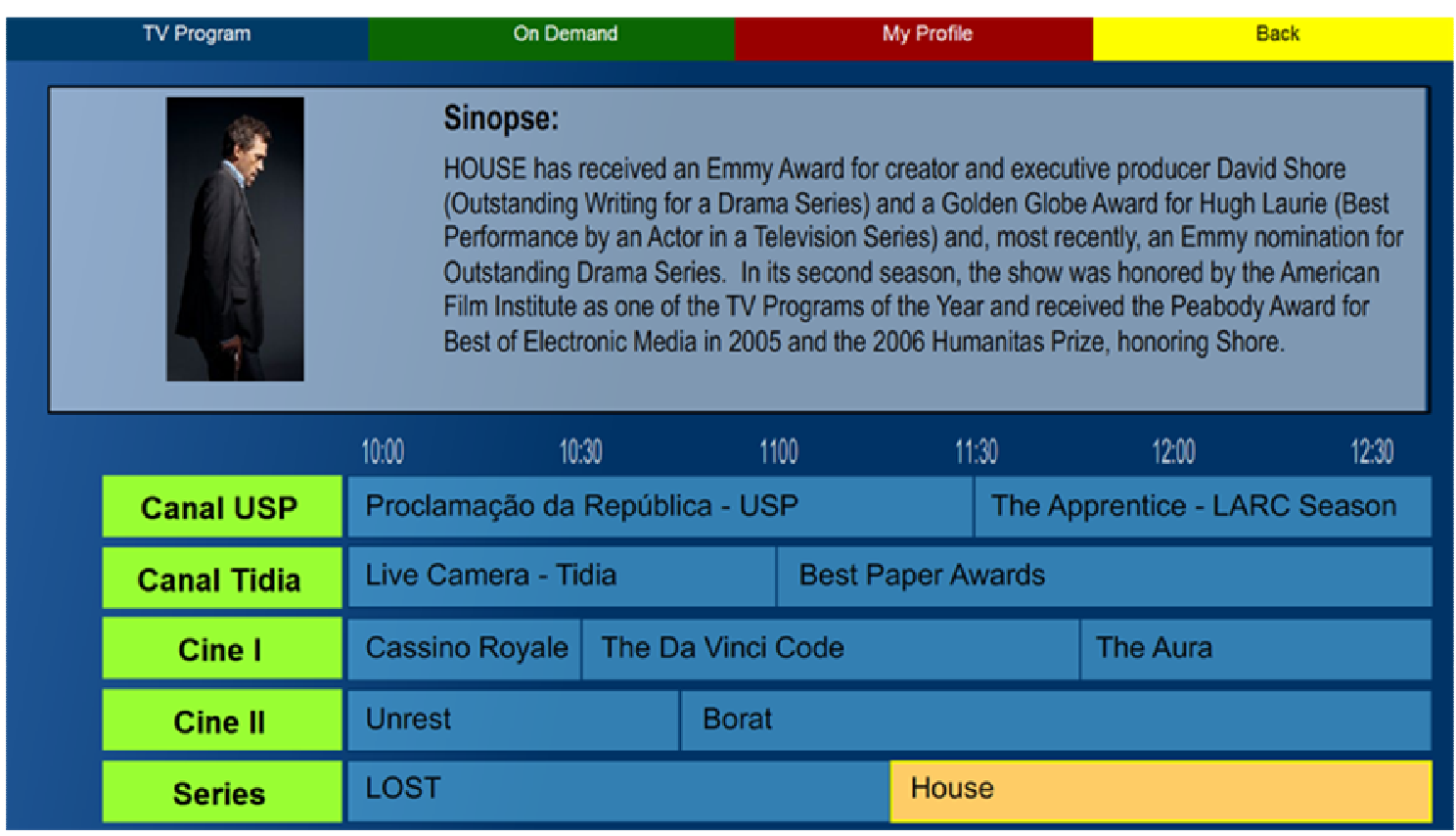

Figura 5.10 - Guia de programação - fluxo de canal de TV. 
A primeira interface (Figura 5.10) apresenta uma grade de programação tradicional de canais de TV, separando os programas por canal e horário, e incluindo uma pequena sinopse no alto da tela. Estas facilidades permitem o usuário navegar rapidamente pelos conteúdos oferecidos.

Já a segunda interface (Figura 5.11) apresenta o conteúdo sob demanda disponível no sistema. A navegação ocorre por categorias (parte inferior da tela), sendo que os conteúdos de maior popularidade (mais assistidos) ficam em destaque no lado direito. Cada conteúdo possui também uma sinopse.

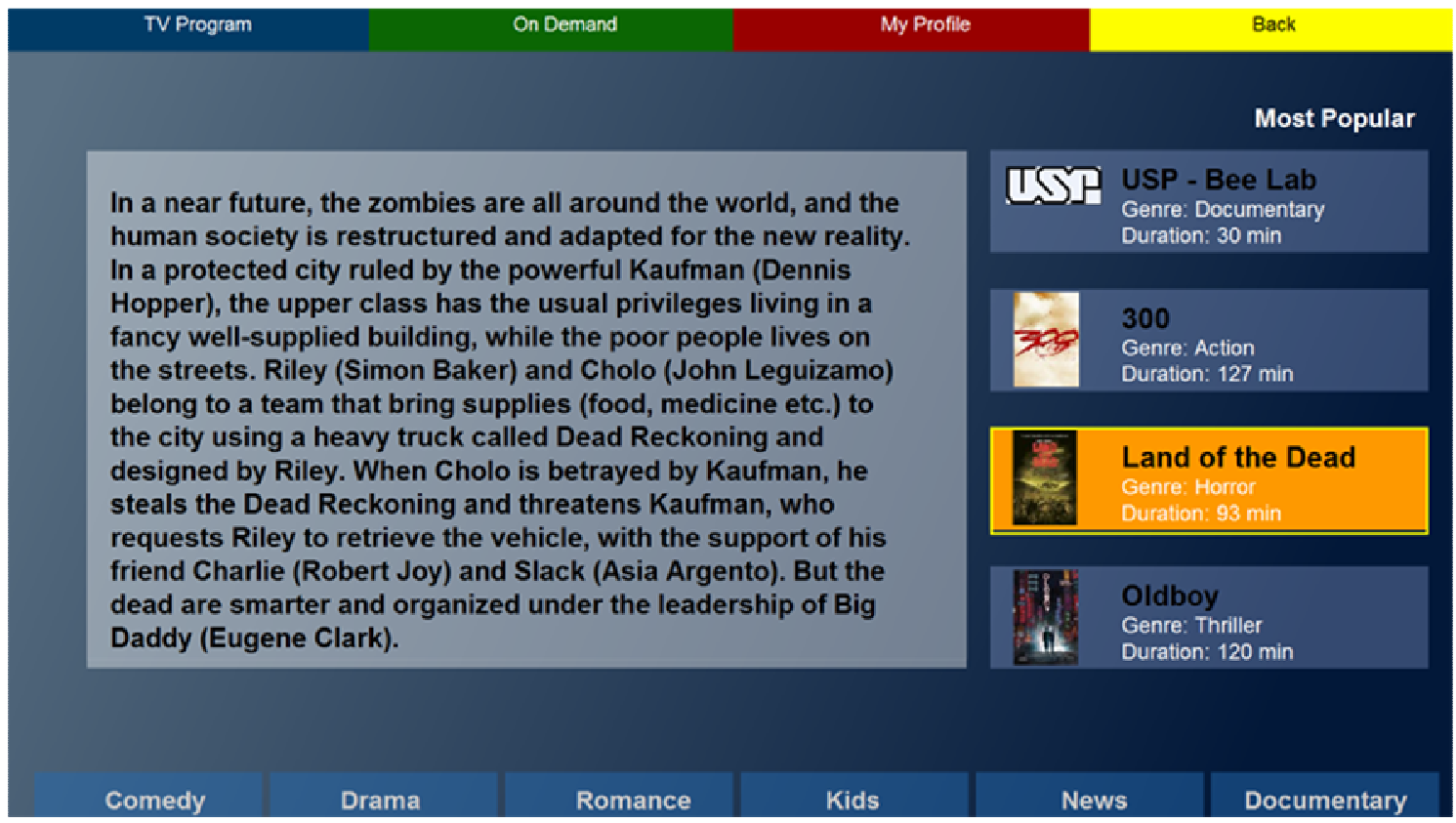

Figura 5.11 - Guia de programação - VoD.

Uma vez que o usuário tenha escolhido o programa que deseja assistir, o aplicativo cliente "sintoniza" o conteúdo desejado para começar a exibição. A partir deste ponto é feita a verificação de disponibilidade da licença na base do Cliente. Caso este possua a licença necessária, o conteúdo já começará a ser exibido corretamente. O modelo para a interface de um cliente do sistema está representado na Figura 5.12: 


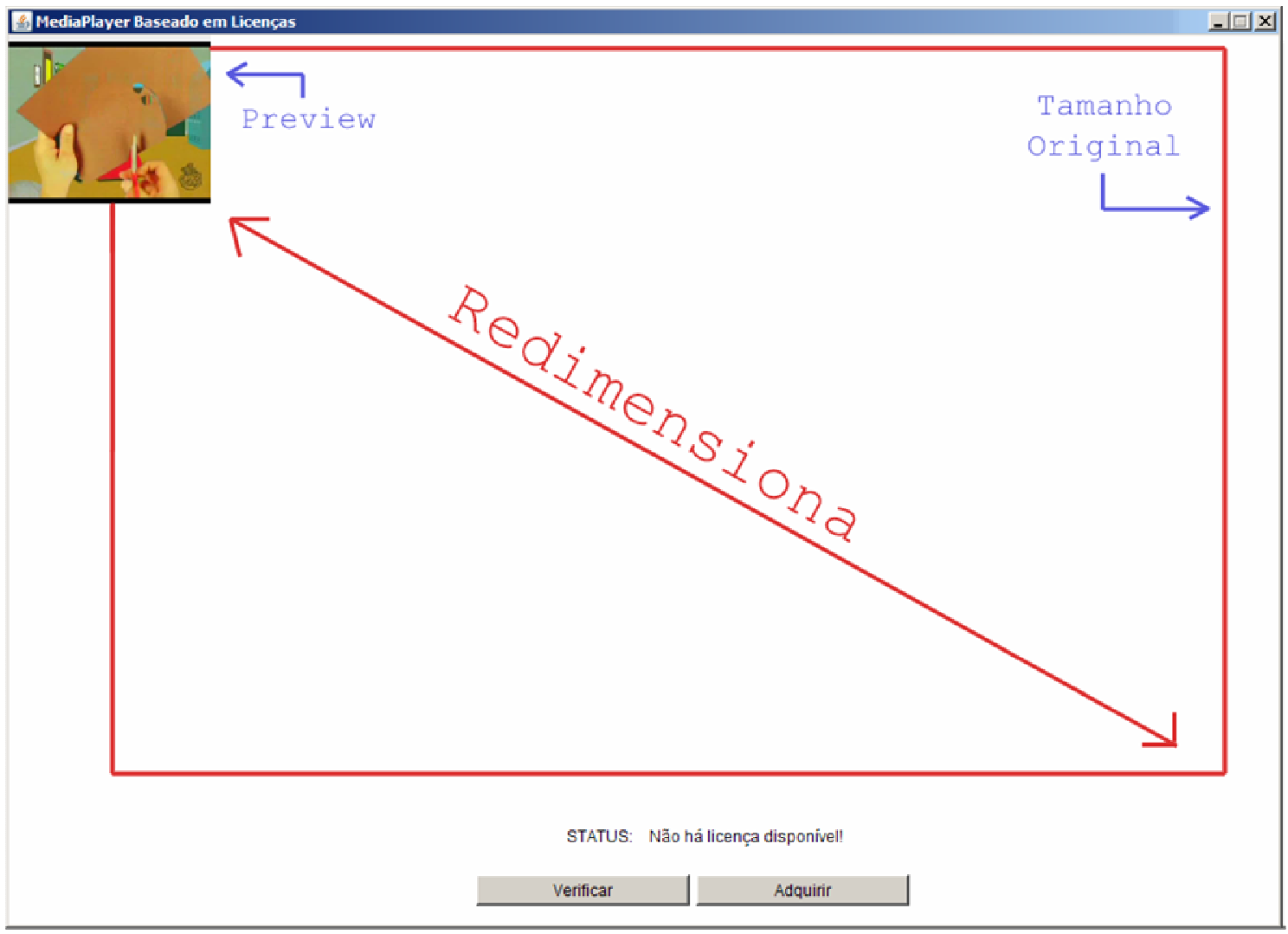

Figura 5.12 - Interface do Cliente.

Esta segunda interface também se baseia em AWT e utiliza o JAVA VideoLAN para a exibição do conteúdo de vídeo. Os mecanismos do MPEG REL SKD são utilizados aqui na fase de verificação da licença de uso.

Para o protótipo foram utilizados três ${ }^{45}$ canais de vídeo em definição standard ou superior, transmitidos simultaneamente aos clientes por RTP através das portas 1501, 1502 e 1503. As transmissões foram realizadas através do VideoLAN Client (VLC). O RTP foi escolhido por ser um mecanismo tradicional de envio, obtendo bons resultados na transmissão; contudo, outros mecanismos poderiam ter sido utilizados dada a flexibilidade do pacote JVLC.

Para facilitar a visualização do funcionamento do software durante o período em que o usuário não tem licença, o vídeo é exibido em uma resolução muito inferior (160x120pixels) à original. Uma vez que seja verificado que o usuário possui a licença e esta é válida para o conteúdo que está sendo exibido, o vídeo é redimensionado para visualização em tamanho real.

\footnotetext{
${ }^{45}$ Este número de canais foi escolhido por ser suficiente para demonstrar a capacidade de chaveamento do cliente. Não existe, contudo, limitação para o número de canais recebidos; esta limitação fica a cargo da capacidade de processamento do servidor que está enviando os fluxos.
} 


\section{Verificacão de Licencas}

A função "Verificar" permite a validação da licença para o conteúdo que está sendo exibido. A função de validação de licença ocorre pela mesma biblioteca utilizada no Distribuidor, de forma a conferir mais confiança na verificação pelo cliente. Um repositório local é indicado ao programa com as licenças que o usuário possui.

\section{Aquisição de licenças}

Caso a licença necessária não esteja disponível no repositório do programa, o usuário poderá solicitar uma nova através do botão "Adquirir". O programa permite que uma nova licença seja acrescentada ao repositório local.

\subsection{Sistemas utilizados}

O protótipo desenvolvido foi feito através da linguagem Java ${ }^{46}$. Esta escolha foi feita principalmente com base nas ferramentas disponíveis para auxílio à implementação, conforme será apresentado nos próximos itens. Não obstante, a linguagem Java ganha cada vez mais espaço pela versatilidade e capacidade de adaptação em diversas plataformas de desenvolvimento. Esta escolha visa contribuir para a reutilização do código em trabalhos futuros.

\subsubsection{ContentGuard SDK}

Para o desenvolvimento do mecanismo de criação e validação de licenças foi utilizado o kit de desenvolvimento de software $(\mathrm{SDK})^{47}$ em Java da ContentGuard, empresa responsável pela linguagem de descrição de direitos XrML (CONTENTGUARD, 2001), que posteriormente viria a se tornar a MPEG-21 REL. A ContentGuard disponibiliza o SDK para agilizar o desenvolvimento de aplicativos baseados na linguagem.

\footnotetext{
${ }^{46}$ A linguagem de programação Java é desenvolvida pela Sun Microsystems: <http://java.sun.com/>. Durante o desenvolvimento do protótipo foi utilizada o J2SE versão 1.6.0_01.

${ }^{47}$ MPEG REL SDK for Java disponível em: < http://www.contentguard.com/MPEGREL_sdk.asp >.
} 
O uso do SDK não só permite a criação mais rápida de um protótipo, mas resolve um grande problema no desenvolvimento de software para licenças: a subjetividade da criação e interpretação das políticas de uso. Ainda que criadas de forma objetiva, apoiadas em uma linguagem descritiva ( $X M L)$ que tem como premissa poder ser claramente lida por pessoas (em oposição a códigos de máquina de baixo nível), as políticas de uso que formam a licença podem facilmente atingir um grau de complexidade alto, complicando seu entendimento.

Não apenas a complexidade, mas principalmente a própria subjetividade inerente à descrição dos direitos de um objeto no mundo digital são alvos de críticas por parte dos que são contra o uso linguagens de expressão de direitos. A utilização do ContentGuard SDK no protótipo garante a conformidade com a linguagem tanto na criação quanto na validação das licenças de uso.

\subsubsection{Java VideoLAN Client}

Para a segunda parte da implementação foi usada a interface de programação do Java VideoLAN Client, ou JVLC ${ }^{48}$. O JVLC é uma biblioteca multimídia para a linguagem Java, que tem intuito de fornecer ao desenvolvedor as mesmas funcionalidades encontradas no VideoLAN ${ }^{49}$, uma poderosa ferramenta de exibição e transmissão de vídeo em redes IP.

Com o JVLC é possível implementar um tocador de mídia para a exibição do conteúdo de forma a emular o lado cliente de recepção de vídeo. O JVLC deve ser utilizado em conjunto com o MPEG REL SDK para criar um tocador de mídia que analise o fluxo (ou $\mathrm{VoD}$ ) recebido e permita a exibição perante a verificação da licença de uso.

O JVLC inclui uma interface para as principais funções disponíveis no VideoLAN. O VideoLAN é um sistema multimídia de código aberto multiplataforma. Este software é distribuído através da licença GNU General Public License ${ }^{50}$ (GPL), que permite distribuição gratuita e alteração no código fonte do programa. Atualmente o VideoLAN é o principal programa de código aberto utilizado na

\footnotetext{
${ }^{48}$ JVLC: <https://trac.videolan.org/jvlc>.

${ }^{49}$ VideoLAN: <http://www.videolan.org $>$.

${ }^{50}$ GNU GPL: < http://www.gnu.org/copyleft/gpl.html>.
} 
comunidade acadêmica para exibição e transmissão de diversos tipos de áudio e vídeo e conta com desenvolvedores espalhados em cerca de vinte países. O VideoLAN foi utilizado para criar os fluxos de vídeo RTP transmitidos continuamente, simulando o comportamento do Distribuidor.

Além das ferramentas descritas acima, a implementação do protótipo utilizou a linguagem Java através do ambiente Eclipse versão 3.2, rodando no Windows XP $S P 2$. Toda a integração de ferramentas ocorreu neste mesmo ambiente.

A implementação deste trabalho se propôs a validar a capacidade de criação, transmissão e interpretação das licenças de uso sobre uma rede IP. Além disso, um tocador de vídeo foi integrado às ferramentas de interpretação da linguagem de expressão do MPEG-21. O protótipo resultante se comportou de forma estável e provou a capacidade de rápida criação das licenças. Futuros trabalhos podem acoplar mecanismos de segurança para efetivamente criar um sistema seguro, e uma análise focada em performance poderia ser realizada a fim de estimar a escalabilidade do sistema. 


\section{Conclusão}

A televisão é um dos meios de comunicação de maior alcance mundialmente, tendo um valor ainda maior no Brasil pela capacidade de levar informação aos locais mais remotos. O avanço das tecnologias propiciou a mudança de padrão do analógico para o digital, proporcionando mais qualidade e experiência interativa. $\mathrm{O}$ IPTV surge neste cenário como um serviço promissor, não só por compartilhar as mesmas características da TV Digital, mas por agregar novos serviços como o vídeo sob demanda.

Contudo, a digitalização do conteúdo pode ser tanto positiva para o usuário final, que espera maior qualidade e flexibilidade do formato digital, quanto negativa para os produtores e distribuidores, que temem a pirataria crescente facilitada por este mesmo formato. Dessa forma, se fazem necessários mecanismos para regular o uso das novas mídias, minimizando problemas de uso indevido do conteúdo.

Esta dissertação iniciou-se com a modelagem do cenário de IPTV, definindo atores envolvidos e o conjunto de serviços desejáveis. Esta contextualização permitiu um maior entendimento das dificuldades existentes no atendimento dos requisitos para distribuição escalável desses serviços. Também foram analisados os requisitos de confidencialidade do conteúdo em toda a cadeia de negócios, desde a concepção até o armazenamento e consumo nos clientes, em uma visão detalhada que fundamentou o estudo de ferramentas para suprir as necessidades do sistema.

A fim de permitir o uso do conteúdo de forma controlada, foram analisadas ainda linguagens de expressão de direitos suficientemente flexíveis para descrever todos os serviços do sistema através das licenças de uso. O estudo destes mecanismos resultou, afinal, na elaboração da proposta do Broker, elemento de distribuição baseado em licenças para atender as necessidades de uma infraestrutura segura de transmissão de conteúdo.

\section{Contribuições}

A presente dissertação contribui de diversas formas com o debate acerca dos sistemas de IPTV. Todo o estudo inicial, passando pelos levantamentos de tecnologias até a especificação do objeto de estudo, foi realizado com a preocupação de facilitar uma futura reutilização do que fora desenvolvido aqui. 
As principais contribuições obtidas deste trabalho foram o desenvolvimento e a validação através do protótipo. A especificação permitiu unir conceitos de segurança e distribuição multimídia para criar um elemento capaz de prover um serviço complexo de distribuição de conteúdo para grandes comunidades de usuários. $\mathrm{O}$ Broker inova por ser uma entidade confiável perante os produtores de conteúdo, permitindo transparência na distribuição das mídias. Além disso, conta com o suporte à linguagem de expressão de direitos para interpretação da lógica de negócios. O conjunto destas características confere ao Broker o grau de flexibilidade e robustez necessário para atuar em um sistema sofisticado de distribuição de mídia, sendo um exemplo da capacidade de integração das tecnologias atuais através da utilização de padrões abertos.

O protótipo gerado no decorrer do trabalho também é considerado uma importante contribuição, podendo ser acoplado a outros sistemas. A utilização da linguagem de direitos do MPEG-21 - padrão de maior relevância na área de descrição e gerência de conteúdos multimídia atualmente - destaca ainda mais a importância deste. Por ser comprovadamente compatível com a linguagem, a implementação realizada também se torna compatível com diversas outras ferramentas existentes.

Outras contribuições incluem ainda os estudos realizados para elencar as tecnologias mais adequadas para subsidiar o transporte de conteúdo de forma segura pela rede IP. O sucesso deste transporte está aliado aos mecanismos de difusão de conteúdo também estudados, como o multicast, a fim de resolver o problema de escalabilidade encontrado nestas redes.

O Broker foi inicialmente idealizado como parte da arquitetura de referência do projeto IPTV, iniciativa que realizou estudos sobre a distribuição de conteúdos em alta definição sobre redes IP, além da análise de mecanismos de DRM para IPTV. Este projeto foi realizado pelo LARC em parceria com a Ericsson Research.

O trabalho também gerou um artigo científico apresentado no XII Simpósio Brasileiro de Sistemas Multimídia e Web (Webmedia), em 2006, denominado "Arquitetura Baseada em Políticas de Uso para Sistemas de IPTV". 


\section{Trabalhos futuros}

Com a convergência de serviços cada vez maior, a integração entre tecnologias para distribuição de conteúdo de forma segura tende a ter uma demanda crescente. Este cenário é extremamente propício para o trabalho aqui realizado, tendo em vista o cuidado tido com a transparência da solução.

De maneira a dar continuidade ao trabalho, são sugeridos estudos acerca dos protocolos de segurança que minimizem o impacto na transmissão do vídeo. Devido à introdução de atrasos na transmissão pela criptografia de canal ou mesmo do vídeo, a otimização dos protocolos utilizados é necessária para reduzir a latência total de transmissão até a exibição no cliente.

Um outro ponto de destaque é a necessidade de escalabilidade do sistema na Rede de Acesso. Uma análise mais aprofundada dos mecanismos de difusão é necessária para se chegar a parâmetros de desempenho do sistema em relação ao número de usuários.

Os levantamentos feitos ao longo deste trabalho apontam caminhos para outros sistemas de distribuição de conteúdo. Este pode ser o caso de projetos como o Grupo de Trabalho de Gerência de Vídeo (GTGV), financiado pela Rede Nacional de Pesquisa (RNP) e desenvolvido pelo LARC. Este projeto encontra-se no escopo da distribuição de vídeo sobre a rede de pesquisa da RNP, gerenciando a transmissão dos conteúdos com auxílio de mecanismos de Overlay.

Da mesma forma que o DRM é criticado por muitos, sendo tachado como uma tecnologia muito restritiva, a falta de soluções para a devida proteção de conteúdos pode prejudicar o crescimento do mercado. São necessários não somente mecanismos de bloqueio, mas mecanismos inteligentes o suficiente para que 0 usuário desfrute da experiência completa que a mídia digital pode proporcionar. De certa forma, a evolução de sistemas como esses só serão possíveis com a conscientização de ambas as partes, criadores e consumidores. As linguagens de expressão de direitos dão um pequeno passo neste caminho, no entanto muitos outros devem ser dados para se chegar a soluções completas. 


\section{BIBLIOGRAFIA}

ALBUQUERQUE, C.; PROENÇA, T.; OLIVEIRA, E. TVoIP: Arquiteturas para Transmissão em Larga Escala. XXIV Simpósio Brasileiro de Redes de Computadores. Minicurso SBRC 2006. Curitiba, maio 2006.

ATM FORUM TECHNICAL COMMITTEE. Technical Committee Audiovisual Multimedia Services: Video on Demand Specification 1.0. Dez. 1995. Disponível em: < http://citeseer.ist.psu.edu/222418.html>. Acesso em: maio 2006.

AUDIN, G. VoIP? A Question of Perspective. Revista Business Communications Review, Abr. 2001. Disponível em: <http://www.spenser.biz/VolP Question of Perspective.pdf>. Acesso em: jul. 2006.

BAUGHER, M. et al. RFC3711: The Secure Real-time Transport Protocol (SRTP).Internet RFCs, RFC Editor United States. Mar. 2004.

ALFONSI, B. I Want My IPTV: Internet Protocol Television Predicted a Winner. IEEE DISTRIBUTED SYSTEMS ONLINE, vol. 6, n², Feb. 2005.

BIRNEY, B.; GILL, T. Microsoft Windows Media Resource Kit. Microsoft Press, Feb. 2003.

BORMANS, J.; BURNETT, I.; HILL, K.; PEREIRA, F.; VAN DE WALLE, R. MPEG21: Goals and Achievements. IEEE Multimedia, vol. 10, no. 6, p. 60-70, Oct./Dec. 2003.

BOUDANI, A.; COUSIN, B. Multicast Tree in MPLS Network. Global Telecommunications Conference, Nov. 2005.

CAIN, B. et al. RFC 3376: Internet Group Management Protocol, Version 3. Internet RFCs, RFC Editor United States. Oct. 2002.

CHONG, C. N. et al. LicenseScript: A Novel Digital Rights Language and its Semantics. IEEE Third International Conference on Web Delivering of Music. 2003.

CONTENTGUARD. The Need for a Rights Language: Technical White Paper. Versão 1.0, 2001. Disponível em: <www.xrml.org/reference/TheNeedForARightsLanguage.pdf>. Acesso em: abr. 2006. 
Driving the Standard for Interoperability in Digital Rights MPEG REL SDK for Java - User's Guide. Disponível em:

<http://www.contentguard.com/MPEGREL_sdk.asp>. 2004.

CROWCROFT, J.; HANDLEY, M.; WAKEMAN, I. Internetworking Multimedia. Morgan Kaufmann Publishers, 1999.

DIGITAL AUDIO-VISUAL COUNCIL. Description of Digital Audio-Visual

Functionalities. DAVIC 1.3.1 Specification Part 1 (Relatório técnico). 1998.

DIGITAL CINEMA INITIATIVES (DCI). Digital Cinema System Specification. Versão 4.3, Dez. 2004. Disponível em: <http://www.dcimovies.com>. Acesso em: mar. 2005.

DEERING, S. et al. Protocol Independent Multicast version 2 Dense Mode Specification. IETF Internet Draft, Aug. 1997.

DEERING, S. RFC 1112: Host Extensions for IP Multicasting. Internet RFCs, RFC Editor United States. Aug. 1989.

DEERING, S. E.; CHERITON, D. R. RFC 996: A Multicast Extension to the Internet Protocol. Internet RFCs, RFC Editor United States. Stanford University. Dec. 1985.

DELGADO, J.; PRADOS, J.; RODRIGUEZ, E. Profiles for interoperability between MPEG-21 REL and OMA DRM. Seventh IEEE International Conference on ECommerce Technology. CEC, 2005.

DIGITAL VIDEO BROADCASTING. Architectural framework for the delivery of DVB-services over IP-based networks. DVB-IPI Technical Report. Abr. 2002.

Disponível em: < http://www.etsi.org>. Acesso em: maio 2006.

DIGITAL WATERMARKING ALLIANCE (DWA). Whitepaper on P2P. [200-?]. Disponível em: <http://www.digitalwatermarkingalliance.org/ presentations.asp >. Acesso em: abr. 2007.

EDWARDS, B.; GIULIANO, L.; WRIGHT, B. Interdomain Multicast Routing. Editora Pearson Education. 2002.

EI-SAYED, A.; ROCA, V.; MATHY, L. A Survey of Proposals for an Alternative Group Communication Service. IEEE Network magazine, Special issue on "Multicasting: An Enabling Technology", Jan./Feb. 2003. 
ESTRIN, D. et al. RFC 2117: Protocol Independent Multicast-Sparse Mode (PIMSM): Protocol Specification. Internet RFCs, RFC Editor United States. June. 1997.

FENNER, B. et al. RFC 4601: Protocol Independent Multicast - Sparse Mode (PIMSM): Protocol Specification (Revised). Internet RFCs, RFC Editor United States. Aug. 2006.

FLEURY, JF. IPTV: The Need for Standards. Internet Broadcast Convention, 2005.

GROSSMAN, D. RFC 3260: New Terminology and Clarifications for Diffserv. Internet RFCs, RFC Editor United States. Apr. 2002.

HEDRICK, C. RFC 1058: Routing Information Protocol. Internet RFCs, RFC Editor United States, Rutgers University. June. 1988.

REALNETWORKS HELIX DRM. 2006. Disponível em: $<$ http://www.realnetworks.com/products/drm/>, <http://www.realnetworks.com/products/producer>. Acesso em: jun. 2006.

HOLBROOK, H.; CAIN, B. RFC 4607: Source-Specific Multicast for IP. Internet RFCs, RFC Editor United States. Aug. 2006.

HOLBROOK, H.; CAIN, B.; HABERMAN, B. RFC 4604: Using Internet Group Management Protocol Version 3 (IGMPv3) and Multicast Listener Discovery Protocol Version 2 (MLDv2) for Source-Specific Multicast. Internet RFCs, RFC Editor United States. Aug. 2006.

INTERNET ASSIGNED NUMBERS AUTHORITY. INTERNET MULTICAST ADDRESSES. Disponível em: <http://www.iana.org/assignments/multicastaddresses $>$. Acesso em: abr. 2006.

IANNELLA, R. Digital Rights Management (DRM) Architectures. D-Lib Magazine, Vol.7, $n^{\circ} 6$, junho de 2001. Disponível em:

<http://www.dlib.org/dlib/june01/iannella/06iannella.html>. Acesso em: fev. de 2006.

. Open Digital Rights Language (ODRL). Versão 1.1. Ago. 2002.

Disponível em: <http://odrl.net/1.1/ODRL-11.pdf>. Acesso em: jun. 2006.

ISO/IEC 13818-1. Information technology - Generic coding of moving pictures and associated audio information: Systems, 1995. 
ISO/IEC 14496-1. Information technology - Coding of audio-visual objects -Part 1: Systems, 2001.

INTERNET STREAMING MEDIA ALLIANCE. Internet Streaming Media Alliance Implementation Specification. Versão 2.0, Apr. 2005. Disponível em: <http://www.isma.tv>. Acesso em: abr. 2006.

LAO, L. et al. A comparative study of multicast protocols: top, bottom, or in the middle? INFOCOM 2005. 24th Annual Joint Conference of the IEEE Computer and Communications Societies. Proceedings IEEE, vol.4, p.2809-2814, Mar. 2005.

LARMAN, C. Utilizando UML e Padrões: uma introdução à análise e ao projeto orientados a objetos. Bookman Companhia Editora. 2000.

MARGI, C. B.; BRESSAN, G.; RUGGIERO,W. V. Um Mecanismo Para Distribuição Segura de Vídeo MPEG. Publicado e apresentado no SSI 2000. São José dos Campos-SP. Out. 2000.

MARPE, D.; WIEGAND, T.; SULLIVAN, G. J. The H.264 / MPEG4 Advanced Video Coding Standard and its Applications. IEEE Communications Magazine, Vol. 44, No. 8, pp. 134-144, Aug. 2006.

MICROSOFT Executive Broadcast Solution White Paper. Junho de 2001. Disponível em: <http://www.approach.com/digitalmedia/>. Acesso em: jul. 2006.

MICROSOFT WINDOWS MEDIA DIGITAL RIGHTS MANAGEMENT. Disponível em: http://www.microsoft.com/windows/windowsmedia/forpros/drm [200-?]. Acesso em: maio 2006.

O'GORMAN, L. Comparing Passwords, Tokens, and Biometrics for User Authentication. Proceedings of the IEEE, vol. 91, no. 12, p. 2019-40, Dec. 2003.

OLSON, C. A Practical Guide to the Fair Use Doctrine in American Copyright Law. Signal/Noise 2k5 Conference, Harvard Law School, Apr. 2005.

OOMS, D.; LIVENS, W. IP Multicast in MPLS Networks. Proceedings of the IEEE Conference on High Performance Switching and Routing. ATM 2000. p. 301-305, July 2000 .

OOMS, D. et. al. RFC 3353: Overview of IP Multicast in a Multi-Protocol Label Switching (MPLS) Environment. Internet RFCs, RFC Editor United States. Aug. 2002. 
PARROT, D. Requirements for a Rights Data Dictionary and Rights Expression Language. Versão 1.0. Em resposta à ISO/IEC JTC1/SC29/WG11 N4044: "Reissue of the Call for Requirements for a Rights Data Dictionary and a Rights Expression Language". Reuters, June 2001.

POLK, J.; DHESIKAN, S. RFC 4495: A Resource Reservation Protocol (RSVP) Extension for the Reduction of Bandwidth of a Reservation Flow. Internet RFCs, RFC Editor United States. May 2006.

RIGHTSCOM. The MPEG-21 Rights Expression Language: A White Paper. Versão 1.0, July 2003. Disponível em: <http://www.itarchitect.com/shared/article/showArticle.jhtml?articleld=18900094>. Acesso em: maio 2006.

ROSEN, E.; VISWANATHAN, A.; CALLON, R. RFC 3031: Multiprotocol Label Switching Architecture. Internet RFCs, RFC Editor United States. Jan. 2001.

ROSENBLATT, B.; TRIPPE, B.; MOONEY, S. Digital Rights Management: Business and Technology. Ed. M\&T Books, 2002.

RUMP. em: E. BECKER et al. Digital Right Management: Technological, Economic, Legal and Political Aspects. LNCS 2770. ed. Springer-Verlag Berlin Heidelberg, 2003.

SCHOEN, U. et al. Convergence Between Public Switching and the Internet. IEEE Communications Magazine, vol. 36, no 1, p. 50-65, Jan. 1998.

SCHULZRINNE, H. et al. RFC 3550: RTP: A Transport Protocol for Real-Time Applications. Internet RFCs, RFC Editor United States. July 2003.

SCHULZRINNE, H.; Rao, A.; Lanphier, R. RFC 2326: Real Time Streaming Protocol (RTSP). Internet RFCs, RFC Editor United States. Apr. 1998.

SHERMAN, A. T.; MCGREW, D. A. Key Establishment in Large Dynamic Groups Using One-Way Function Trees. IEEE Transactions On Software Engineering, vol. 29, número 5, p. 444-458. May. 2003.

SIEMENS COMMUNICATIONS E JUNIPER NETWORKS, INC. High Quality and Resilient IPTV Multicast Architecture - An Overview of RESIP Multicast Architecture. Siemens AG. Disponível em: <www.siemens.com/resip>. Acesso em: ago. 2006. 
SILVEIRA, R. M.; PIRES, D. Concepção Artística de Programas Audio-Visuais Interativos. (Relatório Técnico do Sistema Brasileiro de TV Digital). São Paulo, nov. 2005.

SITARAM, D.; DAN, A. Multimedia Servers: Applications, Enviromments and Design. Ed. Morgan Kaufmann Publishers, 2000.

STALLINGS, W. Cryptography and Network Security: Principles and Practice. Ed. Prentice Hall. 3ª edição. Aug. 2002.

TRUSTED COMPUTING GROUP. Embedded Systems and Trusted Computing Security. Disponível em: <https://www.trustedcomputinggroup.org/specs/TPM>. Acesso em: jul. 2006.

TRUSTED COMPUTING GROUP. TPM Main Part 1 Design Principles. Versão 1.2, revisão 94. Mar. 2006. Disponível em:

<https://www.trustedcomputinggroup.org/specs/TPM>. Acesso em: jul. 2006.

WORLD WIDE WEB CONSORTIUM. XML Schemas Specification. Apr. 2000. Disponível em: <http://www.w3.org/XML/Schema>. Acesso em: jun. 2006.

WORLD WIDE WEB CONSORTIUM. XrML 2.0 Technical Overview. Versão 1.0, Mar. 2002. Disponível em: <http://www.xrml.org/reference.asp>. Acesso em: maio 2006.

WORLD WIDE WEB CONSORTIUM. Extensible Markup Language Specification. Versão 1.1, Apr. 2004. Disponível em: <http://www.w3.org/TR/xml11/>. Acesso em: maio 2006.

WAITZMAN, D.; PARTRIDGE, C.; DEERING, S. RFC 1075: Distance Vector Multicast Routing Protocol. Internet RFCs, RFC Editor United States. Nov. 1988.

WANG, X. et al. The MPEG-21 Rights Expression Language and Rights Data Dictionary. IEEE Transactions on Multimedia, vol. 7, no. 3. Jun. 2005.

$\mathrm{XU}, \mathrm{S}$.; SANDHU, R. Authenticated multicast immune to denial-of-service attack. Applied Computer Journal, ACM Press. 2002. 